This is the peer reviewed version of the following article: Dinić J, Efferth T, García-Sosa AT, Grahovac J, Padrón JM, Pajeva I, Rizzolio F, Saponara S, Spengler G, Tsakovska I. Repurposing old drugs to fight multidrug resistant cancers. Drug Resist Updat. 2020;52:100713. http://dx.doi.org/10.1016/j.drup.2020.100713

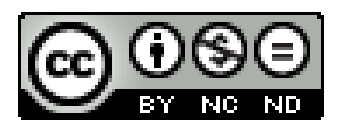

(C) 2020 Elsevier Ltd 


\section{Repurposing old drugs to fight multidrug resistant cancers}

Jelena Dinića ${ }^{a}$ Thomas Efferth ${ }^{b}$, Alfonso T. Garcia-Sosac ${ }^{c}$ Jelena Grahovac ${ }^{d}$, José M. Padrón $^{\mathrm{e}, *}$, Ilza Pajeva ${ }^{f}$, Flavio Rizzoliog ${ }^{\mathrm{gh}}$, Simona Saponara', Gabriella Spengler, Ivanka Tsakovska $^{\mathrm{f}}$

a Department of Neurobiology, Institute for Biological Research "Siniša Stanković" - National Institute of Republic of Serbia, University of Belgrade, Bulevar Despota Stefana 142, 11060 Belgrade, Serbia

${ }^{b}$ Department of Pharmaceutical Biology, Institute of Pharmacy and Biomedical Sciences, Johannes Gutenberg University, Staudinger Weg 5, 55128 Mainz, Germany

${ }^{c}$ Institute of Chemistry, University of Tartu, Ravila 14a, Tartu 50411, Estonia

${ }^{d}$ Department of Experimental Oncology, Institute for Oncology and Radiology of Serbia, Pasterova 14, 11000 Belgrade, Serbia

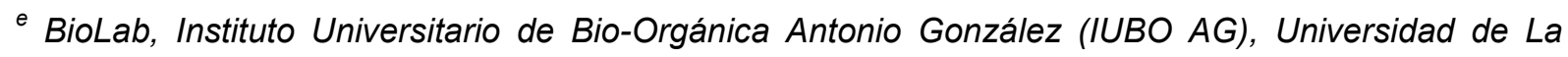
Laguna, Avda. Astrofísico Francisco Sánchez 2, E-38071 La Laguna, Spain

${ }^{f}$ Institute of Biophysics and Biomedical Engineering, Bulgarian Academy of Sciences, Acad. G. Bonchev Str., BI. 105, 1113 Sofia, Bulgaria

${ }^{g}$ Department of Molecular Sciences and Nanosystems, Ca' Foscari University of Venice, 301724 Venezia-Mestre, Italy

${ }^{\text {h }}$ Pathology Unit, Centro di Riferimento Oncologico di Aviano (CRO) IRCCS, 33081, Aviano, Italy

'Department of Life Sciences, University of Siena, Via Aldo Moro 2, 53100 Siena, Italy

${ }^{j}$ Department of Medical Microbiology and Immunobiology, Faculty of Medicine, University of Szeged, H-6720 Szeged, Dóm tér 10, Hungary

* Corresponding author

José M. Padrón jmpadron@ull.es

Running title: Drug repurposing to fight MDR 


\section{Abstract}

Overcoming multidrug resistance represents a major challenge for cancer treatment. In the search for new chemotherapeutics to treat malignant diseases, drug repurposing gained a tremendous interest during the past years. Repositioning candidates have often emerged through several stages of clinical drug development, and may even be marketed, thus attracting the attention and interest of pharmaceutical companies as well as regulatory agencies. Typically, drug repositioning has been serendipitous, using undesired side effects of small molecule drugs to exploit new disease indications. As bioinformatics gain increasing popularity as an integral component of drug discovery, more rational approaches are needed. Herein, we show some practical examples of in silico approaches such as pharmacophore modelling, as well as pharmacophore- and docking-based virtual screening for a fast and cost-effective repurposing of small molecule drugs against multidrug resistant cancers. We provide a timely and comprehensive overview of compounds with considerable potential to be repositioned for cancer therapeutics. These drugs are from diverse chemotherapeutic classes. We emphasize the scope and limitations of anthelmintics, antibiotics, antifungals, antivirals, antimalarials, antihypertensives, psychopharmaceuticals and antidiabetics that have shown extensive immunomodulatory, antiproliferative, proapoptotic, and antimetastatic potential. These drugs, either used alone or in combination with existing anticancer chemotherapeutics, represent strong candidates to prevent or overcome drug resistance. We particularly focus on outcomes and future perspectives of drug repositioning for the treatment of multidrug resistant tumors and discuss current possibilities and limitations of preclinical and clinical investigations.

Keywords: Drug repurposing; multidrug resistant cancer; clinical cancer trials; pharmacophore modelling; virtual screening 


\section{Introduction}

The number of published articles referring to the term 'drug repositioning', or its siblings 'drug repurposing', 'drug reprofiling', 'drug redirecting' and/or 'drug rediscovery' have increased exponentially in the past decade. Those terms relate to a drug discovery strategy, where the ultimate goal is finding new uses for existing drugs (Pushpakom et al., 2018). Although several factors could be attributed to this phenomenon, the economic benefit remains the driving force. This approach grants pharmaceutical companies extended patents as a mean to overcome the difficulties arising from the so-called productivity problem. Additionally, the worldwide pressure on prices, the challenges from generics and the everincreasing regulatory hurdles make drug repositioning an attractive stratagem. Drug reprofiling represents a cost-effective subterfuge over de novo drug discovery and development for diverse reasons since it offers one of the best risk-versus-reward trade-offs of the available drug development strategies (Ashburn and Thor, 2004, Pushpakom et al., 2018). This occurs because repositioning candidates have often been through several stages of development, including efficacy, pharmacokinetics, pharmacodynamics and toxicity, and may even be marketed entities (Figure 1).

The repurposing of drugs has been applied in several chemotherapeutic strategies to treat human health disorders such as cancer (Antoszczak et al., 2020; Armando et al., 2020; Masuda et al., 2020; Mudduluru et al., 2016; Nowak-Sliwinska et al., 2019; Serafin et al., 2019), neurodegenerative diseases (Corbett et al., 2015; De Castro et al., 2018), neglected tropical diseases (Andrade et al., 2019; Sbaraglini et al. 2016), autoimmune diseases (Grammer and Lipsky, 2017), asthma (Huo and Zhang, 2018), psoriasis (Xu and Zhang, 2017), cystic fibrosis (Valeria et al.; 2019), and systemic lupus erythematosus (Grammer et al., 2016), to mention a few. With the development of computational methods and the increasing availability of novel types of big data (Kwon et al., 2019), the major limitation to find a new indication of a known drug lays in the identification of the molecular target of the disease of interest. In this particular context, dedicated computational tools have been developed to identify novel drug-disease connections (Yosipof et al., 2018; Zhang and Gant, 
2009). Among the experimental approaches to unveil new drug-target interactions, binding assays using drug libraries and high-throughput phenotypic screening of compounds using in vitro or in vivo disease models can facilitate the identification of new potential drug candidates for clinical evaluation (Figure 2).

As a matter of fact, drug repositioning arises from the exploitation of the promiscuity of small molecule drugs, i.e., the ability to disturb two or more independent proteins causing undesired side effects. The growing appreciation of network pharmacology as the next drugdiscovery paradigm encourages scientists to better understand and make use of such polypharmacological effects of promiscuous compounds (Chaudhari et al., 2017). Polypharmacological effects offer significant advantages for finding novel therapeutics particularly for the treatment of complex and multifactorial diseases such as cancer. In this context, the antiparasitic drug niclosamide has emerged as a relevant multitarget drug against both cancer cells and cancer stem cells (CSCs). Niclosamide inhibits the Wnt/ $\mathrm{B}$ catenin, mTORC1, STAT3, NF-KB, NFAT and Notch signaling pathways, and targets mitochondria in cancer cells and glutathione biosynthesis, thereby inducing cell cycle arrest, growth inhibition and apoptosis (Hamdoun et al., 2017; Li et al., 2014b). The unexplored offtarget potencies of the approved drugs axitinib and tivantinib led to novel drug repurposing opportunities for cancer treatment (Kuenzi et al., 2019; Pemovska et al., 2015). More importantly, polypharmacology represents a promising strategy to overcome multidrug resistant (MDR) diseases (Stelitano et al., 2020).

In the past decades, several drugs that were originally approved for indications other than cancer treatment have shown cytostatic effect on cancer cells (Hanusova et al., 2015; Yang et al., 2016). Notable examples of drug repositioning can be found in anthelmintics, antibiotics, antifungal, antiviral, antihypertensive drugs, psychopharmaceuticals and antidiabetic drugs due to their extensive immunomodulatory, antiproliferative, pro-apoptotic, and antimetastatic potential. These drugs have the potential to be used in combinations with existing anticancer chemotherapeutics as a mean to prevent or to overcome drug resistance. 
In this review, we highlight the attempts to repurpose selected drugs commonly used for other medical indications, with a particular focus on the outcomes and future perspectives of drug repositioning for the treatment of MDR tumors. We present a brief outline of the computational methods that are relevant for drug reprofiling. In the subsequent sections, different classes of clinically used drugs (Figures 3 and 4) will be outlined and discussed for their anti-tumor properties and, for some of them, the most relevant repositioning studies (Table 1) that have been reported. Our aim is not to summarize all the reported studies but to provide an overview of the current possibilities and limitations.

\section{In silico approaches}

\subsection{Pharmacophores and drug repurposing}

Overexpression of ATP-binding cassette (ABC) transporters in cancer cells, particularly ABCB1 (P-glycoprotein, P-gp), ABCC1 (MDR protein 1, MRP1) and ABCG2 (breast cancer related protein, BCRP), has been identified as a key player in the development of MDR to multiple chemotherapeutic agents (Assaraf et al., 2019; Cui et al., 2018; Gacche and Assaraf, 2018; Gonen and Assaraf 2012; Kopecka et al., 2020; Li et al., 2016; Livney and Assaraf, 2013; Milman et al., 2019; Niewerth et al., 2015; Shapira et al., 2011; Vasconcelos et al., 2019; Wijdeven et al., 2016; Zhitomirsky and Assaraf, 2016; Zhong and Virshup, 2020). These MDR transporters function as efflux pumps which extrude a multitude of structurally and mechanistically distinct anticancer drugs. As such, MDR efflux transporters have been prime therapeutic targets in different strategies to overcome MDR (Amawi et al., 2019; Assaraf et al., 2014; Assaraf et al., 2019; Bar-Zeev et al., 2017; Li et al., 2016; Livney and Assaraf, 2013; Taddia et al., 2015; Taylor et al., 2015). Particularly, over the time the focus has shifted more from inhibitor design towards lowering the likelihood that the drug will be recognized as an ABC-transporter substrate (Montanari and Ecker, 2015). In addition, bioavailability and toxicity of drugs strongly depends on their ability to interact with ABC transporters. 
P-gp is one of the best characterized multidrug efflux transporter not only in MDR cells but also for orally administrated drugs and as such, there has been continuous interest in elucidating, whether existing drugs are potential P-gp substrates/inhibitors. For a long time, these studies have been complicated due to the lack of high-resolution structural information, particularly because of the intrinsic difficulties involved in membrane protein crystallization. Thus, in silico approaches such as pharmacophore modelling and pharmacophore-based virtual screening have gained significant popularity in this research area.

\subsubsection{Pharmacophore concept}

The pharmacophore concept was first introduced by Paul Ehrlich in the late $19^{\text {th }}$ century as specific groups within a molecule that are responsible for its biological activity (Güner and Bowen, 2014). This concept has evolved over the time and according to modern understanding "a pharmacophore is the ensemble of steric and electronic features that are necessary to ensure the optimal supramolecular interactions with a specific biological target structure and to trigger (or to block) its biological response" (Wermuthet et al., 1998). Therefore, the pharmacophore is an abstract concept that accounts for the common molecular interaction capacities of a group of compounds towards their target structure. In the modelling studies depending on the purposes, often a structural (2D) pharmacophore is defined that represents minimum skeleton connecting important binding groups, while 3D pharmacophore defines relative positions of these groups in the space. Pharmacophoric descriptors (features) that are used to define the pharmacophore, include hydrogen bonding (hydrogen bond donors and acceptors), hydrophobic and electrostatic interaction sites, etc., defined by atoms, ring centers and virtual points. The pharmacophore can be identified from the X-ray crystal structure of the protein-ligand complex taken from Protein Data Bank (PDB, https://www.rcsb.org/). If the target structure is unknown, it is derived from the comparison of active compounds binding to the same target in the same active site. Based on this, the following classification of pharmacophore modelling approaches is commonly accepted: (i) 
ligand-based, where the pharmacophore hypothesis is built from a collection of active (and possibly inactive) ligands and no target information is used; (ii) target-based, where the pharmacophore hypothesis is built from the structural data of the receptor only; and (iii) complex-based, where the pharmacophore model is derived from structural data of proteinligand complexes. Further, it can be successfully combined with molecular docking, for instance known active compounds can be docked into the binding pocket of the target. At the next stage, these binding poses can be directly employed to extract the pharmacophore features. The generated pharmacophores lay the ground of the pharmacophore-based virtual screening, where large chemical libraries are screened against pharmacophore models and structures with high correspondence to the model are potential hits, meaning high potential to be active in the experimental testing. The predictive abilities of this approach to estimate the likelihood for a set of compounds to be active against protein targets of interest have stimulated its applications as a computational repurposing method. In this case, the pharmacophore modelling/screening is applied to discover potential targets of a query molecule (known drug) by comparing it with key pharmacophore models of the potential target's binders, thus to search/propose new potential therapeutic applications of this drug (Huang et al., 2018).

\subsubsection{Pharmacophore modelling of MDR modulators}

The P-gp ligands termed MDR modulators or chemosensitizers in drug resistant tumor cells are representatives of different pharmacological classes, including anticancer agents, calcium channel blockers, neuroleptics, antiarrhythmics, antimalarial, antifungal, and many other drugs. Within such a diverse chemical space, it has been a challenge to identify which structural parameters/pharmacophore features are common and required for a molecule to bind P-gp (Borgnia et al., 1996; Pajeva and Wiese, 2002). Historically, after the calcium channel blockers, phenothiazines and related compounds exerting diverse biological effects including psychotropic, antimicrobial, and antifungal, are the second large group of intensively studied MDR modulators. A number of 3D QSAR (quantitative structure-activity 
relationships) studies on phenothiazine-related drugs have outlined the importance of the space structural properties, namely steric, hydrogen bond acceptor and hydrophobic properties as main pharmacophoric features for P-gp binding (Tsakovska and Pajeva, 2006).

To answer the general question how structurally diverse compounds bind P-gp, a comprehensive pharmacophore modelling study based on structurally different compounds binding to the verapamil binding site of P-gp was performed, and a general pharmacophore model of P-gp drugs was proposed (Pajeva and Wiese, 2002). The drugs in the modelling set included anticancer agents, calcium channel blockers, neuroleptic, antifungal, and antimalarial drugs, proton pump inhibitors, and their analogues. The derived general pharmacophore pattern for the verapamil binding site of P-gp involved two hydrophobic planes, three hydrogen bond acceptors, and one hydrogen bond donor. These pharmacophoric features were fixed in the space by calculating distances and angles between them. The study suggested that the broad structural variety of the P-gp substrates and inhibitors may be explained by the presence of several points (receptor atoms and substructures) in the verapamil binding site of P-gp that can participate in hydrophobic and hydrogen bond interactions with the ligands and further by the hypothesis that different drugs can interact with different receptor determinants in different binding modes. This hypothesis is confirmed by the recently resolved structure of human P-gp in a complex with the antitumor drug paclitaxel (PDB ID 6QEX) and two molecules of the third generation MDRmodulator zosuquidar (PDB ID 6QEE) (Alam et al., 2019).

Other studies developed an ensemble of pharmacophore models aiming to predict inhibitors or differentiate between P-gp substrates and non-substrates (Chen et al. 2012; Ekins et al., 2002; Li et al., 2007; Penzotti et al., 2002). The principle was to generate a set of significant pharmacophores that cover the features necessary for the particular group of compounds to occupy particular regions in P-gp. With the aim to predict existing drugs that are P-gp substrates or inhibitors, a pharmacophore model was developed based on 26 known P-gp inhibitors from the flavonoid family (Palmeira et al. 2011). The model included six types of pharmacophoric features, namely hydrogen bond donor and acceptors, aromatic 
centers, hydrophobic centers, negative charge, and positive charge atoms. At the next stage, the DrugBank database (Wishart et al., 2008) was screened against this model. Twenty-one hits were identified that were further subjected to in vitro testing. This resulted in 12 drugs found to significantly increase the intracellular accumulation of the fluorescent P-gp substrate Rhodamine-123 and additionally two tetracyclic antidepressant drugs, discovered to be potent non-competitive inhibitors of P-gp. Overall, the study is an excellent example for the suitability of the pharmacophore modelling as a computational repurposing approach.

Similar successful application of a ligand-based virtual screening and experimental tests was demonstrated in the study of Pan et al., toward identification of old drugs as inhibitors of BCRP (Pan et al., 2013). In this study, Bayesian and pharmacophore models were generated using known BCRP inhibitors and were applied to screen more than 2000 FDA approved drugs. This integrative virtual screening led to selection of 33 drugs that were experimentally tested using cell-based assays. Of them, 19 drugs including amlodipine, nicergoline, nisoldipine, fosinopril, papaverine, prochlorperazine, trifluoperazine, promethazine, thioridazine, and more, significantly inhibited BCRP transport function.

In the recent years, there has been an increasing interest towards small-molecule tyrosine kinase inhibitors (TKIs) (Dal Bo et al., 2020; Gillis and McLeod, 2016; Hochhaus et al., 2020; Leonetti et al., 2019; Sarmento-Ribeiro et al., 2019), which demonstrate effective anticancer activities and some of them have been approved for clinical use or are in clinical trials. At the same time, several TKls (e.g., imatinib, nilotinib, dasatinib, ponatinib, gefitinib, erlotinib, lapatinib, vandetanib, etc.) have demonstrated capabilities to bind ABC-transporters (Wang et al., 2014). This is not surprising, because they possess several pharmacophoric features such as hydrophobic groups, aromatic ring centers, hydrogen bond acceptors that are essential for interaction with the transporters (Demel et al., 2008). The investigations demonstrate that TKls may behave as substrates or inhibitors depending on a number of factors such as the expression of specific pumps, drug concentration, affinity for transporters and types of co-administered agents (Beretta et al., 2017). This opens new strategies in anticancer therapy - to repurpose TKIs as inhibitors of $A B C$ transporters or to design TKIs 
with reduced binding capabilities to $A B C$ transporters. A good example of the latter strategy is the pharmacophore modelling and in vitro experiments of the TKI nilotinib and a series of 25 analogs (Shukla et al., 2014). Pharmacophore models for BCR-ABL kinase inhibitory activity, BCRP and P-gp inhibitory activities were generated and validated on test sets of BCR-ABL, ABCG2, and P-gp inhibitors. The study demonstrates a strategy to design TKI that specifically inhibit the target kinases without interacting with $A B C$ drug transporters.

\subsection{Virtual drug screening and molecular docking studies}

Molecular docking and virtual screening are well-known and an integral component of drug discovery and also for finding targets for compounds (Isca et al., 2020; Shoichet, 2004). The method allows for finding drugs that were approved for a different indication and have potential to be repurposed for anticancer therapy by docking them into targets related to oncology. Inherent advantages of docking and virtual screening are available at relatively low cost, though structural information is required.

\subsubsection{Thalidomide}

Thalidomide was considered initially as possible antitumor agent in virtue of its potential antiangiogenic effects. The PDB database contains several holo X-ray crystal structures of the human cereblon (CRBN) protein - the primary teratogenic target of thalidomide - with the binding site resolved. This allowed docking to be performed, the results showing a good fit of thalidomide to this receptor (with RMSD values ranging from 0.349 to 1.133, scores ranged from -9.9 to $-9.1 \mathrm{kcal} / \mathrm{mol}$ ) (Lagarde et al., 2018). Another study showed that fibroblast growth factor receptors (FGFRs), involved in embryo development and cancer pathophysiology, could be potential targets of thalidomide and its analogs, also endorsing the link between the teratogenicity and antitumor activities of these drugs (Sundaresan et al., 2019).

\subsubsection{Fluspirilene}


Fluspirilene is one of the approved drugs for the treatment of schizophrenia. This antipsychotic drug is administered by intramuscular injection and is thought to mediate the inhibition of the dopamine D2 receptor (Hassel, 1985) and blocking the calcium channel (Wang, 2002). Cyclin-dependent kinase 2 (CDK2), a protein involved in cellular proliferation and tumor growth and a well-known cancer target, was identified by virtual screening of approved small-molecule drugs as a new target for this compound (García-Sosa and Mancera, 2005).

In vitro and in vivo experiments indicated that fluspirilene bears the potential as a possible therapeutic against hepatocellular carcinoma (Shi et al., 2015). More than 300 holo CDK2 Xray crystal structures are available in the PDB. The MTiOpenScreen service was used to virtually screen compounds and crystal structures, obtaining the best result for protein structure PDB ID 1PXO with a Vina score of $-11.1 \mathrm{kcal} / \mathrm{mol}$ (Lagarde et al., 2018). Spirilene, spiperone, and fluspiperone clustered together with fluspirilene (indicating similarity in FragFp descriptors), and were also ranked within the 1,500 best scored drugs (Lagarde et al., 2018). Fluspirilene may thus inhibit CDK2 and may be further developed as drug against liver and colon cancer.

\subsubsection{Mebendazole}

Parasitic infections with helminths in humans and animals have been successfully treated with mebendazole for more than two decades. Mebendazole acts as a tubulin depolymerization agent which induces apoptosis due to blockade of spindle formation, but also has a role in angiogenesis through vascular endothelial growth factor 2 (VEGFR2) (Dakshanamurthy et al., 2012). PDB ID 3U6J revealed the best docking outcomes for mebendazole (confirmed in vitro). The authors also identified closely related compounds such as oxfendazole, nocodazole, luxabendazole, and flubendazole as hits in their procedure (Lagarde et al., 2018).

\subsubsection{Raloxifene}


Treatment and prevention of postmenopausal osteoporosis is the approved indication for raloxifene, a non-hormonal anti-resorptive agent (Xiao et al., 2017). Proliferation, survival, invasiveness, and metastasis of tumor cells and suppression of the anticancer immune response can depend on interleukin-6 (IL-6) and GP130 in the IL-6/JAK/STAT3 pathway (Xiao et al., 2017). Raloxifene and bazedoxifene were discovered as new inhibitors of the protein-protein IL-6/GP130 interaction through multiple ligand simultaneous docking (MLSD) and drug repositioning, where multiple drug scaffolds were simultaneously docked into hot spots of GP130 D1 domain, competing for the key interacting residues of IL-6, and then tethering to generate virtual hits (Xiao et al., 2017). Similarity searches of these in drug databases identified raloxifene and bazedoxifene (also used for postmenopausal osteoporosis) as new potential IL-6/GP130 protein-protein inhibitors, with potential use in the treatment of cancers dependent on this pathway, such as rhabdomyosarcoma (Xiao et al., 2017).

\subsubsection{Sulindac}

Osteoarthritis, ankylosing spondylitis, rheumatoid arthritis, and gout are among the ailments treated by targeting COX enzymes and prostaglandin synthesis with non-steroidal anti-inflammatory agents such as sulindac (also known as imbaral). However, sulindac and other compounds of this class may also inhibit aldo-keto reductase 1C3 (AKR1C3), which is overexpressed in many cancers (Flanagan et al., 2012). In the absence of AKR1C3, $\mathrm{PGD}_{2}$ spontaneously dehydrates and isomerizes to form anti-neoplastic $P G J_{2}$ prostanoids. Structure $3 \mathrm{R} 7 \mathrm{M}$ in the PDB contains the $\mathrm{X}$-ray protein crystal structure of sulindac in complex with AKR1C3. Similar compounds to sulindac include its stereosiomers, as well as exisulind, the sulfone derivative of sulindac approved as an antineoplastic drug for familial adenomatous polyposis (FAP), precancerous sporadic colonic polyps, cervical dysplasia, and the prevention of tumor recurrence in prostate and breast cancer (Goluboff, 2001). The mode of action for exisulind is inhibition of enzyme cyclic guanosine monophosphate phosphodiesterase type 5 (cGMP-PDE). 


\section{Preclinical studies}

\subsection{Immunomodulatory imide drugs (IMiDs)}

Immunomodulatory imide drugs (IMiDs) are chemotherapeutic drugs capable of controlling molecular pathways, relevant in the context of tumor development and secondary spread. The most common known drug of the family is thalidomide. Thalidomide was approved in 1953 for preventing morning sickness in pregnancy and as a sedative, but it was retracted from the market in 1963, because babies exposed to the drug in utero showed severe teratogenic effects. Studies aimed at elucidating the mechanism of thalidomideinduced birth defects led to the discovery of unexpected immuno-adjuvant, anti-inflammatory, anti-proliferative and anti-angiogenic properties (Shortt et al, 2013). Notably, thalidomide has been repurposed twice by the FDA. First in 1998, when it was approved as a leprosy treatment, and then in 2006, as multiple myeloma (MM) therapy. Lenalidomide and pomalidomide, two thalidomide analogues carrying an amino group on the phthaloyl ring, were developed to obtain derivatives endowed with increased anticancer potency and efficacy and reduced side effects. Several mechanisms of action have been proposed for their antitumor activity (Stewart, 2014).

The primary teratogenic target of thalidomide, CRBN (Mori et al., 2018), is a highly conserved protein that forms with the DNA damage-binding protein-1 (DDB1), Cullin 4A, and regulator of Cullins 1 (RoC1), the functional E3 ubiquitin ligase complex (CLR4 ${ }^{\mathrm{CRBN}}$ ), involved in protein degradation through the ubiquitin-proteasome pathway (Fischer et al., 2014). However, CRBN is also required for anti-MM activity of IMiDs (Eichner et al., 2016). By modulating the substrate specificity of the CRL4 ${ }^{\mathrm{CRBN}}$, IMiDs block MEIS2 (myeloid ecotropic insertion site 2) from binding to the ligase complex, inducing the recruitment and proteasomal degradation of transcription factors (TFs) Ikaros family zinc finger protein 1 (IKZF1) and IKZF3. This is ensued by transcriptional repression of myelocytomatosis (MYC) oncogene cellular homolog and interferon regulatory factor 4 (IRF4), two important proteins for MM proliferation and survival (Abbruzzese et al., 2019). In vitro as well as in vivo studies have 
demonstrated that CRBN and IKZF1/3 mutations cause resistance to IMiDs (Barrio et al., 2020). Furthermore, new insights into CRBN ubiquitin-independent function and IMiD antitumor mechanisms were provided. It was shown that CRBN mediates maturation and stabilization of the basigin (CD147) - solute carrier family 16 member 1 (SLC16A1, MCT1) complex, which promotes various biological functions, including angiogenesis, proliferation, invasion and lactate export. Thalidomide and its derivatives compete with CD147 and MCT1 for CRBN binding to exert versatile antitumor effects (Eichner et al., 2016).

The mechanisms underlying the immunomodulatory, antiproliferative and antiangiogenic activities of thalidomide appear interconnected and CRBN plays a key role.

Thalidomide was evaluated initially as an antitumor agent due to its potential antiangiogenic effects. In fact, it inhibited basic fibroblast growth factor (bFGF) as well as vascular endothelial growth factor (VEGF)-induced angiogenesis in rabbit and mouse corneal pocket assays (D'Amato et al, 1994) and, later, in several experimental cell and tissue models (Therapontos et al, 2009; Yabu et al, 2005). Furthermore, the production/expression of proangiogenic factors such as TNF- $\alpha$, NF-KB, IGF-1, IL-6, IL-8, PGE2, stromal cell-derived factor-1 (SDF-1) and C-X-C chemokine receptor type 4 (CXCR4) was suppressed by thalidomide (Bouyssou et al., 2016; Keifer et al., 2001). Thalidomide-mediated disruption of avß3 integrin signalling (Stephens and Fillmore, 2000) and ensuing decreased gelatinase production in response to fibronectin (Segarra et al., 2010), may also contribute to its antiangiogenic effect. Moreover, thalidomide inhibited leukocyte adhesion and intercellular adhesion molecule-1 (ICAM-1), vascular cell adhesion molecule-1 (VCAM-1), and E-selectin expression in TNF-a/LPS-activated human intestinal microvascular endothelial cells (Rafiee et al., 2010). Thalidomide inhibited TGF- $\beta 1$-induced epithelial to mesenchymal transition (EMT) in alveolar epithelial cells via Smad-dependent and Smad-independent signalling pathways (Zhou et al., 2017a).

The anti-inflammatory and immunomodulatory activity of thalidomide mainly relies on its modulation of the secretion and activities of various cytokines including interleukin 6 (IL6), IL-10, IL-12, IL-1, , and TNF- $\alpha$ and these modulatory effects may contribute to its 
antiproliferative and antiangiogenic effects. Thalidomide inhibits TNF- $\alpha$ production in lipopolysaccharide-induced human monocytes and mouse macrophages by enhancing degradation of its mRNA (Rowland et al., 1998). Afterwards, thalidomide was shown to downregulate NF-KB, an essential transcription factor for TNF and other cytokines, through suppression of IKB kinase activity (Keifer et al., 2001).

Immunomodulatory properties of thalidomide include also T-cell co-stimulation, with ensuing augmented production of IL-2, IL-12, and IFN- $\gamma$ and consequent NK cells activation (Kawamata et al., 2006). For thalidomide derivatives, lenalidomide and pomalidomide, it was demonstrated that co-stimulation of T cells and NK activation is linked to degradation of T cell repressors Ikaros and Aiolos via modulation of CLR4 ${ }^{\text {CRBN }}$ (Fionda et al., 2015).

\subsection{Antihypertensives}

Antihypertensives constitute a heterogeneous group of drugs used for the treatment of high blood pressure. Four major pharmacological classes with a relation to the MDR phenotype will be briefly discussed here: calcium channel blockers, angiotensin receptor blockers, diuretics and $\beta$-blockers.

\subsubsection{Calcium channel blockers}

Calcium channel blockers (CCBs) are used in treatment of hypertension, Angina pectoris and supraventricular tachycardia. The first original report on the pharmacological reversal of the MDR phenotype appeared more than 35 years ago with the calcium-channel blocker verapamil (Tsuruo et al., 1981). CCBs are historically significant in MDR research as the first drug repurposing attempt in MDR treatment. Initially, P-gp/MDR1/ABCB1 was identified as the binding target for a series of CCBs (Safa et al., 1987) and later on, most of the dihydropyridine and non-dihydropyridine CCBs (nicardipine, nifedipine, niludipine, nimodipine, nitredipine, diltiazem, quinidine, and trifluoperazine) were shown to increase drug accumulation and cytotoxicity in MDR cells (Bruno et al., 1990; Ford et al., 1989). Some of them not just block P-gp transport activity, but also MRP1/ABCC1 (Abe et al., 1995) and 
BCRP/ABCG2 (Shukla et al., 2006). Unfortunately, even though verapamil is considered as one of the most effective and safe medicines by the World Health Organization (WHO), it failed in clinical trials for reversal of cancer MDR reversal due to adverse pharmacokinetic interactions and toxicity issues. Nifedipine also failed in a phase I clinical trial due to doselimiting cardiovascular effects (Philip et al., 1992). These findings led to the development of a second and third generation of P-gp inhibitors with higher specificity, but clinical trials failed to show MDR reversal benefits (Nobili et al., 2006), in part, because of the presence of the ABC transporter-independent mechanisms of resistance. There are currently no approved inhibitors of P-gp for clinical use in treatment of MDR cancers. Instead, multifunctional drugs targeting several other mechanisms of the MDR phenotype were used or designed in the past few years (Palmeira et al., 2012).

\subsubsection{Angiotensin II receptor inhibitors}

The renin angiotensin system (RAS) is the major regulator of blood pressure and blood volume homeostasis. Major targets addressed by antihypertensive therapy are (1) angiotensin converting enzyme (ACE)- that converts angiotensin I to angiotensin II- and (2) angiotensin receptor 1 (AT1R) to which angiotensin II binds. ACE inhibitors and angiotensin receptor blockers (ARBs) improve cancer patients' survival by mechanisms other than antihypertensive action (Sun et al., 2017). In the past decade, it has been shown that ARBs also act as $A B C$ transporter inhibitors. Losartan, telmisartan, irbesartan, candesartan, and valsartan (collectively Sartans) are well tolerated ARBs. Telmisartan showed the most prominent effects on $A B C$ transporter function: it is a strong transport inhibitor of $\mathrm{P}$ gp/MDR1/ABCB1 (more potent in inhibition of P-gp than the known inhibitors verapamil and quinidine), and a moderate inhibitor of BCRP/ABCG2 and MRP2/ABCC2 (Weiss et al., 2010). Candesartan is also a P-gp/MDR1/ABCB1 and BCRP/ABCG2 inhibitor, while irbesartan is a rather weak P-gp/MDR1/ABCB1 inhibitor (Weiss et al., 2010). Given that telmisartan has the highest volume of distribution of all ARBs with long duration of action (Schmidt and Schieffer, 2003), it represents a promising agent for repurposing to treat MDR. 
Physiologically achievable concentrations of telmisartan in patients and healthy volunteers may affect the concentration of BCRP/ABCG2 substrates. A daily dose of $40 \mathrm{mg}$ telmisartan increased the systemic exposure to rosuvastatin (statins are used to prevent cardiovascular disease and are BCRP/ABCG2 substrates), presumably due to telmisartan inhibition of BCRP/ABCG2 efflux activity (Hu et al., 2016). Telmisartan also increased the area under the curve (AUC) for digoxin, a prototypical P-gp/MDR1/ABCB1 transport substrate, in healthy volunteers (Stangier et al., 2000). In addition to AT1R inhibition, telmisartan also has partial PPARY agonistic activity at physiological concentrations (Benson et al., 2004) and influenced the BCRP/ABCG2 membrane localization (see section 3.3. on antidiabetic drugs).

\subsubsection{Diuretics}

Diuretics increase the elimination of excess salt and water through kidneys and are one of the first line antihypertensives prescribed either alone or in combination with CCBs, ACE inhibitors or ARBs (James et al., 2014). In the early 1990s, it was described that MDR cells display increased intracellular $\mathrm{pH}$ and increased $\mathrm{Na}^{+} / \mathrm{H}^{+}$exchanger (NHE) activity (Boscoboinik et al., 1990), which led to the hypothesis that cytosolic acidification through $\mathrm{Na}^{+} / \mathrm{H}^{+}$exchanger (NHE) inhibition may contribute to sensitization of intrinsic MDR (Harguindey and Cragoe, 1992). The potassium-sparing diuretic amiloride, which is an NHE inhibitor, was the first diuretic tested in MDR in vitro, but did not cause reversal of drug resistance in Chinese hamster ovary $(\mathrm{CHO})$ cells. Nevertheless, a series of amiloride analogs were later synthetized which were found to sensitize $\mathrm{CHO}$ cells to vinblastine (Epand et al., 1991). Decades later, amiloride analogs were shown to increase doxorubicin accumulation and to inhibit proliferation in MDR colon carcinoma cells (Pannocchia et al., 1996). Amiloride itself modulated the splicing of apoptotic genes and synergized with imatinib in chronic myeloid leukemia cells (Chang et al., 2011). As NHEs increased both intracellular $\mathrm{pH}$ as well as the pHof the tumor microenvironment (Harguindey et al., 2005), NHE inhibitors are still explored (Harguindey et al., 2013) in the context of MDR reversal (e.g. cariporide) (Chen et al., 2019), as agents promoting apoptosis (Li et al., 2014a; Gao et al., 2011); as 
well as detection agents for the localization of tumor acidity and monitoring of therapy response in brain tumors (Albatany et al., 2018; Albatany et al., 2019).

Several loop diuretics that act on the Henle loop in the kidney in patients with impaired kidney function can be exploited for MDR reversal. Low doses of furosemide increased epirubicin accumulation in MDR bladder cancer cells, although the exact mechanism was not elucidated (Speers, 2006). Ethacrynic acid is an inhibitor of $\mathrm{Na}^{+} / \mathrm{K}^{+} / \mathrm{Cl}^{-}$ cotransporter and glutathione S-transferases. It partially reversed resistance to doxorubicin in sarcoma cells (Efferth and Volm, 1993).

\subsection{4. $\beta$-blockers}

$\beta$-blockers are competitive inhibitors of $\beta$-adrenergic receptors used against heart rhythm disturbances as well as second line medications against hypertension (Wiysonge et al., 2017). Carvedilol - a selective third generation $\beta_{1}$-agonist, which also has $\alpha_{1}$-blocking and antioxidant activity, reduced P-gp transport activity and increased doxorubicin toxicity in triple negative breast cancer Hs578T-Dox cells (Jonsson et al., 1999). The concentration needed to achieve this effect was $10 \mu \mathrm{M}$, which was much higher than the clinically achievable levels. Later on, more realistic concentrations of carvedilol $(1 \mu \mathrm{M})$ were tested and shown to increase the efficacy of vinblastine, paclitaxel, doxorubicin, and daunorubicin via inhibition of P-gp-overexpressing HeLa cells (Kakumoto et al., 2003). In the same study, propranolol ( $\beta_{1}$ - and $\beta_{2}$-adrenoreceptor blocker), metoprolol and atenolol ( $\beta_{1 \text {-selective }}$ blocker) did not affect P-gp efflux function, implying that the effects were independent of $\beta$ blocker activity (Takara et al., 2004).

\subsection{Antidiabetics}

MDR cells have a higher ATP demand, as ABC transporters hydrolyze ATP to energize the efflux of cytotoxic substrates and are therefore more sensitive to glucose deprivation (Kam et al., 2015). This feature has been harnessed to limit the growth of MDR cells in vitro in two ways: first, by treating cells with non-toxic drug substitutes that are $A B C$ 
substrates, thus forcing MDR cells to "waste" ATP on drug efflux rather than cell proliferation; second, by preventing ATP generation by targeting cancer cell metabolism. To this end, antidiabetic drugs have been intensively investigated for cancer treatment (Klil-Drori et al., 2016; Saraei et al., 2019). Intriguingly, mechanisms other than ATP depletion contribute to anti-MDR effects of select anti-hyperglycemic drugs. For instance, metformin mainly modulates AMPK activation through LKB1 which activates and/or inactivates various downstream signaling targets such as mTOR, PTEN/PI3K-Akt, MAPKs, transcription factors (NF-KB, FOXO) and p53 (Kamarudin et al., 2019).

\subsubsection{Biguanides}

Biguanides are oral anti-hyperglycemic drugs used to treat diabetes mellitus or its precursor stages. The most widely used drug from this class is metformin, while phenformin and buformin were withdrawn from the market due to toxicity. Metformin also has widely recognized anti-cancer properties (Saraei et al., 2019) through modulation of mitochondrial bioenergetics and decrease of ATP supply (Vial et al., 2019). It selectively killed CSCs in mouse models of triple-negative breast cancer (TNBC) (Hirsch et al., 2009) and inhibited stem cell population maintenance by transcriptional repression of EMT (Vazquez-Martin et al., 2010). Metformin reversed the MDR phenotype in several cancer models. The expression of P-gp/MDR1/ABCB1 and MRP1/ABCC1, as well as of HIF-1 $\alpha$ was downregulated through the AMPK/mTOR pathway in 5-fluorouracil (5-FU)-resistant hepatocellular carcinoma cells, which sensitized cells to 5-FU (Ling et al., 2014). The doxorubicin-induced expression of P-gp/MDR1/ABCB1 and HIF-1 $\alpha$ was decreased in the presence of metformin both in vitro in MCF7-Dox breast cancer cells and in vivo in patientderived breast cancer xenograft model (Davies et al., 2017). In another study, the expression of P-gp/MDR1/ABCB1 was not changed in MCF7-Dox cells upon metformin treatment, but the activity of P-gp/MDR1/ABCB1 was decreased and the cytotoxicity of doxorubicin increased due to ATP depletion (Shafiei-Irannejad et al., 2018b). In resistant MCF7-FU cells, metformin reversed MDR by activation of the AMPK pathway and reversed the epithelial- 
mesenchymal transition (EMT) (Qu et al., 2014). In MCF7-ADR cells, metformin also inhibited P-gp/MDR1/ABCB1 expression through AMPK activation, inhibition of NF-kB and CREB-mediated transcription (Kim et al., 2011). Both metformin and phenformin increased the sensitivity of radiation- and 5-FU-resistant rectal cancer cells by attenuation of antiapoptotic gene expression and inhibition of EMT (Park et al., 2019). The combination of metformin and 2-deoxyglucose (2-DG) induced severe metabolic stress and autophagy in several in vitro models (prostate, MCF7-Dox, K562-Dox) and increased intracellular accumulation of chemotherapeutics and p53-mediated apoptosis (Ben Sahra et al., 2010; Xue et al., 2016; Xue et al., 2017). Most recently, nanoparticle-based co-encapsulation of doxorubicin and metformin showed increased cytotoxicity compared to the combination of the free drugs in vitro in MCF7-Dox cells through increased accumulation of doxorubicin (Shafiei-Irannejad et al., 2018a).

Given that metformin is an AMPK activator and ETC Complex I inhibitor (Wheaton et al., 2014) that decreases glucose oxidation (Fendt et al., 2013), modulates autophagy (Kim and You, 2017) and eradicates CSCs in combination with chemotherapy (Hirsch et al., 2009), it holds great promise in drug repurposing for cancer treatment, regardless of its effects on MDR.

\subsubsection{Thiazolidinedones}

Thiazolidinedones (glitazones) are a class of anti-hyperglycemic drugs that activate peroxisome proliferator receptor $\mathrm{Y}$ (PPARY). PPARY-induced transcription regulates increased storage of fatty acids in adipocytes, thus promoting oxidation of glucose to yield energy. Pioglitazone and rosiglitazone are approved for the treatment of diabetes mellitus type 2, while several experimental glitazones were withdrawn from clinical studies due to hepatotoxicity (e.g. troglitazone). As a result of an updated review in 2016, the FDA concluded that the use of pioglitazone may be linked to an increased risk of bladder cancer. In 2011, France and Germany suspended the use of pioglitazone, and five years later the marketing authorization in the European Union expired. Nevertheless, glitazones are still 
preclinically studied as anticancer agents. Although contradictory results were reported regarding both tumor inhibiting and tumor promoting roles of PPARY (Krishnan et al., 2007), therapeutic combinations with PPARY agonists have been suggested for the treatment of several cancer types (Skelhorne-Gross and Nicol, 2012; Veliceasa et al., 2008). With regards to MDR, PPARy agonists inhibited ABC transporter mRNA transcription, altered their membrane localization and decreased drug efflux. Rosiglitazone and troglitazone were significant inhibitors of P-gp/MDR1/ABCB1 and BCRP/ABCG2 function in hepatocellular carcinoma cells (Weiss et al., 2009) and downregulated the mRNA expression of Pgp/MDR1/ABCB1 in lung cancer cells (Konieczna et al., 2015) and K562-DOX cells (Yousefi et al., 2015). Rosiglitazone treatment decreased resistance to paclitaxel, doxorubicin, cisplatin, and 5-FU in MDR ovarian cancer cells, where it reduced both P-gp/MDR1/ABCB1mediated drug efflux and mRNA transcription, the latter one through reduction of $T C F 4 / \beta-$ catenin transcriptional activity (Zhang et al., 2015a). Pioglitazone and rosiglitazone induced PTEN-Akt-mediated translocation of BCRP/ABCG2 away from the membrane thus limiting drug efflux, while they were weak inhibitors of this pump itself (To and Tomlinson, 2013). Telmisartan, a partial PPARy agonist also exerted this effect. Pioglitazone prevented doxorubicin-induced P-gp/MDR1/ABCB1 expression and doxorubicin resistance in 134B osteosarcoma cells (Higuchi et al., 2019). Importantly, the combination of pioglitazone and doxorubicin was tested in vivo in a patient-derived osteosarcoma model. It induced significant tumor necrosis and was superior to doxorubicin treatment alone. Although these in vivo effects were not solely the consequences of the P-gp/MDR1/ABCB1 modulation, these findings represent an important step for drug repurposing of glitazones. As only discrete reports on glitazones' effects on the mRNA expression and function of single ABC transporters are available, more comprehensive studies on MDR-mediating drug efflux pumps are needed. In addition, given the toxicity of glitazones in clinical trials for diabetes, special formulation strategy (e.g. tumor-targeted, nano-encapsulation) are of importance for advancing clinical cancer trials. 


\subsection{Anthelmintics}

\subsubsection{Niclosamide}

Niclosamide, a safe and well-tolerated anthelmintic agent, has been identified as a potential anticancer agent with cytotoxic and/or anti-invasive effects against a variety of cancers, such as leukemia (Jin et al., 2010), lung cancer (Lee et al., 2014), and osteosarcoma (Liao et al., 2015). In a recent study, niclosamide showed good activity against the acute lymphocytic leukemia CCRF-CEM cell line and its MDR counterpart CEM/ADR5000 which showed similar sensitivity as the parental cell line (Hamdoun et al., 2017). Niclosamide elevated reactive oxygen species (ROS) and glutathione levels in leukemia cells, and molecular docking studies revealed that niclosamide probably bound to the ATP-binding site of glutathione synthetase. Decreased NFAT (nuclear factor of activated T-cells) activity was also identified as a relevant mechanism for niclosamide's anticancer activity against resistant leukemia cells. In combination with cisplatin, niclosamide inhibited EMT and tumor growth in cisplatin-resistant TNBC cells (Liu et al., 2016). Niclosamide treatment also suppressed cell migration and invasion in enzalutamide-resistant prostate cancer cells via Stat3-AR axis inhibition (Liu et al., 2015).

\subsubsection{Mebendazole}

Mebendazole is an FDA-approved drug extensively used in anthelmintic therapy with a good safety profile for human use (Bai et al., 2011). Numerous studies showed that mebendazole displayed anticancer activities in a variety of human cancer types both in vitro and in vivo (Nygren et al., 2013). In a study, where 2,000 small molecules were screened, mebendazole was selected for further mechanistic studies of cancer cell growth inhibition based on its promising pharmacokinetic profile (Doudican et al., 2008). While it was largely nontoxic to normal melanocytes, mebendazole inhibited the growth of M-14 and SK-Mel-19, two chemoresistant melanoma cell lines. This anthelmintic triggered microtubule depolymerization and induced a dose- and time-dependent intrinsic apoptotic response in melanoma cells through phosphorylation of Bcl-2 (Doudican et al., 2008). In combination 
treatment with a gemcitabine derivative, mebendazole exerted cytotoxic activity against chemoresistant mammary adenocarcinoma SKBr-3 cells (Coyne et al., 2013).

\subsubsection{Albendazole}

Albendazole is a microtubule-targeting benzimidazole derivative introduced as anthelmintic drug in 1982. Albendazole has been increasingly recognized as an effective anticancer agent due to its low toxicity to normal cells and high efficacy against certain cancer types. In addition, there is emerging evidence supporting the repositioning of albendazole for the treatment of resistant cancers. Albendazole strongly inhibited the proliferation of human paclitaxel-resistant 1A9PTX22 ovarian cancer cells (Chu et al., 2009). Albendazole also evaded the MDR phenotype in epothilone- and paclitaxel-resistant leukemic CEM/dEpoB300 cells (Khalilzadeh et al., 2007). Indeed, albendazole was not found to be a P-gp substrate using various experimental approaches (Merino et al., 2002).

\subsubsection{Ivermectin}

Ivermectin is a macrocyclic lactone that was FDA-approved as an anthelmintic drug for human use in 1987. The potential of ivermectin to reverse MDR phenotype was recognized decades ago (Gros et al., 1986) and this drug was shown to be a substrate in vivo (Schinkel et al., 1994) as well as an inhibitor of P-gp in human MDR lymphocytic leukemia cells (Didier and Loor, 1996). Abamectin, the synthetic precursor of ivermectin, significantly reduced tumor growth and enhanced vincristine-induced suppression of Ehrlich carcinoma growth in vivo (Drinyaev et al., 2004). Ivermectin restored tamoxifen sensitivity in human TNBC MDA-MB-231 cells (Kwon et al., 2015).

\subsection{Antimalarials}

\subsubsection{Chloroquine and hydroxychloroquine}


Chloroquine (CQ) and hydroxychloroquine (HCQ) are well-known 4-aminoquinolines with a long history in anti-malarial therapeutics. Various preclinical studies supported the use of $\mathrm{CQ}$ and $\mathrm{HCQ}$ as anticancer agents, particularly if combined with conventional chemotherapeutics. Current anticancer therapies frequently induce autophagy in cancer cells, which is linked with resistance to therapy. CQ and HCQ act as autophagy inhibitors and therefore sensitize cancer cells to chemotherapy. Preclinical data highlight an anti-tumor effect of $C Q$ in different cancer mouse models with some reports that show also a protumorigenic function. These results are connected to the dual role of autophagy and Iysosomal biogenesis in cancer and MDR (Stark et al., 2020; Zhitomirsky and Assaraf, 2014; Zhitomirsky and Assaraf, 2016) and highlight possible secondary mechanisms, which include among the others alterations of Toll-like receptor 9, p53 and CXCR4-CXCL12 pathways. In combination with chemo-, radio- and targeted therapies, CQ increased anti-tumor efficacy in many mouse models (Verbaanderd et al., 2017).

$\mathrm{CQ}$ has sensitized cell lines of a variety of cancer types to chemotherapeutics, both in vitro and in vivo, including glioblastoma (Golden et al., 2014; Shen et al., 2013), melanoma (Goodall et al., 2014; Xie et al., 2013), breast cancer (Cook et al., 2014; Cufí et al., 2013; Maycotte et al., 2012), gastric cancer (Zhang et al., 2015b), hepatocarcinoma (Ding et al., 2011; Guo et al., 2012), colon cancer (Kaneko et al., 2014; Sasaki et al., 2012), and lung cancer (Divac Rankov et al., 2017; Tang et al., 2015).

$\mathrm{CQ}$ also sensitized cancer cells to chemotherapy via autophagy-independent mechanisms. This antimalarial drug induced alkalization of the $\mathrm{pH}$ of intracellular acidic compartments including lysosomes and prevented the entrapment of protonated chemotherapeutic drugs, thereby increasing their efficacy (Maycotte et al., 2012; Pascolo, 2016; Zhitomirsky and Assaraf, 2014; Zhitomirsky and Assaraf, 2016). CQ restored the sensitivity of doxorubicin-resistant myeloid leukemia cells to daunorubicin and doxorubicin by this mechanism. If applied in combination, CQ sensitized mouse breast cancer cells to cisplatin by a mechanism independent of autophagy inhibition (Maycotte et al., 2012). 


\subsubsection{Primaquine and mefloquine}

In addition to $C Q$, other anti-malarial drugs also modulated MDR. CQ, primaquine and mefloquine, are P-gp substrates and inhibited the efflux of other substrates (Chairat et al., 2018; Pham et al., 2000; Rijpma et al., 2014) as additional sensitization mechanism in drugresistant cancers with $\mathrm{P}$-gp overexpression. The chemosensitizing potential of $\mathrm{CQ}$, primaquine, and mefloquine was demonstrated in P-gp-overexpressing vinblastine-resistant KBV20C oral cancer cells (Choi et al., 2016). Vinblastine co-treatment with primaquine or mefloquine increased the sensitization of KBV20C cells, whereas this effect was not achieved by co-treatment with CQ (Kim et al., 2013b). Primaquine also sensitized KBV20C cells to other anti-mitotic drugs such as vinblastine, vinorelbine, paclitaxel, docetaxel, vincristine, and halaven (eribulin). Mefloquine also sensitized vinblastine-resistant cancer cells to all investigated anti-mitotic drugs. However, CQ showed some specificity and displayed synergy only in co-treatment with anti-mitotic drugs (paclitaxel, docetaxel, vincristine, and halaven).

\subsubsection{Amodiaquine}

Amodiaquine, an FDA-approved antimalarial drug with a known safety and pharmacology profile that was identified as an anticancer agent candidate by a computational approach and also suppressed chemoresistance in a multiple myeloma cancer cell line through inhibition of the heat shock protein 27 chaperone function (Salentin et al., 2017).

\subsubsection{Artemisinin derivatives}

Artemisinin and its derivatives are well-established antimalarial drugs. The sesquiterpenoid artemisinin has been isolated from Artemisia annua L., a plant that was used for centuries in traditional Chinse medicine. Since the middle of the 1990s, it turned out that this class of compounds is also active against cancer cells (Efferth et al., 1996; Efferth et al., 2001; Lai and Singh, 1995). During the subsequent years, a plethora of data was published 
unambiguously demonstrating the anticancer activity of artemisinin-type drugs in vitro and in vivo (Efferth, 2005; Efferth, 2017). Investigation of animal models did not only include syngeneic and xenograft tumor models in rodents, but also spontaneously occurring tumors in pets (dogs and cats) treated in veterinary medicine (Hosoya et al., 2014; Rutteman et al., 2013). Artemisinin and derivatives induce reactive oxygen and nitrogen species and, thereby, DNA damage, which can be repaired by single and double-strand break DNA repair mechanisms (Berdelle et al., 2011; Li et al., 2008). Artemisinin also binds to specific target proteins (e.g. translationally controlled tumor protein, TCTP). The inhibition of diverse

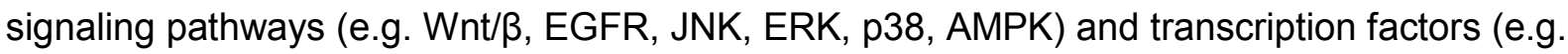
$\mathrm{NF}-\mathrm{kB}, \mathrm{mTOR}, \mathrm{Myc}, \mathrm{AP} 1$ ) results in inhibition of proliferation, angiogenesis, and metastasis and ultimately induction of several cell death mechanisms, such as apoptosis, autophagy, and ferroptosis (Efferth, 2017). As approved drugs, their untoward toxicity profile is wellknown from numerous malaria studies. Artemisinin-type drugs are generally well tolerated and severe toxicities are infrequent, although not absent (Efferth and Kaina, 2010). This makes them attractive candidates for drug repurposing.

\subsection{Antifungals}

\subsubsection{Itraconazole}

Itraconazole (ITZ) is an FDA-approved and relatively safe antifungal medication increasingly recognized for its anticancer potential (Pounds et al., 2017). As antifungal drug, the mechanism of action of ITZ involves the inhibition of lanosterol 14- $\alpha$-demethylase, an enzyme that produces ergosterol in fungi and cholesterol in mammals. The anticancer action of ITZ is achieved via mechanisms such as Hedgehog $(\mathrm{HH})$ pathway inhibition, inhibition of angiogenesis and endothelial cell proliferation, cell cycle arrest, and MDR reversal (Pantziarka et al., 2015). The reversal of MDR in vitro was shown in doxorubicin- and etoposide-resistant human leukemia cells (Kurosawa et al., 1996).

ITZ and arsenic trioxide, alone or in combination, inhibited the activation of the $\mathrm{HH}$ pathway, reduced the growth of medulloblastoma and basal cell carcinoma in vivo, and 
prolonged survival of mice with intracranial drug-resistant medulloblastoma (Kim et al., 2013a). ITZ inhibited P-gp in NIH-3T3-G185 cells (Wang et al., 2002). The ability of ITZ to inhibit BCRP was demonstrated in human topotecan-resistant BCRP-expressing human embryonic kidney (HEK) cells (Gupta et al., 2007). Treatment with ITZ also significantly reversed resistance to topotecan. ITZ-dependent growth suppression of endothelial cells and cancer-associated fibroblasts resulted in synergistic effects with bevacizumab in bevacizumab-resistant human gastrointestinal cancer cells (Hara et al., 2016). In nude mice, the combined treatment of ITZ and bevacizumab significantly reduced xenograft tumor volume and weight, as well as microvessel density.

\subsection{Antibiotics}

\subsubsection{Anisomycin}

Anisomycin is an antibiotic produced by Streptomyces griseolus and a well-known inhibitor of protein synthesis. This antibiotic sensitized melanoma and mesothelioma cells to apoptosis induced by TNF-related apoptosis-inducing ligand (TRAIL) (Slipicevic et al., 2013). In glucocorticoid resistant acute lymphoblastic leukemia (ALL) CEM-C1 cells, anisomycin induced apoptosis via activation of mitogen-activated protein kinases p38 and JNK (Liu et al., 2012). Anisomycin induced dramatic growth inhibition and apoptosis in a concentration- and time-dependent manner, and induced cell cycle arrest at $\mathrm{G}_{0} / \mathrm{G}_{1}$ phase in CEM-C1 cells by increasing expressions of p21 and p27, and decreasing cyclin A expression. In contrast, cell death induced by anisomycin and anisomycin analogs did not require JNK activation and protein synthesis inhibition in MDR breast cancer cells (Monaghan et al., 2014). More than 1,200 approved compounds were screened in the MDR P-gp-overexpressing TNBC cell line MDA16, and anisomycin was identified as candidate drug with good activity against the MDR phenotype that could be repurposed. Anisomycin-induced cell death in MDA16 cells was caspase-independent and no correlation was found between cell death and protein synthesis or JNK activation. This suggests that cell death was triggered by a ribosome-anisomycin complex or anisomycin bound to another target. 


\subsubsection{Monensin}

Monensin is a polyether ionophore antibiotic produced by Streptomyces cinnamonensis which acts as a monovalent cation ionophore. Due to its toxicity monensin is not used in human medicine, and is approved by the FDA as a veterinary drug. Although research of monensin as repurposed drug in cancer therapy is still in its infancy, it demonstrated therapeutic potential against resistant cancers. Monensin effectively sensitized glioma cells, but not normal astrocytes, to TRAIL-mediated apoptosis (Yoon et al., 2013). This is a promising finding considering that many human cancers exhibit intrinsic or acquired resistance to TRAIL-induced apoptosis. Monensin displayed significant cytotoxic activity towards human ovarian HeyA8 and SKOV3 cancer cells by suppressing multiple cancerrelated pathways including Elk1/SRF, AP1, NFkB and STAT (Deng et al., 2015). Monensin synergized with oxaliplatin in inhibiting cell proliferation and inducing apoptosis of ovarian cancer cells. In vivo, monensin inhibited tumor xenograft growth by suppressing EGFR signaling (Deng et al., 2015). It also increased doxorubicin accumulation in MDR DLKP-A10 lung cancer cells and promoted its redistribution from the cytoplasm to the nucleus (Clary et al., 1997). The potential of repurposing monensin was also studied to treat chemoresistant pancreatic cancer (Wang et al., 2018). Monensin inhibited cell proliferation, migration, and cell cycle progression, and triggered apoptosis in PANC-1 and MiaPaCa-2 cells. In combination treatments with gemcitabine and erlotinib, monensin synergistically suppressed cell growth and induced cell death in chemoresistant pancreatic cancer cells. Monensin suppressed cancer-associated pathways, including E2F/DP1, STAT1/2, NFkB, AP-1, Elk1/SRF, and EGFR. In vivo, monensin reduced the proliferation and growth of pancreatic ductal adenocarcinoma xenografts in nude mice via targeting the EGFR pathway.

\subsubsection{Salinomycin}

Salinomycin, another ionophore polyether antibiotic, is produced by Streptomyces albus and is used in veterinary medicine against coccidiosis. However, salinomycin also 
possesses significant anticancer properties and specifically kills breast CSCs (Gupta et el., 2009). Salinomycin is also a potent P-gp inhibitor in MDR cancer cell lines (Riccioni et al., 2010). Treatment of MDR CEM-VBL 10 and CEM-VBL 100 leukemia, and A2780/ADR human ovarian carcinoma cells with salinomycin restored their sensitivity to drugs. This antibiotic also overcame MDR in human KG-1a promyeloblastic leukemia cells expressing Pgp, breast cancer resistance protein (BCRP) and MRP8 transporters (Fuchs et al., 2010). KG-1a cells, which display stem cell features (e.g. CD34 expression) and are resistant to various chemotherapeutic drugs, exhibited significant sensitivity to apoptosis induction by salinomycin. The long-term presence of low doses of this compound prevented the development of resistance towards bortezomib and doxorubicin.

\subsubsection{Gramicidin A}

Gramicidin A is a pore-forming pentadecapeptide antibiotic produced by Bacillus brevis that changes cellular transmembrane potential by activating the $\mathrm{Na}^{+} / \mathrm{K}^{+}$-ATPase (Stankovic et al., 1989). Gramicidin A acts as a channel for inorganic monovalent ions such $\mathrm{K}^{+}$and $\mathrm{Na}^{+}$. A combination of gramicidin $\mathrm{A}$ and curcumin was used to further stimulate ATP exhaustion in ABCG2-transfected HEK-293 cells and flavopiridol-selected MCF-7/FLV1 cells (Rao et al., 2014). Furthermore, it should be noted that gramicidin D was found to be a bona fide substrate of P-gp and that upon gradual selection of cultured $\mathrm{CHO}$ cells, a marked mdr1 gene amplification occurred (Assaraf and Borgnia, 1994; Eytan et al., 1994). While single treatments with gramicidin A or curcumin did not cause collateral sensitivity, depletion of intracellular ATP in combined treatments selectively killed resistant cancer cells. Moreover, gramicidin A inhibited tumor growth and angiogenesis in therapy-resistant renal cell carcinoma via inhibition of the transcription factor hypoxia-inducible factor (HIF) (David et al., 2014). Gramicidin A destabilized HIF-1 $\alpha$ and HIF-2 $\alpha$ in normoxic and hypoxic conditions, which reduced HIF transcriptional activity and the expression of different hypoxia-response genes. Gramicidin A treatment reduced the growth of human renal cell carcinoma xenografts without significant toxicity in mice. 


\subsubsection{Minocycline}

Minocycline, an FDA-approved antibiotic, also showed a noteworthy potential regarding repurposing for anticancer treatment. Minocycline overcame chemoresistance and enhanced the efficacy of irinotecan, a chemotherapeutic agent used for treating refractory peritoneal carcinomatosis as well as colorectal, pancreatic, and small cell lung cancer. (de Man et al., 2018; Huang et al., 2017). Minocycline synergistically enhanced irinotecaninduced cell death in platinum-resistant epithelial ovarian cancer cells in vitro and reduced micrometastases in vivo.

\subsection{Antivirals}

\subsubsection{Brivudine}

Brivudine is a nucleoside analog with antiviral activity against Herpes simplex virus which also demonstrated significant anticancer properties by suppressing the development of chemoresistance (Heinrich et al., 2016). Brivudine combined with bortezomib effectively inhibited cell growth of bortezomib-resistant MM cells. Brivudine was a potent inhibitor of heat shock protein Hsp27 chaperone function by inhibiting the interaction of Hsp27 with proapoptotic proteins, which in turn restored the cellular capability to induce apoptosis.

The enhanced expression of human endogenous retroviruses was linked to chemoresistance in colon cancer. The antiviral drugs amantadine and pleconaril target components of human endogenous retroviruses endogenously expressed in drug-resistant colorectal cancer cells (Díaz-Carballo et al., 2015). Treatment with antiviral drugs alone or in combination with established chemotherapeutics such as doxorubicin, 5-FU or cisplatin, produced a synergistic antiproliferative effect and downregulated different endoretroviral elements in etoposide-resistant HCT8 colorectal cancer cells.

\subsection{Phenotiazines}


Phenothiazines demonstrated various pharmacological activities. Since the first synthesis and discovery of phenothiazines in the late $19^{\text {th }}$ century, a multitude of properties have been described such antiemetic, antipsychotic, antihistaminic, and anticholinergic effects (Ohlow and Moosmann, 2011; Varga et al., 2017). The $N$-substituted phenothiazines such as antihistaminic agents and antipsychotics were introduced into the clinical praxis in the 1940s and 1950s, respectively. Besides their various biological activities (antiviral, antimalarial, antiplasmid, antibacterial, antitumor, and anti-neurodegenerative) their rediscovery raised considerable interest to improve the treatment success of cancer patients by the phenothiazines' engrossing characteristics (Motohashi et al., 1999).

Phenothiazines exert their anticancer activities via different mechanisms. The potential of these compounds in cancer therapy is related to their adjuvant role sensitizing MDR cancer cells to conventional chemotherapeutic agents and radiotherapy.

\subsubsection{Influence on cell cycle and induction of apoptosis}

Thioridazine is an apoptosis inducer in different cancer cell lines in vitro (Kang et al., 2012; Spengler et al., 2011). Furthermore, trifluoperazine and chlorpromazine displayed antitumor activity in clinically relevant concentrations (Tuynder et al., 2004). Phenothiazines are capable of interfering with DNA repair mechanisms, e.g. DNA-dependent protein kinase and endonuclease activity (Eriksson et al., 2001). In addition, numerous proteins regulating the cell cycle can be influenced by phenothiazines. Tousled-like kinases (TLKs) controlling chromatin rearrangement are highly expressed in the $S$ phase of cell cycle and their inhibition can lead to genomic instability and apoptosis (Ronald et al., 2013). TCTP regulates the cell cycle and promethazine and thioridazine can eliminate cancer cells and significantly decrease the level of TCTP (Tuynder et al., 2004). Thioridazine decreases the expression of cyclin D1 and cyclin-dependent kinase 4 (CDK4) inhibiting the $\mathrm{G}_{1} / \mathrm{S}$ transition (Kang et al., 2012). Thioridazine, fluphenazine, and trifluoperazine were able to reduce tumor progression and formation of metastases in mice bearing TNBC xenografts reducing PI3K/AKT/mTOR and ERK signaling (Goyete et al., 2019). 


\subsubsection{Inhibition of MDR efflux pumps}

One of the best characterized mechanisms of MDR is the ability of cancer cells to extrude multiple anticancer drugs out of the cells due to the overexpression of ATPdependent efflux pumps. Phenothiazines can interfere with multidrug efflux pumps (e.g. Pgp) and increase the accumulation of anticancer agents in cancer cells (Akiyama et al., 1986). Moreover, P-gp-mediated drug efflux was inhibited by thioridazine treatment in mouse T-lymphoma cells (Spengler et al., 2014).

\subsubsection{Inhibition of angiogenesis}

Thioridazine blocks the angiogenesis stimulating effect of tumors. The administration of thioridazine into human ovarian tumor xenografts in nude mice significantly inhibited tumor growth and decreased tumor vascularity (Park et al., 2014). In addition, thioridazine exhibited anti-angiogenic activity in a melanoma model (Jiang et al., 2018).

\subsubsection{Generation of reactive oxygen species (ROS)}

Thioridazine caused nuclear condensation, loss of mitochondrial membrane potential, release of mitochondrial cytochrome $\mathrm{c}$ and induced the mitochondrial apoptotic pathway in cervical cancer. Thioridazine increased ROS production and ER stress leading to apoptosis (Seervi et al., 2018).

\subsubsection{Anti-cancer stem cell activity}

CSCs form a subpopulation within heterogeneous tumors. These cells are capable of self-renewal and they are responsible for metastases and chemoresistance. Thioridazine can inhibit the proliferation and invasion of colorectal CSCs. Furthermore, it increased the expression of pro-apoptotic genes, disrupted the mitochondrial membrane potential, thereby inducing apoptosis (Zhang et al., 2016). Chlorpromazine inhibited the stemness properties of 
breast cancer cells and enhanced the efficacy of doxorubicin and paclitaxel in combination towards breast cancer cells (Yang et al., 2019).

\section{Clinical studies to repurpose old drugs}

\subsection{Immunomodulatory imide drugs (IMiDs)}

Thalidomide induced marked and durable responses in some patients with MM, including those who relapsed after high-dose chemotherapy (Singhal et al., 1999). In 2006, the FDA approved thalidomide for MM therapy in combination with dexamethasone. In 2005, the FDA approved the use of lenalidomide in the treatment of myelodysplastic syndrome (MDS) with 5q deletion, of MM in 2006, of either relapsed or refractory mantle cell lymphoma in 2013 , as well as of adult patients with previously treated follicular lymphoma or marginal zone lymphoma in combination with rituximab, in 2019. Pomalidomide received the clinical approval for relapsed and/or refractory (advanced) MM in 2013. Moreover, clinical benefit from pomalidomide has been also described in other hematological malignancies, including chronic lymphocytic leukemia and non-Hodgkin lymphoma.

Despite the introduction of lenalidomide and pomalidomide, thalidomide is still included in therapeutic protocols for a number of hematological malignancies and several clinical trials are recruiting patients to evaluate its effects on oncology outcomes.

According to the American Society of Clinical Oncology (ASCO) and Cancer Care Ontario (CCO) MM treatment guideline (Mikhael et al., 2019), the use of a proteasome inhibitor with IMIDs and dexamethasone is the preferred induction therapy in transplanteligible patients. In an open-label phase III randomized trial enrolling 340 patients with newly diagnosed MM, bortezomib-thalidomide-dexamethasone (VTd) regimen was shown to be superior compared to bortezomib-cyclophosphamide-dexamethasone (VCd) before highdose therapy and autologous stem cell transplantation (ASCT) (Moreau et al., 2016). In September 2019, the FDA approved the use of human anti-CD38 monoclonal antibody daratumumab in combination with VTd (D-VTd) in newly diagnosed MM patients who are eligible for ASCT. The decision was taken after phase III CASSIOPEIA trial demonstrated 
that four pre-transplant (induction) and two post-transplant (consolidation) cycles of D-VTd induced a stringent complete response and a significant improvement in the secondary endpoint of minimal residual disease negativity compared to VTd regimen (Moreau et al., 2019).

The ECOG E1A06 trial (Stewart et al., 2015) demonstrated in transplant-ineligible MM patients that the disease-focused outcomes of a melphalan-prednisone-thalidomide (MPT) combination regimen is similar to that of melphalan-prednisone-lenalidomide (MPL), though quality of life was better with the MPL combination. The phase 3 FIRST trial demonstrated that treatment with lenalidomide and low-dose dexamethasone significantly improved survival outcomes versus MPT (Facon et al., 2018). Additionally, thalidomide may represent an option for MM relapsed patients especially if they are thalidomide-naïve or not eligible for bortezomib (Mikhael et al., 2019) and as maintenance treatment in association with bortezomib (Gay et al., 2018).

Currently, numerous clinical trials are recruiting MM patients to assess the efficacy of thalidomide, lenalidomide and pomalidomide, respectively, in newly diagnosed MM, relapsed and/or refractory MM and in consolidation therapy regimen (https://clinicaltrials.gov/).

\subsection{Antihypertensives}

Hydralazine $(\mathrm{HA})$ has been utilized as a smooth muscle relaxant and vasodilator against hypertensive disorders and heart failure. In cancer, HA acts as demethylating agent through inhibition of the DNA methyltransferase DNMT1 (Angeles et al., 2005). Since the correction of epigenetic alterations is a valid option in cancer therapy already approved for MDS and cutaneous T-cell lymphoma (CTCL), HA is under investigation together with magnesium valproate deacetylating agent (TRANSKRIP ${ }^{T M}$ ) (Dueñas-Gonzalez et al., 2014). It is well-tolerated as an anti-hypertensive drug. As a demethylating agent, it weakly inhibited DNMT1 avoiding toxicity associated with potent inhibitors. Dose ranging from $10 \mathrm{mg}$ four times a day in hypertensive patients up to $800 \mathrm{mg} / \mathrm{day}$ for heart failure did not show clear dose-response effects. HA was inactivated by acetylation in bowel and liver with a half-life 
time of $1 \mathrm{~h}$ and low systemic bioavailability (Dueñas-Gonzalez et al., 2014). The dosage depends on the ability of each single patient to acetylate the drug (slow and fast acetylators). An oral dose of $83 \mathrm{mg} /$ day (slow acetylators) or $182 \mathrm{mg} /$ day (fast acetylators) HA in combination with $700 \mathrm{mg} / \mathrm{TID}$ of valproate gave similar pharmacological parameters and were accepted for subsequent clinical trials (Garcés-Eisele et al., 2014). With this schedule, 16 locally advanced breast cancer patients were treated starting from day -7 to the end of four cycles of chemotherapy with doxorubicin and cyclophosphamide. Complete clinical response was obtained in $31 \%$ of patients with an overall response of $81 \%$ and reduced DNA methylation (Arce et al., 2006). Refractory cancer patients are eligible for epigenetic therapies due to the general effect of DNA methylation and histone acetylation. Seventeen solid tumors pretreated with different regimens were subject to TRANSKRIP therapy in association with the last administered chemotherapy. Out of the 15 evaluable patients, $80 \%$ had partial response or stable disease. The progression free survival (PFS) was 2.4-5.7 months and survival of 3.8-12.8 months suggesting a positive effect of the treatment (Candelaria et al., 2007). These data were confirmed in a phase II clinical trial, in which HA and valproate were added to cisplatin plus radiation therapy in 22 cervical cancer patients at FGO stage IIIB. All evaluable patients displayed a complete clinical response (Candelaria et al., 2010). From the preliminary results of a phase III double-blind, placebo-controlled, randomized trial in advanced cervical cancer patients, the addition of HA and valproate to chemotherapy increased the PFS from 6 to 10 months $(p=0.038)$. These data were sufficient for the approval of this regimen in Mexico (Coronel et al., 2011).

Epigenetic therapies have been approved for MDS and CTCL. For this reason, $\mathrm{HA} /$ valproate treatment was utilized in an open phase II clinical trial in 12 MDS patients. One complete response, one partial response and four transfusion independencies were obtained without serious toxicity. Two patients progressed to acute myeloid leukemia (AML) (Candelaria et al., 2011). The same clinical group reported a retrospective analysis of 14 MDS patients treated in a compassionate manner in which five achieved a complete response, one partial response, and two became transfusion-independent (Candelaria et al., 
2017). In previously untreated and progressive/refractory CTCL patients, the HA/valproate treatment achieved $50 \%$ complete response and $21 \%$ partial responses. FDA approved $\mathrm{HA} /$ valproate as an orphan drug treatment for MDS and CTCL (Espinoza-Zamora et al., 2017).

\subsection{Antidiabetics}

In 2005, a pilot case-control study demonstrated a dose-dependent inverse relationship between exposure of diabetics to metformin and risk of cancer (Evans et al., 2005). Since then, several epidemiological studies (Libby et al., 2009; Ruiter et al., 2012; Tsilidis et al., 2014) and meta-analyses (Coyle et al., 2016; Gandini et al., 2014; Soranna et al., 2012; Stevens et al., 2012; Tang et al., 2018; Thakkar et al., 2013; Wu et al., 2015; Yin et al., 2013; Zhang and Li, 2014; Zhang et al., 2018; Zhou et al., 2017b) evaluated the role of metformin in reducing overall or site-specific cancer incidence in patients with type 2 diabetes (T2D) and, most of them confirmed its preventive value. Furthermore, as metformin is widely prescribed alongside anticancer agents in patients with concurrent cancer and T2D, the adjuvant effect of this insulin sensitizer on cancer outcomes has been also investigated in several meta-analyses, that showed a reduced overall cancer mortality rate, although with conflicting results for individual tumor types (Lega et al., 2014; Yu et al, 2019).

For example, a meta-analysis of 21 observational studies demonstrated a reduction in both all-cause and cancer-specific mortality in T2D patients exposed to metformin. A subgroup analysis showed this association for colon cancer, but not for breast and prostate cancers (Lega et al., 2014). Another meta-analysis of 27 observational studies on 24,178 participants, metformin administration was associated with a significant improvement in recurrence-free survival (RFS), overall survival (OS) and cancer-specific survival (CSS) in patients with early-stage colorectal and prostate cancer but not with breast or urothelial cancer (Coyle et al., 2016). Accordingly, these differences in the adjuvant effects of metformin could be explained by patient characteristics and tumor biology. However, the inter-trial heterogeneity, a number of potential biases (i.e. time-related ones) and 
confounding factors, which are less controlled in observational studies than in clinical trials, limit the robustness of these results and the extrapolation of these evidences to the general population (Campbell et al., 2017; Morales and Morris, 2015; Yu et al., 2019). Furthermore, even the meta-analysis of randomized controlled trials (Gandini et al., 2014; Stevens et al., 2012; Wu et al., 2015) did not allow generalization of the results, as these trials were designed to assess the efficacy of metformin in T2D and in preventing/reducing the cardiovascular events associated with T2D (Heckman-Stoddard et al., 2017). Therefore, such limitations can only be overcome by randomized controlled trials with larger sample sizes and oncological outcomes, specifically designed to determine either the preventive or the adjuvant role of metformin. For this purpose, 132 completed, 85 still recruiting, and 32 still active but not recruiting trials, are enlisted (https://clinicaltrials.gov/). Some of these "metformin (neo)-adjuvant" trials are presented below.

TAXOMET (NCT01796028) was the first multicenter phase II trial evaluating the combination of metformin ( $850 \mathrm{mg}$ twice a day) with docetaxel $\left(75 \mathrm{mg} / \mathrm{m}^{2}\right.$ every 21 days) plus prednisone (5 $\mathrm{mg}$ twice a day), up to 10 cycles, in 99 non-diabetic metastatic castrationresistant prostate cancer (CRPC) patients (https://clinicaltrials.gov/). The results presented at the 2019 ASCO Annual Meeting showed that the addition of metformin to the standard of care did not add a meaningful clinical benefit over placebo in prostate specific antigen (PSA)response rate, progression-free survival (PFS), OS and quality of life (QoL) (Pujalte Martin et al., 2019). The small number of patients enrolled, the late stage of the disease and the short metformin exposure time may have clearly affected the results of the study.

The STAMPEDE trial (NCT00268476) is a multi-arm, multi-stage randomized controlled trial which started in 2005 with the aim to evaluate multiple therapeutic strategies in the management of high-risk localized or metastatic hormone-naïve prostate cancer (Clarke et al., 2019; James et al., 2017; Mason et al., 2017; Parker et al., 2018; Sydes et al., 2018). Since 2016, it has been recruiting non-diabetic prostate cancer patients for 7 years to assess whether metformin (850 $\mathrm{mg}$ twice a day) in addition to standard-of-care treatment (docetaxel or abiraterone) improved survival times and mitigated androgen deprivation and 
therapy-related metabolic dysfunction (Gillessen et al., 2016). The investigators planned to enroll 2,800 subjects, including 1,700 metastatic patients, with OS as both intermediate and definitive primary outcome measures.

Regarding breast cancer, the recently completed phase II, placebo-controlled METEOR study (NCT01589367) enrolled 203 post-menopausal participants with estrogen receptor-positive breast cancer to identify the anti-tumor effect of metformin (2000 mg/day) with preoperatively given letrozole $(2.5 \mathrm{mg} /$ day) applied for 24 weeks (Kim et al., 2014b). Women with a history of diabetes were excluded. The results presented so far obtained from 153 subjects (72 metformin, 75 placebo) showed that neither the primary outcome, the overall clinical response rate $(66.7 \%$ metformin and $56.4 \%$ placebo, $p=0.193)$, nor the secondary outcomes (breast conservation rate of, 68\%) reached statistical significance between the two arms. Importantly however, after four weeks of treatment, a greater number of patients displayed Ki-67 positivity of less than $10 \%$ in the metformin-treated group compared to the placebo group ( $87.5 \%$ vs. $33.3 \%, p=0.017$ ) (Kim et al., 2019).

The MA32 phase III, one of the largest ongoing trials, randomly assigned 3,649 nondiabetic breast cancer patients, stratified according to hormone-receptor and HER2 status, body mass index and prior chemotherapy, in order to apply metformin (850 mg twice a day) versus placebo for five years, in addition to standard adjuvant therapy (NCT01101438). The primary outcome was DFS, and main secondary outcomes were OS, distant DFS (DDFS) and breast cancer-free interval. Unfortunately, data on cancer outcomes are not yet available from this study, but only those on the metabolic profile, biomarkers and sex hormone levels of the women enrolled. After six months, metformin significantly improved weight and metabolic factors (insulin, glucose, leptin, highly sensitive C-reactive protein) in the first 492 patients (Goodwin et al., 2015). Another analysis on 3,256 women showed reduced levels of the tumor marker CA15-3 (Dowling et al., 2018). Moreover, metformin lowered estradiol in a subgroup of post-menopausal women with estrogen and progesterone receptor negative breast cancer (Pimentel et al., 2019). 
The open-label, phase II randomized METTEN (metformin and trastuzumab in neoadjuvancy) study (EudraCT number 2011-000490-30) evaluated the efficacy and safety of adding metformin (850 mg twice-daily) for 24 weeks to neo-adjuvant chemotherapy (paclitaxel, 5-fluorouracil, epirubicin, and cyclophosphamide) plus trastuzumab (MartinCastillo et al., 2018) in HER2-positive primary breast cancers. Metformin failed to significantly improve the pathologic complete response rate or to reduce the need for mastectomy in 84 women, although, a subsequent, prospective analysis showed a decreased proliferative capacity of residual breast cancer disease (Lopez-Bonet et al., 2019). The ongoing HERMET trial (NCT03238495) is still randomizing 100 participants with HER2positive, operable breast cancers treated with neo-adjuvant chemotherapy (docetaxel, carboplatin, herceptin plus pertuzumab) with or without addition of metformin.

In the context of adjuvant trials, ALTTO (adjuvant lapatinib and/or trastuzumab treatment optimization) is an ongoing, not recruiting phase III study (NCT00490139) that randomly assigned 8,381 HER2-positive breast cancer patients for one year to four different arms: trastuzumab or lapatinib alone, their sequence, or their combination (Piccart-Gebhart et al., 2016). A sub-section of this study (Sonnenblick et al, 2017) evaluated the impact of diabetes and the use of metformin on patient outcomes in ALTTO participants $(7,935$ subjects with no history of diabetes at study entry, 260 with diabetes and metformin treatment and 186 with diabetes, but no-metformin treatment). Use of metformin may reverse the worse prognosis associated with diabetes; in fact, patients with diabetes, not treated with metformin, experienced worse DFS (multivariable hazard ratio [HR], 1.40; $95 \% \mathrm{Cl}, 1.01$ to 1.94; $p=0.043$ ), DDFS (multivariable $\mathrm{HR}, 1.56 ; 95 \% \mathrm{Cl}, 1.10$ to $2.22 ; p=0.013$ ), and OS (multivariable HR, $1.87 ; 95 \% \mathrm{Cl}, 1.23$ to $2.85 ; p=0.004$ ) (Sonnenblick et al, 2017).

Therefore, the results of these already completed and still ongoing prospective trials are of paramount importance, although they do not allow yet to formulate general recommendations on the use of metformin in cancer patients.

\subsection{Anthelmintics}


Niclosamide is an essential drug utilized to fight tapeworm infection by interfering with mitochondrial oxidative phosphorylation. Numerous preclinical studies showed that niclosamide could alter many oncogenic pathways including NFAT, Wnt, STAT3 and mTOR leading to clinical trials on prostate and colorectal cancer (Barbosa et al., 2019; Hamdoun et al., 2017). As an anthelmintic drug, oral delivery of $2 \mathrm{~g} /$ day is sufficient to kill tapeworms in the gastrointestinal tract. The first clinical trial designed by the University of Washington tested at two doses at 500 or $1000 \mathrm{mg}$ three times a day in CRPC in combination with enzalutamide after abiraterone therapy (Schweizer et al., 2018). Five-hundred milligrams were considered as the maximal tolerated dose (MTD), since two patients reported adverse effects as diarrhea, colitis and nausea at $1000 \mathrm{mg}$ of niclosamide. The drug concentrations in the blood were under the threshold levels $(35.7-182 \mathrm{ng} / \mathrm{ml})$ necessary to reach effectiveness as established in preclinical studies. In fact, the circulating PSA levels did not decline, and it was concluded that oral niclosamide is not suitable for repurposing in CRPC treatment. In a different setting, the University of Davis designed a phase I clinical trial with niclosamide in combination with abiraterone and prednisone up to $1600 \mathrm{mg}$ three times daily (Pan et al., 2018). No signs of toxicity were reported, and PSA reduction was recorded in four patients with blood concentration between 100 and $162 \mathrm{ng} / \mathrm{ml}$. This result was confirmed in colorectal carcinoma, where $2 \mathrm{~g} /$ day niclosamide were not toxic and higher $\mathrm{C}_{\max }$ values were achieved (429-1777 $\mathrm{ng} / \mathrm{ml}$ ) (Burock et al., 2018). The authors concluded that the $C_{\max }$ values might positively correlate with a delay in disease progression. On this bases, phase II clinical trials were proposed. It remains to be established, whether the MTD allows to reach therapeutic dosages high enough to be effective against tumors (Frayha et al., 1997).

\subsection{Antimalarials}

$\mathrm{CQ}$ has been utilized to treat malaria. If Plasmodia degrade hemoglobin to obtain essential amino acids for anabolic processes, CQ binds the porphyrin ring $\mathrm{Fe}(\mathrm{II})$ protoporphyrin IX (FP) to form the FP-CQ complex, a toxic compound, which destroys the membrane of the malaria parasites. In human cells, CQ is an inhibitor of autophagy, a 
process utilized by normal cells to obtain energy under stress conditions such as glucose or oxygen deprivations. Autophagy and apoptosis networks are strictly connected and inhibition or activation of autophagy in cancer cells could have beneficial or detrimental effects. CQ inhibits autophagy by lysosome-endosome-autophagosome alkalization and fusion of autophagosome with lysosomes (Cuomo et al., 2019).

$\mathrm{CQ}$ is administered orally as phosphate $\mathrm{CQ}$ at a dose of $250 \mathrm{mg} / \mathrm{day}$. Long-term exposure is avoided because of severe toxicity such as renal dysfunction and cardiomyopathy. Different from niclosamide, CQ is a hydrophobic weak base that easily crosses cell membranes reaching a high bioavailability $(>80 \%)$ and a large volume of biodistribution. In the liver, $\mathrm{CQ}$ is dealkylated producing two active metabolites: monodesethylchloroquine and bisdesethylchloroquine. $\mathrm{CQ}$ is mainly excreted through the kidney and can be found in the urine for months (Verbaanderd et al., 2017).

Several clinical cancer trials are ongoing with $\mathrm{CQ}$ alone or in combination with chemotherapy and radiotherapy. The positive preclinical data obtained on rats with glioma treated with quinacrine (a $C Q$ analog) and carmustine led to the design of an open prospective randomized controlled study. Thus, glioblastoma multiforme (GBM) patients underwent surgery, radiotherapy (total dose $6000 \mathrm{~Gy}$ ), and four cycles of carmustine (i.v., $200 \mathrm{mg} / \mathrm{m}^{2}$ ) once every 6 weeks. CQ was administered every day (150 mg) after surgery on 9 patients which were paired with other 9 patients treated with placebo. Two years after surgery, all control patients died. By contrast, five patients died in the CQ-treated arm and Kaplan Meyer analysis denoted a significant longer survival (Briceño et al., 2003). In a second clinical trial started in 2000, the same research group studied 15 GBM patients treated with $\mathrm{CQ}$ following conventional radio- and chemotherapy (randomized, double-blind, placebo-controlled trial). Although not statistically significant, the data suggested the same trend of results obtained in the first clinical trial (Sotelo et al., 2006). In 2007, the retrospective analysis of 41 new GBM patients treated with CQ showed that the survival time almost doubled compared to the placebo arm (25 +/- 3.4 vs 11.4 +/- 1.3 months). Importantly, significant side effects were not noted (Briceño et al., 2007). In a phase II clinical 
trial, CQ was tested as a radiosensitizer in 39 patients with brain metastasis. Although the OS did not change, PFS at 1 year improved $(p=0.046)$ (Rojas-Puentes et al., 2013). This study was confirmed by another pilot trial in which 20 patients with brain metastases were treated with $C Q$ in combination with whole brain radiotherapy. A slight increase in OS was observed in patients with wild-type indoleamine 2,3-dioxygenase 2 (IDO2), an immunemodulatory enzyme inhibited by CQ, when compared to mutant IDO2 (Eldredge et al., 2013).

CQ (500 mg/day) was administered in combination with bortezomib and cyclophosphamide in 8 relapsed and refractory MM patients. A partial sensitization to bortezomib was observed and three patients had partial response and one patient presented with stable disease (Montanari et al., 2014). The combination of CQ with cyclophosphamide and prednisone did not improve the response of MM patients (Verbaanderd et al., 2017).

$\mathrm{HCQ}$ is under evaluation in clinical trials since a lower risk of retinal toxicity has been reported. A partial response was reported in different types of tumors, but it remained unclear which drug between $\mathrm{CQ}$ or $\mathrm{HCQ}$ had a better efficacy since comparative studies were not reported (Verbaanderd et al., 2017). A recent meta-analysis on three CQ and four HCQ trials showed better ORR, 1-year OS and 6-months PFS rates in GBM patients treated with CQ or HCQ (Xu et al., 2018).

Case reports on the compassionate treatment of cancer patients with artemisinin-type drugs indicated that these compounds may not only be active in the preclinical setting, but also in patients (Berger et al., 2005; Singh and Panwar, 2006). In subsequent years, several clinical trials have been published.

Twenty-three metastatic breast cancer patients were treated with 100-200 mg artesunate/day orally. Adverse side effects were observed in few patients (leuco- and neutropenia, auditory system disturbances, asthenia). Concentrations up to $200 \mathrm{mg} /$ day were considered as safe (von Hagens et al., 2017).

Dose-limiting toxicities in patients suffering from various solid tumors were investigated at doses 12 and $25 \mathrm{mg} / \mathrm{kg}$ intravenous artesunate. Recorded side effects were neutropenic fever, nausea and vomiting, hypersensitivity reactions and hepatic enzyme 
anomalies. In general, the treatment was well tolerated, and an MTD of $18 \mathrm{mg} / \mathrm{kg}$ was determined (Deeken et al., 2018).

Oral artenimol treatment of 10 women from the Ivory Coast with advanced cervical carcinoma led to the disappearance of disease symptoms (pain, vaginal discharge) within 7 days in median. In 6 patients, a relapse occurred after 6 months on average, while the remaining four patients had a median survival time of 12 months (Jansen et al., 2011).

Twenty-three colorectal cancer patients were treated with oral artesunate prior to surgery in a randomized double-blind placebo-controlled pilot study. A follow-up for 42 months showed that $1 / 9$ patients $(11.1 \%)$ treated with artesunate and $6 / 11$ placebo-treated patients (54.5\%) developed a recurrent disease (Krishna et al., 2014).

\subsection{Antifungals}

ITZ was developed more than 30 years ago to interfere with the synthesis of ergosterol, a sterol found in the fungal membrane. Preclinical studies indicated that ITZ inhibited the expression of P-gp and Wnt/ $\beta$-catenin, as well as angiogenesis and stromal stem cells signaling (Tsubamoto et al., 2017). As antifungal therapy, it was dosed as oral solution or tablets in the range of $100-600 \mathrm{mg}$ daily for one month. Inter- and intra-patient pharmacokinetic variability was observed with an average bioavailability of $55 \%$. ITZ is highly lipophilic and accumulates more in tissues than in plasma. It is well tolerated, but is not indicated during pregnancy or in patients with cardiac dysfunction (Pantziarka et al., 2015).

There are many clinical studies, which assessed the antifungal activity of ITZ as concomitant therapy in cancer patients. This is not the focus of the present review. Here we are evaluating the direct antitumor effect of ITZ. In phase II randomized controlled clinical trials, ITZ was evaluated in combination with daunorubicin in ALL and acute myeloid leukemia (AML) patients to reverse daunorubicin resistance as demonstrated in preclinical studies (Gupta et al., 1991). ITZ improved the DFS of 11 out of 23 ALL patients, although statistical significance was not reached $(p>0.05)$ (Vreugdenhil et al., 1993). In CRPC, 29 patients were treated with high dose ITZ (600 mg/day) showing a 2-years PFS of $48 \%$ 
compared to low dose $(200 \mathrm{mg} /$ day) treated patients $(n=17)$. However, the median PFS was similar to other treatments under evaluation (phase II, non-comparative randomized study). At high doses, $14 \%$ of patients experienced toxicity but not grade 4 (Antonarakis et al., 2013). Preclinical data indicated that ITZ downregulates the $H H$ pathway. Since $H H$ is important in basal cell carcinoma, 15 patients were treated twice a day with 100 or $200 \mathrm{mg}$ of ITZ in a phase II trial. The comparative analysis of primary endpoints (Ki-67 and $\mathrm{HH}$ biomarkers) in biopsies taken at baseline and at excision 1 month later demonstrated decreased cell proliferation and decreased GLI1 mRNA levels (Kim et al., 2014a). A phase II randomized controlled clinical trial was conducted in metastatic non-small-cell lung carcinoma (NSCLC) patients as second line therapy. The ITZ concentration used was 200 $\mathrm{mg} /$ day. The trial was interrupted on pre-term due to increased usage of pemetrexed in the first line therapy. The primary endpoint of PFS at three months was not reached (15 patients treated with pemetrexed versus 8 patients treated with pemetrexed + ITZ) (29\% versus 67\%; $p=0.11)$. However, the median OS was 8 months vs. 32 months $(H R=0.194, p=0.012)$. ITZ did not increase untoward toxicity (Rudin et al., 2013). As inhibitor of angiogenesis and drug efflux, ITZ was administered to refractory ovarian cancer patients in second- or third-line therapy (19 patients) at a dose of $400-600 \mathrm{mg} /$ day on days -2 to 2 or 3 , on a 2-week cycle. Median PFS and OS improved in ITZ-treated patients compared to standard therapy with an PFS HR $=0.24(p=0.002)$ and OS HR $=0.27(p=0.006)$. A survival advantage was also registered in a retrospective analysis of patients suffering from TNBC (Tsubamoto et al., 2014a), recurrent ovarian clear cell carcinoma (Tsubamoto et al., 2014b), pancreatic cancer (Tsubamoto et al., 2015a), or biliary tract tumors (Tsubamoto et al., 2015b) treated with chemotherapy in combination with ITZ.

The inhibition of $\mathrm{HH}$, angiogenesis or drug efflux by ITZ could impact the survival of different types of patients including tumors of prostate, ovarian, and NSCLC as well as leukemia (Pantziarka et al., 2015).

\section{Conclusions and future perspectives}


As there are currently no clinically approved cancer MDR chemosensitizing agents, drug repurposing provides a practical therapeutic strategy to resensitize MDR cancers to conventional chemotherapeutic agents. Drug repositioning offers the possibility of high rewards because of shorter times to market and higher possibility of differentiation as compared with in-licensing and reformulation strategies. An additional commercial incentive of drug repurposing is the possibility to prolong patents through the orphan status designation. In the past decade, over 100 drugs have been designated as orphan drugs by the FDA for the treatment of diverse tumor subtypes (Vokinger and Kesselheim, 2019). The majority of these cancer drugs that were approved with orphan status were indicated for solid tumors. Drug repurposing does not always succeed, however the causes for failure cannot be attributed to untoward toxicity, because the safety profiles of the candidates were previously characterized (Pushpakom et al., 2018).

In drug discovery processes, the starting point is a disease or condition without appropriate treatment options. Drug candidates that enter the time- and cost-intensive clinical trials will be tested for the main indication, but not for all possible diseases. Thus, there is a considerable probability that the drug could be used for different indications, although it was not initially identified as such. New applications can be discovered during clinical practice, and drug prescription can accordingly evolve, even if the alternative indication is not legally approved. For this approach, publicly available databases of clinical trials are essential. At present, access to clinical trial data is limited or requires mining of enormous amounts of unstructured data. In this respect, a variety of predictive computational approaches have been developed to identify drug repositioning opportunities, each based around a biological target of interest. The first step in a computational strategy for drug reprofiling is virtual screening using a variety of in silico methods that provide new predictions for compounds shown to have pharmacological activity. This approach requires well-curated macromolecular target databases that provide accurate structural information (Kharkar et al., 2014; Markosian et al., 2018). As highlighted in the current review, pharmacophore modelling, and pharmacophore- and docking-based virtual screening have proved to provide efficient and 
reliable solutions. Although outside the scope of this review, other remarkable computational tools are those that explore the genetic messengers to seek for drug repurposing opportunities (GNS et al., 2019). Such is the case of the web-based tool CMap that helped in the identification of sirolimus reversal of dexamethasone resistance in ALL patients (Wei et al., 2006).In the particular cases of cancer, immortalized human cancer cell lines (CCLs) represent plausible sources of data for drug repurposing. Keeping aside the known limitations of working with cell cultures, diverse studies showed a correlation between the pharmacological data sets resulting from cell viability screenings and the genomic characterization of the probed CCLs (Pushpakom et al., 2018). These pharmacogenomics interactions were comparable to the observed clinical data. Additionally, the overlap of genomic features from primary tumors and the effects of chemotherapeutics in CCLs led to the identification of novel drug repurposing opportunities in specific cancer types (lorio et al., 2016).

Limitations of most of the current knowledge of drugs with the potential for repositioning may be good starting points for future investigations. The effect of dosing and clinically attainable blood serum concentrations has been insufficiently addressed in many studies. For example, aspirin in high doses acts against pain and can be used as preventive coagulant at low doses. In other cases, it may be that drugs were approved at a lower dose for a specific disease, but act only at high doses against MDR cancers. Here, the question arises, whether or not sufficient concentrations are achievable in patients to obtain comparable pharmacological effects as those observed under experimental conditions.

Another caveat relates to drug interactions with standard chemotherapy. Some authors focused on synergistic interactions between repurposing drug candidates and standard medication. This is a favorable result which demonstrates that drug interactions have to be taken into consideration. Another aspect that has been neglected thus far is that drug interactions could also exert negative effects. Antagonistic effects may diminish the tumor killing efficacy of standard chemotherapy and synergistic effects may increase the 
toxicity in normal tissues leading to non-tolerable side effects. Studies on these topics are largely missing as of yet.

In summary, drug repurposing represents a powerful strategy for accelerated drug discovery programs. However, there are still limitations that prevent higher efficiency. Frequent factors limiting many current drug development approaches are insufficiently structured data. Therefore, efforts should be made to organize the available information in a more productive manner and to set the basis for proper data acquisition resulting from previous preclinical and clinical studies. Typically, repurposing has been achieved serendipitously. However, the development of more powerful computational tools and the homogenization of clinical trials data should provide a more rational approach to identify new drug candidates to treat MDR tumors.

\section{Conflict of interest}

The authors declare no potential conflict of interest.

\section{Acknowledgments}

This article is based upon work from COST Action CA17104 STRATAGEM - "New diagnostic and therapeutic tools against multidrug resistant tumors", supported by COST (European Cooperation in Science and Technology). JD acknowledges the financial support from The Ministry of Education, Science and Technological Development of the Republic of Serbia (451-03-68/2020-14/200007). TE acknowledges the grants from the German Research Foundation (Deutsche Forschungsgemeinschaft) and Germany Cancer Aid (Deutsche Krebshilfe). ATG-S thanks Haridus- ja Teadusministeerium for grant IUT34-14. JG is supported by Grant III41026 from the Serbian Ministry of Education, Science and Technological Development. JMP thanks the Spanish Government for financial support through project PGC2018-094503-B-C22 (MCIU/AEI/FEDER, UE). IT acknowledges the financial support from the National Science Fund of Bulgaria (grant No. KP-06COST/3/18.06.2019). FR acknowledges Fondazione AIRC per la Ricerca sul Cancro (grant No. IG23566). 


\section{References}

Abe, T., Koike, K., Ohga, T., Kubo, T., Wada, M., Kohno, K., Mori, T., Hidaka, K., Kuwano, M., 1995. Chemosensitisation of spontaneous multidrug resistance by a 1,4dihydropyridine analogue and verapamil in human glioma cell lines overexpressing MRP or MDR1. British Journal of Cancer 72, 418-423.

Abruzzese, M.P., Bilotta, M.T., Fionda, C., Zingoni, A., Soriani, A., Petrucci, M.T., Ricciardi, M.R., Molfetta, R., Paolini, R., Santoni, A., Cippitelli, M., 2019. The homeobox transcription factor MEIS2 is a regulator of cancer cell survival and IMiDs activity in multiple myeloma: modulation by bromodomain and extra-terminal (BET) protein inhibitors. Cell Death \& Disease 10, 324.

Akiyama, S., Shiraishi, N., Kuratomi, Y., Nakagawa, M., Kuwano, M., 1986. Circumvention of multiple-drug resistance in human cancer cells by thioridazine, trifluoperazine, and chlorpromazine. Journal of the National Cancer Institute 76, 839-844.

Alam, A., Kowal, J., Broude, E., Roninson, I., Locher, K.P., 2019. Structural insight into substrate and inhibitor discrimination by human P-glycoprotein. Science 363, 753-756.

Albatany, M., Li, A., Meakin, S., Bartha, R., 2018. In vivo detection of acute intracellular acidification in glioblastoma multiforme following a single dose of cariporide. International Journal of Clinical Oncology 23, 812-819.

Albatany, M., Ostapchenko, V.G., Meakin, S., Bartha, R., 2019. Brain tumor acidification using drugs simultaneously targeting multiple $\mathrm{pH}$ regulatory mechanisms. Journal of Neuro-Oncology 144, 453-462.

Amawi, H., Sim, H.-M., Tiwari, A.K., Ambudkar, S.V., Shukla, S., 2019. ABC Transportermediated multidrug-resistant cancer, In: Advances in experimental medicine and biology. Springer Singapore, pp. 549-580.

Andrade, C.H., Neves, B.J., Melo-Filho, C.C., Rodrigues, J., Silva, D.C., Braga, R.C., Cravo, P.V.L., 2019. In silico chemogenomics drug repositioning strategies for neglected tropical diseases. Current Medicinal Chemistry 26, 4355-4379. 
Angeles, E., Vazquez-Valadez, V.H., Vazquez-Valadez, O., Velazquez-Sanchez, A., Ramirez, A., Martinez, L., Diaz-Barriga, S., Romero-Rojas, A., Cabrera, G., LopezCastanares, R., Duenas-Gonzalez, A., 2005. Computational studies of 1hydrazinophthalazine (hydralazine) as antineoplasic agent. Docking studies on methyltransferase. Letters in Drug Design \& Discovery 2, 282-286.

Antonarakis, E.S., Heath, E.I., Smith, D.C., Rathkopf, D., Blackford, A.L., Danila, D.C., King, S., Frost, A., Ajiboye, A.S., Zhao, M., Mendonca, J., Kachhap, S.K., Rudek, M.A., Carducci, M.A., 2013. Repurposing itraconazole as a treatment for advanced prostate cancer: A noncomparative randomized phase II trial in men with metastatic castrationresistant prostate cancer. The Oncologist 18, 163-173.

Antoszczak, M., Markowska, A., Markowska, J., Huczyński, A., 2020. Old wine in new bottles: Drug repurposing in oncology. European Journal of Pharmacology 866, 172784.

Arce, C., Pérez-Plasencia, C., González-Fierro, A., de la Cruz-Hernández, E., RevillaVázquez, A., Chávez-Blanco, A., Trejo-Becerril, C., Pérez-Cárdenas, E., Taja-Chayeb, L., Bargallo, E., Villarreal, P., Ramírez, T., Vela, T., Candelaria, M., Camargo, M.F., Robles, E., Dueñas-González, A., 2006. A proof-of-principle study of epigenetic therapy added to neoadjuvant doxorubicin cyclophosphamide for locally advanced breast cancer. PLoS ONE 1, e98.

Armando, R.G., Mengual Gómez, D.L., Gomez, D.E., 2020. New drugs are not enough-drug repositioning in oncology: An update. International Journal of Oncology.

Ashburn, T.T., Thor, K.B., 2004. Drug repositioning: Identifying and developing new uses for existing drugs. Nature Reviews Drug Discovery 3, 673-683.

Assaraf, Y.G., Borgnia, M.J., 1994. Probing the interaction of the multidrug-resistance phenotype with the polypeptide ionophore gramicidin $D$ via functional channel formation. European Journal of Biochemistry 222, 813-824.

Assaraf, Y. G., Brozovic, A., Gonçalves, A. C., Jurkovicova, D., Linē, A., Machuqueiro, M., Saponara, S., Sarmento-Ribeiro, A. B., Xavier, C. P., Vasconcelos, M. H., 2019. The 
multi-factorial nature of clinical multidrug resistance in cancer. Drug Resistance Updates 46, 100645.

Assaraf, Y.G., Leamon, C.P., Reddy, J.A., 2014. The folate receptor as a rational therapeutic target for personalized cancer treatment. Drug Resistance Updates 17, 89-95.

Bai, R.-Y., Staedtke, V., Aprhys, C.M., Gallia, G.L., Riggins, G.J., 2011. Antiparasitic mebendazole shows survival benefit in 2 preclinical models of glioblastoma multiforme. Neuro-Oncology 13, 974-982.

Bar-Zeev, M., Livney, Y.D., Assaraf, Y.G., 2017. Targeted nanomedicine for cancer therapeutics: Towards precision medicine overcoming drug resistance. Drug Resistance Updates 31, 15-30.

Barbosa, E.J., Löbenberg, R., de Araujo, G.L.B., Bou-Chacra, N.A., 2019. Niclosamide repositioning for treating cancer: Challenges and nano-based drug delivery opportunities. European Journal of Pharmaceutics and Biopharmaceutics 141, 58-69.

Barrio, S., Munawar, U., Zhu, Y.X., Giesen, N., Shi, C.-X., Da Viá, M., Sanchez, R., Bruins, L., Demler, T., Müller, N., Haertle, L., Garitano, A., Steinbrunn, T., Danhof, S., Cuenca, I., Barrio-Garcia, C., Braggio, E., Rosenwald, A., Martinez-Lopez, J., Rasche, L., Raab, M.S., Stewart, A.K., Einsele, H., Stühmer, T., Kortüm, K.M., 2020. IKZF1/3 and CRL4CRBN E3 ubiquitin ligase mutations and IMiD resistance in multiple myeloma. Haematologica 105, e237-e241

Ben Sahra, I., Laurent, K., Giuliano, S., Larbret, F., Ponzio, G., Gounon, P., Le MarchandBrustel, Y., Giorgetti-Peraldi, S., Cormont, M., Bertolotto, C., Deckert, M., Auberger, P., Tanti, J.-F., Bost, F., 2010. Targeting Cancer Cell Metabolism: The Combination of Metformin and 2-Deoxyglucose Induces p53-Dependent Apoptosis in Prostate Cancer Cells. Cancer Research 70, 2465-2475.

Benson, S.C., Pershadsingh, H.A., Ho, C.I., Chittiboyina, A., Desai, P., Pravenec, M., Qi, N., Wang, J., Avery, M.A., Kurtz, T.W., 2004. Identification of telmisartan as a unique angiotensin ii receptor antagonist with selective PPARy-modulating activity. Hypertension 43, 993-1002. 
Berdelle, N., Nikolova, T., Quiros, S., Efferth, T., Kaina, B., 2011. Artesunate induces oxidative DNA damage, sustained DNA double-strand breaks, and the ATM/ATR damage response in cancer cells. Molecular Cancer Therapy 10, 2224-2233.

Beretta, G.L., Cassinelli, G., Pennati, M., Zuco, V., Gatti, L., 2017. Overcoming ABC transporter-mediated multidrug resistance: The dual role of tyrosine kinase inhibitors as multitargeting agents. European Journal of Medicinal Chemistry 142, 271-289.

Berger, T.G., Dieckmann, D., Efferth, T., Schultz, E.S., Funk, J.O., Baur, A., Schuler, G., 2005. Artesunate in the treatment of metastatic uveal melanoma--first experiences. Oncology Reports 14, 1599-1603.

Borgnia, M.J., Eytan, G.D., Assaraf, Y.G., 1996. Competition of hydrophobic peptides, cytotoxic drugs, and chemosensitizers on a common P-glycoprotein pharmacophore as revealed by its ATPase activity. Journal of Biological Chemistry 271, 3163-3171.

Boscoboinik, D., Gupta, R., Epand, R., 1990. Investigation of the relationship between altered intracellular $\mathrm{pH}$ and multidrug resistance in mammalian cells. British Journal of Cancer 61, 568-572.

Bouyssou, J.M., Ghobrial, I.M., Roccaro, A.M., 2016. Targeting SDF-1 in multiple myeloma tumor microenvironment. Cancer Letterrs 380, 315-318.

Briceño, E., Calderon, A., Sotelo, J., 2007. Institutional experience with chloroquine as an adjuvant to the therapy for glioblastoma multiforme. Surgical Neurology 67, 388-391.

Briceño, E., Reyes, S., Sotelo, J., 2003. Therapy of glioblastoma multiforme improved by the antimutagenic chloroquine. Neurosurgical Focus 14, 1-6.

Bruno, N.A., Slate, D.L., 1990. Effect of exposure to calcium entry blockers on doxorubicin accumulation and cytotoxicity in multidrug-resistant cells. Journal of the National Cancer Institute 82, 419-424.

Burock, S., Daum, S., Tröger, H., Kim, T.D., Krüger, S., Rieke, D.T., Ochsenreither, S., Welter, K., Herrmann, P., Sleegers, A., Walther, W., Keilholz, U., Stein, U., 2018. Niclosamide a new chemotherapy agent? Pharmacokinetics of the potential anticancer drug in a patient cohort of the NIKOLO trial. Journal of Clinical Oncology 36, e14536. 
Campbell, J.M., Bellman, S.M., Stephenson, M.D., Lisy., K., 2017. Metformin reduces allcause mortality and diseases of ageing independent of its effect on diabetes control: A systematic review and meta-analysis. Ageing Research Reviews 40, 31-44.

Candelaria, M., Burgos, S., Ponce, M., Espinoza, R., Dueñas-Gonzalez, A., 2017. Encouraging results with the compassionate use of hydralazine/valproate (TRANSKRIP TM) as epigenetic treatment for myelodysplastic syndrome (MDS). Annals of Hematology 96, 1825-1832.

Candelaria, M., Cetina, L., Pérez-Cárdenas, E., de la Cruz-Hernández, E., González-Fierro, A., Trejo-Becerril, C., Taja-Chayeb, L., Chanona, J., Arias, D., Dueñas-González, A., 2010. Epigenetic therapy and cisplatin chemoradiation in FIGO stage IIIB cervical cancer. European Journal of Gynaecological Oncology 31, 386-391.

Candelaria, M., Gallardo-Rincón, D., Arce, C., Cetina, L., Aguilar-Ponce, J.L., Arrieta, Ó., González-Fierro, A., Chávez-Blanco, A., de la Cruz-Hernández, E., Camargo, M.F., Trejo-Becerril, C., Pérez-Cárdenas, E., Pérez-Plasencia, C., Taja-Chayeb, L., Wegman-Ostrosky, T., Revilla-Vazquez, A., Dueñas-González, A., 2007. A phase II study of epigenetic therapy with hydralazine and magnesium valproate to overcome chemotherapy resistance in refractory solid tumors. Annals of Oncology 18, 15291538.

Candelaria, M., Herrera, A., Labardini, J., González-Fierro, A., Trejo-Becerril, C., TajaChayeb, L., Pérez-Cárdenas, E., de la Cruz-Hernández, E., Arias-Bofill, D., Vidal, S., Cervera, E., Dueñas-Gonzalez, A., 2011. Hydralazine and magnesium valproate as epigenetic treatment for myelodysplastic syndrome. Preliminary results of a phase-II trial. Annals of Hematology 90, 379-387.

Chairat, K., Jittamala, P., Hanboonkunupakarn, B., Pukrittayakamee, S., Hanpithakpong, W., Blessborn, D., White, N.J., Day, N.P.J., Tarning, J., 2018. Enantiospecific pharmacokinetics and drug-drug interactions of primaquine and blood-stage antimalarial drugs. Journal of Antimicrobial Chemotherapy 73, 3102-3113. 
Chang, W.-H., Liu, T.-C., Yang, W.-K., Lee, C.-C., Lin, Y.-H., Chen, T.-Y., Chang, J.-G., 2011. Amiloride modulates alternative splicing in leukemic cells and resensitizes BcrAbIT315I mutant cells to imatinib. Cancer Research 71, 383-392.

Chaudhari, R., Tan, Z., Huang, B., Zhang, S., 2017. Computational polypharmacology: a new paradigm for drug discovery. Expert Opinion on Drug Discovery 12, 279-291.

Chen, L., Li, Y., Yu, H., Zhang, L., Hou, T., 2012. Computational models for predicting substrates or inhibitors of P-glycoprotein. Drug Discovery Today 17, 343-351.

Chen, Q., Liu, Y., Zhu, X., Feng, F., Yang, H., Xu, W., 2019. Increased NHE1 expression is targeted by specific inhibitor cariporide to sensitize resistant breast cancer cells to doxorubicin in vitro and in vivo. BMC Cancer 19, 211.

Choi, A.R., Kim, J.H., Woo, Y.H., Kim, H.S., Yoon, S., 2016. Anti-malarial drugs primaquine and chloroquine have different sensitization effects with anti-mitotic drugs in resistant cancer cells. Anticancer Research 36, 1641-1648.

Chu, S.W., Badar, S., Morris, D.L., Pourgholami, M.H., 2009. Potent inhibition of tubulin polymerisation and proliferation of paclitaxel-resistant 1A9PTX22 human ovarian cancer cells by albendazole. Anticancer Research 29, 3791-3796.

Clarke, N.W., Ali, A., Ingleby, F.C., Hoyle, A., Amos, C.L., Attard, G., Brawley, C.D., Calvert, J., Chowdhury, S., Cook, A., Cross, W., Dearnaley, D.P., Douis, H., Gilbert, D., Gillessen, S., Jones, R.J., Langley, R.E., MacNair, A., Malik, Z., Mason, M.D., Matheson, D., Millman, R., Parker, C.C., Ritchie, A.W.S., Rush, H., Russell, J.M., Brown, J., Beesley, S., Birtle, A., Capaldi, L., Gale, J., Gibbs, S., Lydon, A., Nikapota, A., Omlin, A., O'Sullivan, J.M., Parikh, O., Protheroe, A., Rudman, S., Srihari, N.N., Simms, M., Tanguay, J.S., Tolan, S., Wagstaff, J., Wallace, J., Wylie, J., Zarkar, A., Sydes, M.R., Parmar, M.K.B., James, N.D., 2019. Addition of docetaxel to hormonal therapy in low- and high-burden metastatic hormone sensitive prostate cancer: longterm survival results from the STAMPEDE trial. Annals of Oncology 30, 1992-2003. 
Clary, I., Doherty, G., Moran, E., Clynes, M., 1997. The multidrug-resistant human lung tumour cell line, DLKP-A10, expresses novel drug accumulation and sequestration systems. Biochemical Pharmacology 53, 1493-1502.

Cook, K.L., Warri, A., Soto-Pantoja, D.R., Clarke, P.A., Cruz, M.I., Zwart, A., Clarke, R., 2014. Chloroquine inhibits autophagy to potentiate antiestrogen responsiveness in ER+ breast cancer. Clinical Cancer Research 20, 3222-3232.

Corbett, A., Williams, G., Ballard, C., 2015. Drug repositioning in Alzheimer's disease. Frontiers in bioscience (Scholar edition), 7, 184-188.

Coronel, J., Cetina, L., Pacheco, I., Trejo-Becerril, C., González-Fierro, A., de la CruzHernandez, E., Perez-Cardenas, E., Taja-Chayeb, L., Arias-Bofill, D., Candelaria, M., Vidal, S., Dueñas-González, A., 2010. A double-blind, placebo-controlled, randomized phase III trial of chemotherapy plus epigenetic therapy with hydralazine valproate for advanced cervical cancer. Preliminary results. Medical Oncology 28, 540-546.

Coyle, C., Cafferty, F.H., Vale, C., Langley, R.E., 2016. Metformin as an adjuvant treatment for cancer: a systematic review and meta-analysis. Annals of Oncology 27, 2184-2195.

Coyne, C. P., Jones, T., Bear, R., 2013. Gemcitabine-(C4-amide)-[anti-HER2/neu] antineoplastic cytotoxicity in dual combination with mebendazole against chemotherapeutic-resistant mammary adenocarcinoma. Journal of Clinical \& Experimental Oncology, 2, 1000109.

Cufí, S., Vazquez-Martin, A., Oliveras-Ferraros, C., Corominas-Faja, B., Cuyàs, E., LópezBonet, E., Martin-Castillo, B., Joven, J., Menendez, J.A., 2013. The anti-malarial chloroquine overcomes primary resistance and restores sensitivity to trastuzumab in HER2-positive breast cancer. Scientific Reports 3, 2469.

Cui, Q., Wang, J., Assaraf, Y., Ren, L., Gupta, P., Wei, L., Ashby, C., Yang, D., Chen, Z., 2018. Modulating ROS to overcome multidrug resistance in cancer. Drug Resistance Updates 41, 1-25.

Cuomo, F., Altucci, L., Cobellis, G., 2019. Autophagy Function and Dysfunction: Potential Drugs as Anti-Cancer Therapy. Cancers 11, 1465. 
D’Amato, R.J., Loughnan, M.S., Flynn, E., Folkman, J., 1994. Thalidomide is an inhibitor of angiogenesis. Proceedings of the National Academy of Sciences 91, 4082-4085.

Dakshanamurthy, S., Issa, N.T., Assefnia, S., Seshasayee, A., Peters, O.J., Madhavan, S., Uren, A., Brown, M.L., Byers, S.W., 2012. Predicting new indications for approved drugs using a proteochemometric method. Journal of Medicinal Chemistry 55, 68326848.

Dal Bo, M., De Mattia, E., Baboci, L., Mezzalira, S., Cecchin, E., Assaraf, Y., Toffoli, G., 2020. New insights into the pharmacological, immunological, and CAR-T-cell approaches in the treatment of hepatocellular carcinoma. Drug Resistance Updates 51, 100702.

David, J.M., Owens, T.A., Inge, L.J., Bremner, R.M., Rajasekaran, A.K., 2014. Gramicidin A blocks tumor growth and angiogenesis through inhibition of hypoxia-inducible factor in renal cell carcinoma. Molecular Cancer Therapeutics 13, 788-799.

Davies, G., Lobanova, L., Dawicki, W., Groot, G., Gordon, J.R., Bowen, M., Harkness, T., Arnason, T., 2017. Metformin inhibits the development, and promotes the resensitization, of treatment-resistant breast cancer. PLOS ONE 12, e0187191.

De Castro, A.A., Da Cunha, E.F.F., Pereira, A.F., Soares, F.V., Leal, D.H.S., Kuca, K., Ramalho, T.C., 2018. Insights into the drug repositioning applied to the Alzheimer's disease treatment and future perspectives. Current Alzheimer Research 15, $1161-$ 1178.

de Man, F.M., Goey, A.K.L., van Schaik, R.H.N., Mathijssen, R.H.J., Bins, S., 2018. Individualization of irinotecan treatment: A review of pharmacokinetics, pharmacodynamics, and pharmacogenetics. Clinical Pharmacokinetics 57, 1229-1254.

Deeken, J.F., Wang, H., Hartley, M., Cheema, A.K., Smaglo, B., Hwang, J.J., He, A.R., Weiner, L.M., Marshall, J.L., Giaccone, G., Liu, S., Luecht, J., Spiegel, J.Y., Pishvaian, M.J., 2018. A phase I study of intravenous artesunate in patients with advanced solid tumor malignancies. Cancer Chemotherapy and Pharmacology 81, 587-596. 
Demel, M.A., Schwaha, R., Krämer, O., Ettmayer, P., Haaksma, E.E., Ecker, G.F., 2008. In silicoprediction of substrate properties for ABC-multidrug transporters. Expert Opinion on Drug Metabolism \& Toxicology 4, 1167-1180.

Deng, Y., Zhang, J., Wang, Z., Yan, Z., Qiao, M., Ye, J., Wei, Q., Wang, J., Wang, X., Zhao, L., Lu, S., Tang, S., Mohammed, M.K., Liu, H., Fan, J., Zhang, F., Zou, Y., Liao, J., Qi, H., Haydon, R.C., Luu, H.H., He, T.-C., Tang, L., 2015. Antibiotic monensin synergizes with EGFR inhibitors and oxaliplatin to suppress the proliferation of human ovarian cancer cells. Scientific Reports 5, 17523.

Díaz-Carballo, D., Acikelli, A.H., Klein, J., Jastrow, H., Dammann, P., Wyganowski, T., Guemues, C., Gustmann, S., Bardenheuer, W., Malak, S., Tefett, N.S., Khosrawipour, V., Giger-Pabst, U., Tannapfel, A., Strumberg, D., 2015. Therapeutic potential of antiviral drugs targeting chemorefractory colorectal adenocarcinoma cells overexpressing endogenous retroviral elements. Journal of Experimental \& Clinical Cancer Research 34, 81.

Didier, A., Loor, F., 1996. The abamectin derivative ivermectin is a potent P-glycoprotein inhibitor. Anti-Cancer Drugs 7, 745-751.

Ding, Z.-B., Hui, B., Shi, Y.-H., Zhou, J., Peng, Y.-F., Gu, C.-Y., Yang, H., Shi, G.-M., Ke, A.W., Wang, X.-Y., Song, K., Dai, Z., Shen, Y.-H., Fan, J., 2011. Autophagy Activation in Hepatocellular Carcinoma Contributes to the Tolerance of Oxaliplatin via Reactive Oxygen Species Modulation. Clinical Cancer Research 17, 6229-6238.

Divac Rankov, A., Ljujić, M., Petrić, M., Radojković, D., Pešić, M., Dinić, J., 2017. Targeting autophagy to modulate cell survival: a comparative analysis in cancer, normal and embryonic cells. Histochemistry and Cell Biology 148, 529-544.

Doudican, N., Rodriguez, A., Osman, I., Orlow, S.J., 2008. Mebendazole induces apoptosis via Bcl-2 inactivation in chemoresistant melanoma cells. Molecular Cancer Research 6, $1308-1315$.

Dowling, R.J., Parulekar, W.R., Gelmon, K.A., Shepherd, L.E., Virk, S., Ennis, M., Mao, F., Ligibel, J.A., Hershman, D.L., Rastogi, P., Mayer, I.A., Hobday, T.J., Lemieux, J., 
Thompson, A.M., Rabaglio-Poretti, M., Whelan, T.J., Stambolic, V., Chen, B.E., Goodwin, P.J., 2018. CA15-3/MUC1 in CCTG MA-32 (NCT01101438): A phase III RCT of the effect of metformin vs. placebo on invasive disease free and overall survival in early stage breast cancer (BC). Journal of Clinical Oncology 36, 557-557.

Drinyaev, V.A., Mosin, V.A., Kruglyak, E.B., Novik, T.S., Sterlina, T.S., Ermakova, N.V., Kublik, L.N., Levitman, M.K., Shaposhnikova, V.V., Korystov, Y.N., 2004. Antitumor effect of avermectins. European Journal of Pharmacology 501, 19-23.

Dueñas-Gonzalez, A., Coronel, J., Cetina, L., González-Fierro, A., Chavez-Blanco, A., TajaChayeb, L., 2014. Hydralazine-valproate: a repositioned drug combination for the epigenetic therapy of cancer. Expert Opinion on Drug Metabolism \& Toxicology 10, $1433-1444$.

Efferth, T., 2005. Mechanistic perspectives for 1,2,4-trioxanes in anti-cancer therapy. Drug Resistance Updates 8, 85-97.

Efferth, T., 2017. From ancient herb to modern drug: Artemisia annua and artemisinin for cancer therapy. Seminars in Cancer Biology 46, 65-83.

Efferth, T., Dunstan, H., Sauerbrey, A., Miyachi, H., Chitambar, C.R., 2001. The anti-malarial artesunate is also active against cancer. International Journal of Oncology $18,767-$ 773.

Efferth, T., Kaina, B., 2010. Toxicity of the antimalarial artemisinin and its dervatives. Critical Reviews in Toxicology 40, 405-421.

Efferth, T., Rücker, G., Falkenberg, M., Manns, D., Olbrich, A., Fabry, U., Osieka, R., 1996. Detection of apoptosis in KG-1a leukemic cells treated with investigational drugs. Arzneimittelforschung 46, 196-200.Efferth, T., Volm, M., 1993. Reversal of doxorubicinresistance in sarcoma 180 tumor cells by inhibition of different resistance mechanisms. Cancer Letters 70, 197-202.

Ehrlich, P. Über die constitution des diphtheriegiftes. Deutsch. Med. Wochschr. 1898, 24, $597-600$. 
Eichner, R., Heider, M., Fernández-Sáiz, V., van Bebber, F., Garz, A.-K., Lemeer, S., Rudelius, M., Targosz, B.-S., Jacobs, L., Knorn, A.-M., Slawska, J., Platzbecker, U., Germing, U., Langer, C., Knop, S., Einsele, H., Peschel, C., Haass, C., Keller, U., Schmid, B., Götze, K.S., Kuster, B., Bassermann, F., 2016. Immunomodulatory drugs disrupt the cereblon-CD147-MCT1 axis to exert antitumor activity and teratogenicity. Nature Medicine 22, 735-743.

Ekins, S., Kim, R.B., Leake, B.F., Dantzig, A.H., Schuetz, E.G., Lan, L.-B., Yasuda, K., Shepard, R.L., Winter, M.A., Schuetz, J.D., Wikel, J.H., Wrighton, S.A., 2002. Threedimensional quantitative structure-activity relationships of inhibitors of P-glycoprotein. Molecular Pharmacology 61, 964-973.

Eldredge, H.B., DeNittis, A., DuHadaway, J.B., Chernick, M., Metz, R., Prendergast, G.C., 2013. Concurrent whole brain radiotherapy and short-course chloroquine in patients with brain metastases: a pilot trial. Journal of Radiation Oncology 2, 315-321.

Epand, R.F., Epand, R.M., Gupta, R.S., Cragoe, E.J., Jr, 1991. Reversal of intrinsic multidrug resistance in Chinese hamster ovary cells by amiloride analogs. British Journal of Cancer 63, 247-251.

Eriksson, Å., Yachnin, J., Lewensohn, R., Nilsso, A., 2001. DNA-Dependent Protein Kinase Is Inhibited by Trifluoperazine. Biochemical and Biophysical Research Communications $283,726-731$.

Espinoza-Zamora, J.R., Labardini-Méndez, J., Sosa-Espinoza, A., López-González, C., Vieyra-García, M., Candelaria, M., Lozano-Zavaleta, V., Toledano-Cuevas, D.V., Zapata-Canto, N., Cervera, E., Dueñas-González, A., 2017. Efficacy of hydralazine and valproate in cutaneous T-cell lymphoma, a phase II study. Expert Opinion on Investigational Drugs 26, 481-487.

Evans, J.M.M., Donnelly, L.A., Emslie-Smith, A.M., Alessi, D.R., Morris, A.D., 2005. Metformin and reduced risk of cancer in diabetic patients. BMJ 330, 1304-1305. 
Eytan, G.D., Borgnia, M.J., Regev, R., Assaraf, Y.G., 1994. Transport of polypeptide ionophores into proteoliposomes reconstituted with rat liver P-glycoprotein. The Journal of Biological Chemistry 269, 26058-26065.

Facon, T., Dimopoulos, M.A., Dispenzieri, A., Catalano, J.V., Belch, A., Cavo, M., Pinto, A., Weisel, K., Ludwig, H., Bahlis, N.J., Banos, A., Tiab, M., Delforge, M., Cavenagh, J.D., Geraldes, C., Lee, J.-J., Chen, C., Oriol, A., De La Rubia, J., White, D., Binder, D., Lu, J., Anderson, K.C., Moreau, P., Attal, M., Perrot, A., Arnulf, B., Qiu, L., Roussel, M., Boyle, E., Manier, S., Mohty, M., Avet-Loiseau, H., Leleu, X., Ervin-Haynes, A., Chen, G., Houck, V., Benboubker, L., Hulin, C., 2018. Final analysis of survival outcomes in the phase 3 FIRST trial of up-front treatment for multiple myeloma. Blood 131, 301310.

Fendt, S.-M., Bell, E.L., Keibler, M.A., Davidson, S.M., Wirth, G.J., Fiske, B., Mayers, J.R., Schwab, M., Bellinger, G., Csibi, A., Patnaik, A., Blouin, M.J., Cantley, L.C., Guarente, L., Blenis, J., Pollak, M.N., Olumi, A.F., Vander Heiden, M.G., Stephanopoulos, G., 2013. Metformin Decreases Glucose Oxidation and Increases the Dependency of Prostate Cancer Cells on Reductive Glutamine Metabolism. Cancer Research 73, $4429-4438$.

Fionda, C., Abruzzese, M.P., Zingoni, A., Cecere, F., Vulpis, E., Peruzzi, G., Soriani, A., Molfetta, R., Paolini, R., Ricciardi, M.R., Petrucci, M.T., Santoni, A., Cippitelli, M., 2015 The IMiDs targets IKZF-1/3 and IRF4 as novel negative regulators of NK cell-activating ligands expression in multiple myeloma. Oncotarget 6, 23609-23630.

Fischer, E.S., Böhm, K., Lydeard, J.R., Yang, H., Stadler, M.B., Cavadini, S., Nagel, J., Serluca, F., Acker, V., Lingaraju, G.M., Tichkule, R.B., Schebesta, M., Forrester, W.C., Schirle, M., Hassiepen, U., Ottl, J., Hild, M., Beckwith, R.E., Harper, J.W., Jenkins, J.L., Thomä N.H., 2014. Structure of the DDB1-CRBN E3 ubiquitin ligase in complex with thalidomide. Nature 512, 49-53. 
Flanagan, J.U., Yosaatmadja, Y., Teague, R.M., Chai, M.Z.L., Turnbull, A.P., Squire, C.J., 2012. Crystal structures of three classes of non-steroidal anti-inflammatory drugs in complex with aldo-keto reductase 1C3. PLoS ONE 7, e43965.

Ford, J.M., Prozialeck, W.C., Hait, W.N., 1989. Structural features determining activity of phenothiazines and related drugs for inhibition of cell growth and reversal of multidrug resistance. Molecular Pharmacology 35, 105-115.

Frayha, G.J., Smyth, J.D., Gobert, J.G., Savel, J., 1997. The mechanisms of action of antiprotozoal and anthelmintic drugs in man. General Pharmacology: The Vascular System 28, 273-299.

Fuchs, D., Daniel, V., Sadeghi, M., Opelz, G., Naujokat, C., 2010. Salinomycin overcomes $\mathrm{ABC}$ transporter-mediated multidrug and apoptosis resistance in human leukemia stem cell-like KG-1a cells. Biochemical and Biophysical Research Communications 394, 1098-1104.

Gacche, R. and Assaraf, Y., 2018. Redundant angiogenic signaling and tumor drug resistance. Drug Resistance Updates 36, 47-76.

Gandini, S., Puntoni, M., Heckman-Stoddard, B.M., Dunn, B.K., Ford, L., DeCensi, A., Szabo, E., 2014. Metformin and Cancer Risk and Mortality: A systematic review and meta-analysis taking into account biases and confounders. Cancer Prevention Research 7, 867-885.

Gao, W., Chang, G., Wang, J., Jin, W., Wang, L., Lin, Y., Li, H., Ma, L., Li, Q., Pang, T., 2011. Inhibition of K562 leukemia angiogenesis and growth by selective $\mathrm{Na}+\mathrm{H}+$ exchanger inhibitor cariporide through down-regulation of pro-angiogenesis factor VEGF. Leukemia Research 35, 1506-1511.

Garcés-Eisele, S.J., Cedillo-Carvallo, B., Reyes-Núñez, V., Estrada-Marín, L., VázquezPérez, R., Juárez-Calderón, M., Guzmán-García, M.O., Dueñas-González, A., RuizArgüelles, A., 2014. Genetic selection of volunteers and concomitant dose adjustment leads to comparable hydralazine/valproate exposure. Journal of Clinical Pharmacy and Therapeutics 39, 368-375. 
García-Sosa, A.T., Mancera, R.L., 2005. The effect of a tightly bound water molecule on scaffold diversity in the computer-aided de novo ligand design of CDK2 inhibitors. Journal of Molecular Modeling 12, 422-431.

Gay, F., Jackson, G., Rosiñol, L., Holstein, S.A., Moreau, P., Spada, S., Davies, F., Lahuerta, J.J., Leleu, X., Bringhen, S., Evangelista, A., Hulin, C., Panzani, U., Cairns, D.A., Di Raimondo, F., Macro, M., Liberati, A.M., Pawlyn, C., Offidani, M., Spencer, A., Hájek, R., Terpos, E., Morgan, G.J., Bladé, J., Sonneveld, P., San-Miguel, J., McCarthy, P.L., Ludwig, H., Boccadoro, M., Mateos, M.-V., Attal, M., 2018. Maintenance treatment and survival in patients with myeloma. JAMA Oncology 4, 1389.

Gillessen, S., Gilson, C., James, N., Adler, A., Sydes, M.R., Clarke, N., 2016. Repurposing metformin as therapy for prostate cancer within the STAMPEDE trial platform. European Urology 70, 906-908.

Gillis, N.K., McLeod, H.L., 2016. The pharmacogenomics of drug resistance to protein kinase inhibitors. Drug Resistance Updates 28, 28-42.

GNS, H.S., GR, S., Murahari, M., Krishnamurthy, M., 2019. An update on drug repurposing: Re-written saga of the drug's fate. Biomedicine \& Pharmacotherapy 110, 700-716.

Golden, E.B., Cho, H.-Y., Jahanian, A., Hofman, F.M., Louie, S.G., Schönthal, A.H., Chen, T.C., 2014. Chloroquine enhances temozolomide cytotoxicity in malignant gliomas by blocking autophagy. Neurosurgical Focus 37, E12.

Goluboff, E.T., 2001. Exisulind, a selective apoptotic antineoplastic drug. Expert Opinion on Investigational Drugs 10, 1875-1882.

Gonen, N., Assaraf, Y.G., 2012. Antifolates in cancer therapy: structure, activity and mechanisms of drug resistance. Drug Resistance Updates 15, 183-210.

Goodall, M.L., Wang, T., Martin, K.R., Kortus, M.G., Kauffman, A.L., Trent, J.M., Gately, S., MacKeigan, J.P., 2014. Development of potent autophagy inhibitors that sensitize oncogenic BRAF V600E mutant melanoma tumor cells to vemurafenib. Autophagy 10 , 1120-1136. 
Goodwin, P.J., Parulekar, W.R., Gelmon, K.A., Shepherd, L.E., Ligibel, J.A., Hershman, D.L., Rastogi, P., Mayer, I.A., Hobday, T.J., Lemieux, J., Thompson, A.M., Pritchard, K.I., Whelan, T.J., Mukherjee, S.D., Chalchal, H.I., Oja, C.D., Tonkin, K.S., Bernstein, V., Chen, B.E., Stambolic, V., 2015. Effect of metformin vs placebo on and metabolic factors in NCIC CTG MA.32. Journal of the National Cancer Institute 107, djv006djv006.

Goyette, M.A., Cusseddu, R., Elkholi, I., Abu-Thuraia, A., El-Hachem, N., Haibe-Kains, B., Gratton, J.P., Côté, J.F., 2019. AXL knockdown gene signature reveals a drug repurposing opportunity for a class of antipsychotics to reduce growth and metastasis of triple-negative breast cancer. Oncotarget 10, 2055-2067.

Grammer, A.C., Lipsky, P.E., 2017. Drug repositioning strategies for the identification of novel therapies for rheumatic autoimmune inflammatory diseases. Rheumatic Disease Clinics of North America 43, 467-480.

Grammer, A.C., Ryals, M.M., Heuer, S.E., Robl, R.D., Madamanchi, S., Davis, L.S., Lauwerys, B., Catalina, M.D., Lipsky, P.E., 2016. Drug repositioning in SLE: crowdsourcing, literature-mining and Big Data analysis. Lupus 25, 1150-1170.

Gros, P., Neriah, Y.B., Croop, J.M., Housman, D.E., 1986. Isolation and expression of a complementary DNA that confers multidrug resistance. Nature 323, 728-731.

Güner, O.F., Bowen, J.P., 2014. Setting the record straight: The origin of the pharmacophore concept. Journal of Chemical Information and Modeling 54, 1269-1283.

Guo, X., Li, D., Hu, F., Song, J., Zhang, S., Deng, W., Sun, K., Zhao, Q., Xie, X., Song, Y., Wu, M., Wei, L., 2012. Targeting autophagy potentiates chemotherapy-induced apoptosis and proliferation inhibition in hepatocarcinoma cells. Cancer Letters 320, $171-179$.

Gupta, A., Unadkat, J.D., Mao, Q., 2007. Interactions of azole antifungal agents with the human breast cancer resistance protein (BCRP). Journal of Pharmaceutical Sciences 96, 3226-3235. 
Gupta, P.B., Onder, T.T., Jiang, G., Tao, K., Kuperwasser, C., Weinberg, R.A., Lander, E.S., 2009. Identification of selective inhibitors of cancer stem cells by high-throughput screening. Cell 138, 645-659.

Gupta, S., Kim, J., Gollapudi, S., 1991. Reversal of daunorubicin resistance in P388/ADR cells by itraconazole. Journal of Clinical Investigation 87, 1467-1469.

Hamdoun, S., Jung, P., Efferth, T., 2017. Drug repurposing of the anthelmintic niclosamide to treat multidrug-resistant leukemia. Frontiers in Pharmacology 8, 110.

Hanusova, V., Skalova, L., Kralova, V., Matouskova, P., 2015. Potential Anti-cancer Drugs Commonly Used for Other Indications. Current Cancer Drug Targets 15, 35-52.

Hara, M., Nagasaki, T., Shiga, K., Takeyama, H., 2016. Suppression of cancer-associated fibroblasts and endothelial cells by itraconazole in bevacizumab-resistant gastrointestinal cancer. Anticancer Research, 36, 169-177.

Harguindey, S., Arranz, J., Polo Orozco, J., Rauch, C., Fais, S., Cardone, R., Reshkin, S.J., 2013. Cariporide and other new and powerful NHE1 inhibitors as potentially selective anticancer drugs - an integral molecular/biochemical/metabolic/clinical approach after one hundred years of cancer research. Journal of Translational Medicine 11, 282.

Harguindey, S., Cragoe, E.J., Jr, 1992. The antiporter in oncology in the light of the spontaneous regression of cancer and cell metabolism. Medical Hypotheses 39, 229_ 237.

Harguindey, S., Orive, G., Luis Pedraz, J., Paradiso, A., Reshkin, S.J., 2005. The role of pH dynamics and the $\mathrm{Na}+/ \mathrm{H}+$ antiporter in the etiopathogenesis and treatment of cancer. Two faces of the same coin-one single nature. Biochimica et Biophysica Acta (BBA) Reviews on Cancer 1756, 1-24.

Hassel, P., 1985. Experimental comparison of low doses of $1.5 \mathrm{mg}$ fluspirilene and bromazepam in out-patients with psychovegetative disturbances. Pharmacopsychiatry 18, 297-302. 
Heckman-Stoddard, B.M., DeCensi, A., Sahasrabuddhe, V.V., Ford, L.G., 2017. Repurposing metformin for the prevention of cancer and cancer recurrence. Diabetologia 60, 1639-1647.

Heinrich, J.C., Donakonda, S., Haupt, V.J., Lennig, P., Zhang, Y., Schroeder, M., 2016. New HSP27 inhibitors efficiently suppress drug resistance development in cancer cells. Oncotarget 7, 68156-68169

Higuchi, T., Sugisawa, N., Miyake, K., Oshiro, H., Yamamoto, N., Hayashi, K., Kimura, H., Miwa, S., Igarashi, K., Kline, Z., Bouvet, M., Singh, S.R., Tsuchiya, H., Hoffman, R.M., 2019. Pioglitazone, an agonist of PPARy, reverses doxorubicin-resistance in an osteosarcoma patient-derived orthotopic xenograft model by downregulating $\mathrm{P}$ glycoprotein expression. Biomedicine \& Pharmacotherapy 118, 109356.

Hirsch, H.A., Iliopoulos, D., Tsichlis, P.N., Struhl, K., 2009. Metformin selectively targets cancer stem cells, and acts together with chemotherapy to block tumor growth and prolong remission. Cancer Research 69, 7507-7511.

Hochhaus, A., Breccia, M., Saglio, G., García-Gutiérrez, V., Réa, D., Janssen, J., Apperley, J., 2020. Expert opinion-management of chronic myeloid leukemia after resistance to second-generation tyrosine kinase inhibitors. Leukemia 10.1038/s41375-020-0842-9.

Hosoya, K., Couto, C.G., London, C.A., Kisseberth, W.C., Phelps, M.A., Dalton, J.T., 2014. Comparison of high-dose intermittent and low-dose continuous oral artemisinin in dogs with naturally occurring tumors. Journal of the American Animal Hospital Association 50, 390-395.

Hu, M., Lee, H.-K., To, K.K.W., Fok, B.S.P., Wo, S.-K., Ho, C.-S., Wong, C.-K., Zuo, Z., Chan, T.Y.K., Chan, J.C.N., Tomlinson, B., 2016. Telmisartan increases systemic exposure to rosuvastatin after single and multiple doses, and in vitro studies show telmisartan inhibits ABCG2-mediated transport of rosuvastatin. European Journal of Clinical Pharmacology 72, 1471-1478. 
Huang, H., Zhang, G., Zhou, Y., Lin, C., Chen, S., Lin, Y., Mai, S., Huang, Z., 2018. Reverse screening methods to search for the protein targets of chemopreventive compounds. Frontiers in Chemistry 6, 138.

Huang, H.-C., Liu, J., Baglo, Y., Rizvi, I., Anbil, S., Pigula, M., Hasan, T., 2017. Mechanisminformed repurposing of minocycline overcomes resistance to topoisomerase inhibition for peritoneal carcinomatosis. Molecular Cancer Therapeutics 17, 508-520.

Huo, Y., Zhang, H.-Y., 2018. Genetic mechanisms of asthma and the implications for drug repositioning. Genes 9, 237.

Iorio, F., Knijnenburg, T.A., Vis, D.J., Bignell, G.R., Menden, M.P., Schubert, M., Aben, N., Gonçalves, E., Barthorpe, S., Lightfoot, H., Cokelaer, T., Greninger, P., van Dyk, E., Chang, H., de Silva, H., Heyn, H., Deng, X., Egan, R.K., Liu, Q., Mironenko, T., Mitropoulos, X., Richardson, L., Wang, J., Zhang, T., Moran, S., Sayols, S., Soleimani, M., Tamborero, D., Lopez-Bigas, N., Ross-Macdonald, P., Esteller, M., Gray, N.S., Haber, D.A., Stratton, M.R., Benes, C.H., Wessels, L.F.A., Saez-Rodriguez, J., McDermott, U., Garnett, M.J., 2016. A landscape of pharmacogenomic interactions in cancer. Cell 166, 740-754.

Isca, V.M.S., Sencanski, M., Filipovic, N., Dos Santos, D.J.V.A., Čipak Gašparović, A., Saraíva, L., Afonso, C.A.M., Rijo, P., García-Sosa, A.T., 2020. Activity to breast cancer cell lines of different malignancy and predicted interaction with protein kinase C isoforms of royleanones. International Journal of Molecular Sciences 21, 3671.

James, N.D., de Bono, J.S., Spears, M.R., Clarke, N.W., Mason, M.D., Dearnaley, D.P., Ritchie, A.W.S., Amos, C.L., Gilson, C., Jones, R.J., Matheson, D., Millman, R., Attard, G., Chowdhury, S., Cross, W.R., Gillessen, S., Parker, C.C., Russell, J.M., Berthold, D.R., Brawley, C., Adab, F., Aung, S., Birtle, A.J., Bowen, J., Brock, S., Chakraborti, P., Ferguson, C., Gale, J., Gray, E., Hingorani, M., Hoskin, P.J., Lester, J.F., Malik, Z.I., McKinna, F., McPhail, N., Money-Kyrle, J., O’Sullivan, J., Parikh, O., Protheroe, A., Robinson, A., Srihari, N.N., Thomas, C., Wagstaff, J., Wylie, J., Zarkar, A., Parmar, 
M.K.B., Sydes, M.R., 2017. Abiraterone for Prostate Cancer Not Previously Treated with Hormone Therapy. New England Journal of Medicine 377, 338-351.

James, P.A., Oparil, S., Carter, B.L., Cushman, W.C., Dennison-Himmelfarb, C., Handler, J., Lackland, D.T., LeFevre, M.L., MacKenzie, T.D., Ogedegbe, O., Smith, S.C., Jr, Svetkey, L.P., Taler, S.J., Townsend, R.R., Wright, J.T., Jr, Narva, A.S., Ortiz, E., 2014. Evidence-based guideline for the management of high blood pressure in adults. JAMA 311, 507.

Jansen, F.H., Adoubi, I., J C K.C., De Cnodder, T., Jansen, N., Tschulakow, A., Efferth, T., 2011. First study of oral Artenimol-R in advanced cervical cancer: clinical benefit, tolerability and tumor markers. Anticancer Research 31, 4417-4422.

Jiang, X., Chen, Z., Shen, G., Jiang, Y., Wu, L., Li, X., Wang, G., Yin, T., 2018. Psychotropic agent thioridazine elicits potent in vitro and in vivo anti-melanoma effects. Biomedicine \& Pharmacotherapy 97, 833-837.

Jin, Y., Lu, Z., Ding, K., Li, J., Du, X., Chen, C., Sun, X., Wu, Y., Zhou, J., Pan, J., 2010. Antineoplastic mechanisms of niclosamide in acute myelogenous leukemia stem cells: inactivation of the NF-B pathway and generation of reactive oxygen species. Cancer Research 70, 2516-2527.

Jonsson, Ö., Behnam-Motlagh, P., Persson, M., Henriksson, R., Grankvist, K., 1999. Increase in doxorubicin cytotoxicity by carvedilol inhibition of P-glycoprotein activity. Biochemical Pharmacology 58, 1801-1806.

Kakumoto, M., Sakaeda, T., Takara, K., Nakamura, T., Kita, T., Yagami, T., Kobayashi, H., Okamura, N., Okumura, K., 2003. Effects of carvedilol on MDR1 -mediated multidrug resistance: comparison with verapamil. Cancer Science 94, 81-86.

Kam, Y., Das, T., Tian, H., Foroutan, P., Ruiz, E., Martinez, G., Minton, S., Gillies, R.J., Gatenby, R.A., 2015. Sweat but no gain: Inhibiting proliferation of multidrug resistant cancer cells with "ersatzdroges." International Journal of Cancer 136, E188-E196. 
Kamarudin, M.N.A., Sarker, M.M.R., Zhou, J.R., Parhar, I., 2019. Metformin in colorectal cancer: molecular mechanism, preclinical and clinical aspects. Journal of Experimental \& Clinical Cancer Research 38, 491.

Kawamata, A., Ito, D., Odani, T., Isobe, T., Iwase, M., Hatori, M., Nagumo, M., 2006. Thalidomide suppresses melanoma growth by activating natural killer cells in mice. Oncology Reports 16, 1231-1236.

Kaneko, M., Nozawa, H., Hiyoshi, M., Tada, N., Murono, K., Nirei, T., Emoto, S., Kishikawa, J., lida, Y., Sunami, E., Tsuno, N.H., Kitayama, J., Takahashi, K., Watanabe, T., 2014. Temsirolimus and chloroquine cooperatively exhibit a potent antitumor effect against colorectal cancer cells. Journal of Cancer Research and Clinical Oncology 140, 769781.

Kang, S., Dong, S.M., Kim, B.-R., Park, M.S., Trink, B., Byun, H.-J., Rho, S.B., 2012. Thioridazine induces apoptosis by targeting the PI3K/Akt/mTOR pathway in cervical and endometrial cancer cells. Apoptosis 17, 989-997.

Keifer, J.A., Guttridge, D.C., Ashburner, B.P., Baldwin, A.S. Jr., 2001. Inhibition of NF-kB activity by thalidomide through suppression of IkB kinase activity. Journal of Biological Chemistry 276, 22382-22387.

Khalilzadeh, A., Wangoo, K.T., Morris, D.L., Pourgholami, M.H., 2007. Epothilone-paclitaxel resistant leukemic cells CEM/dEpoB300 are sensitive to albendazole: Involvement of apoptotic pathways. Biochemical Pharmacology 74, 407-414.

Kharkar, P.S., Warrier, S., Gaud, R.S., 2014. Reverse docking: a powerful tool for drug repositioning and drug rescue. Future Medicinal Chemistry 6, 333-342.

Kim, D.J., Kim, J., Spaunhurst, K., Montoya, J., Khodosh, R., Chandra, K., Fu, T., Gilliam, A., Molgo, M., Beachy, P.A., Tang, J.Y., 2014a. Open-label, exploratory phase II trial of oral itraconazole for the treatment of basal cell carcinoma. Journal of Clinical Oncology $32,745-751$.

Kim, H.G., Hien, T.T., Han, E.H., Hwang, Y.P., Choi, J.H., Kang, K.W., Kwon, K., Kim, B.-H., Kim, S.K., Song, G.Y., Jeong, T.C., Jeong, H.G., 2011. Metformin inhibits P- 
glycoprotein expression via the NF-KB pathway and CRE transcriptional activity through AMPK activation. British Journal of Pharmacology 162, 1096-1108.

Kim, J., Aftab, B.T., Tang, J.Y., Kim, D., Lee, A.H., Rezaee, M., Kim, J., Chen, B., King, E.M., Borodovsky, A., Riggins, G.J., Epstein, E.H., Jr., Beachy, P.A., Rudin, C.M., 2013a. Itraconazole and arsenic trioxide inhibit hedgehog pathway activation and tumor growth associated with acquired resistance to smoothened antagonists. Cancer Cell 23, 2334.

Kim, J., Han, W., Kim, E.-K., Jung, Y., Kim, H.-A., Chae, S.M., Lee, E.S., Ahn, S.-H., Kim, T.H., Jeong, J., Choi, S.Y., Nam, S.J., Paik, N.-S., Kim, L.S., Gong, G., Yu, J.H., Jung, S.-Y., Kim, H.J., Ahn, S.G., Kim, M.K., 2019. Phase II randomized study of neoadjuvant metformin plus letrozole versus placebo plus letrozole for ER-positive postmenopausal breast cancer [METEOR Study]. Journal of Clinical Oncology 37, 576-576.

Kim, J., Lim, W., Kim, E.-K., Kim, M.-K., Paik, N.-S., Jeong, S.-S., Yoon, J., Park, C.H., Ahn, S.H., Kim, L.S., Han, S., Nam, S.J., Kang, H.-S., Kim, S.I., Yoo, Y.B., Jeong, J., Kim, T.H., Kang, T., Kim, S.-W., Jung, Y., Lee, J.E., Kim, K.S., Yu, J.-H., Chae, B.J., Jung, S.-Y., Kang, E., Choi, S.Y., Moon, H.-G., Noh, D.-Y., Han, W., 2014b. Phase II randomized trial of neoadjuvant metformin plus letrozole versus placebo plus letrozole for estrogen receptor positive postmenopausal breast cancer (METEOR). BMC Cancer $14,170$.

Kim, J., You, Y.-J., 2017. Regulation of organelle function by metformin. IUBMB Life 69, 459-469.

Kim, J.-H., Choi, A.-R., Kim, Y.K., Yoon, S., 2013b. Co-treatment with the anti-malarial drugs mefloquine and primaquine highly sensitizes drug-resistant cancer cells by increasing P-gp inhibition. Biochemical and Biophysical Research Communications 441, 655-660.

Klil-Drori, A.J., Azoulay, L., Pollak, M.N., 2016. Cancer, obesity, diabetes, and antidiabetic drugs: is the fog clearing? Nature Reviews Clinical Oncology 14, 85-99. doi:10.1038/nrclinonc.2016.120 
Konieczna, A., Nováková, V., Medalová, J., Erceg, S., Klabusay, M., 2015. Thiazolidinediones regulate the level of $A B C$ transporters expression on lung cancer cells. Klinicka onkologie 28, 431-438.

Kopecka, J., Trouillas, P., Gašparović, A.Č., Gazzano, E., Assaraf, Y.G., Riganti, C., 2020. Phospholipids and cholesterol: Inducers of cancer multidrug resistance and therapeutic targets. Drug Resistance Updates 49, 100670.

Krishna, S., Ganapathi, S., Ster, I.C., Saeed, M.E., Cowan, M., Finlayson, C., Kovacsevics, H., Jansen, H., Kremsner, P.G., Efferth, T., Kumar, D., 2014. A randomised, double blind, placebo-controlled pilot study of oral artesunate therapy for colorectal cancer. EBioMedicine 2, 82-90

Krishnan, A., Nair, S., Pillai, M., 2007. Biology of PPARy in cancer: A critical review on existing lacunae. Current Molecular Medicine 7, 532-540.

Kuenzi, B.M., Remsing Rix, L.L., Kinose, F., Kroeger, J.L., Lancet, J.E., Padron, E., Rix, U., 2019. Off-target based drug repurposing opportunities for tivantinib in acute myeloid leukemia. Scientific Reports 9, 606.

Kurosawa, M., Okabe, M., Hara, N., Kawamura, K., Suzuki, S., Sakurada, K., Asaka, M., 1996. Reversal effect of itraconazole on adriamycin and etoposide resistance in human leukemia cells. Annals of Hematology 72, 17-21.

Kwon, O.-S., Kim, W., Cha, H.-J., Lee, H., 2019. In silico drug repositioning: from large-scale transcriptome data to therapeutics. Archives of Pharmacal Research 42, 879-889.

Kwon, Y.-J., Petrie, K., Leibovitch, B.A., Zeng, L., Mezei, M., Howell, L., Gil, V., Christova, R., Bansal, N., Yang, S., Sharma, R., Ariztia, E.V., Frankum, J., Brough, R., Sbirkov, Y., Ashworth, A., Lord, C.J., Zelent, A., Farias, E., Zhou, M.-M., Waxman, S., 2015. Selective inhibition of SIN3 corepressor with avermectins as a novel therapeutic strategy in triple-negative breast cancer. Molecular Cancer Therapeutics 14, 18241836.Lagarde, N., Rey, J., Gyulkhandanyan, A., Tufféry, P., Miteva, M.A., Villoutreix, B.O., 2018. Online structure-based screening of purchasable approved drugs and 
natural compounds: retrospective examples of drug repositioning on cancer targets. Oncotarget 9, 32346-32361.

Lai, H., Singh, N.P., 1995. Selective cancer cell cytotoxicity from exposure to dihydroartemisinin and holotransferrin. Cancer Letters 91, 41-46.

Lee, S., Son, A.-R., Ahn, J., Song, J.-Y., 2014. Niclosamide enhances ROS-mediated cell death through c-Jun activation. Biomedicine \& Pharmacotherapy 68, 619-624.

Lega, I.C., Shah, P.S., Margel, D., Beyene, J., Rochon, P.A., Lipscombe, L.L., 2014. The effect of metformin on mortality following cancer among patients with diabetes. Cancer Epidemiology Biomarkers \& Prevention 23, 1974-1984.

Leonetti, A., Wever, B., Mazzaschi, G., Assaraf, Y., Rolfo, C., Quaini, F., Tiseo, M. and Giovannetti, E., 2019. Molecular basis and rationale for combining immune checkpoint inhibitors with chemotherapy in non-small cell lung cancer. Drug Resistance Updates 46, 100644 .

Li, H., Chang, G., Wang, J., Wang, L., Jin, W., Lin, Y., Yan, Y., Wang, R., Gao, W., Ma, L., Li, Q., Pang, T., 2014a. Cariporide sensitizes leukemic cells to tumor necrosis factor related apoptosis-inducing ligand by up-regulation of death receptor 5 via endoplasmic reticulum stress-CCAAT/enhancer binding protein homologous protein dependent mechanism. Leukemia \& Lymphoma 55, 2135-2140.

Li, P.C., Lam, E., Roos, W.P., Zdzienicka, M.Z., Kaina, B., Efferth, T., 2008. Artesunate derived from traditional Chinese medicine induces DNA damage and repair. Cancer Research 68, 4347-4351.

Li, W., Zhang, H., Assaraf, Y., Zhao, K., Xu, X., Xie, J., Yang, D. and Chen, Z., 2016. Overcoming $A B C$ transporter-mediated multidrug resistance: Molecular mechanisms and novel therapeutic drug strategies. Drug Resistance Updates 27, 14-29.

Li, W.-X., Li, L., Eksterowicz, J., Ling, X.B., Cardozo, M., 2007. Significance analysis and multiple pharmacophore models for differentiating P-glycoprotein substrates. Journal of Chemical Information and Modeling 47, 2429-2438. 
Li, Y., Li, P.-K., Roberts, M.J., Arend, R.C., Samant, R.S., Buchsbaum, D.J., 2014b. Multitargeted therapy of cancer by niclosamide: A new application for an old drug. Cancer Letters 349, 8-14.

Liao, Z., Nan, G., Yan, Z., Zeng, L., Deng, Y., Ye, J., Zhang, Z., Qiao, M., Li, R., Denduluri, S., Wang, J., Wei, Q., Geng, N., Zhao, L., Lu, S., Wang, X., Zhou, G., Luu, H., Haydon, R., He, T.-C., Wang, Z., 2015. The anthelmintic drug niclosamide inhibits the proliferative activity of human osteosarcoma cells by targeting multiple signal pathways. Current Cancer Drug Targets 15, 726-738.

Libby, G., Donnelly, L.A., Donnan, P.T., Alessi, D.R., Morris, A.D., Evans, J.M.M., 2009. New Users of Metformin Are at Low Risk of Incident Cancer: A cohort study among people with type 2 diabetes. Diabetes Care 32, 1620-1625.

Ling, S., Tian, Y., Zhang, H., Jia, K., Feng, T., Sun, D., Gao, Z., Xu, F., Hou, Z., Li, Y., Wang, L., 2014. Metformin reverses multidrug resistance in human hepatocellular carcinoma Bel-7402/5-fluorouracil cells. Molecular Medicine Reports 10, 2891-2897.

Liu, C., Lou, W., Armstrong, C., Zhu, Y., Evans, C.P., Gao, A.C., 2015. Niclosamide suppresses cell migration and invasion in enzalutamide resistant prostate cancer cells via Stat3-AR axis inhibition. The Prostate 75, 1341-1353.

Liu, J., Chen, X., Ward, T., Pegram, M., Shen, K., 2016. Combined niclosamide with cisplatin inhibits epithelial-mesenchymal transition and tumor growth in cisplatin-resistant triplenegative breast cancer. Tumor Biology 37, 9825-9835.

Liu, Y., Ge, J., Li, Q., Gu, L., Guo, X., Ma, Z.G., Zhu, Y.P., 2012. Anisomycin Induces apoptosis of glucocorticoid resistant acute lymphoblastic leukemia CEM-C1 cells via activation of mitogen-activated protein kinases p38 and JNK. Neoplasma 60, 101-110.

Livney, Y.D., Assaraf, Y.G., 2013. Rationally designed nanovehicles to overcome cancer chemoresistance. Advanced Drug Delivery Reviews 65, 1716-1730.

Lopez-Bonet, E., Buxó, M., Cuyàs, E., Pernas, S., Dorca, J., Álvarez, I., Martínez, S., PérezGarcia, J.M., Batista-López, N., Rodríguez-Sánchez, C.A., Amillano, K., Domínguez, S., Luque, M., Morilla, I., Stradella, A., Viñas, G., Cortés, J., Oliveras, G., Meléndez, C., 
Castillo, L., Verdura, S., Brunet, J., Joven, J., Garcia, M., Saidani, S., Martin-Castillo, B., Menendez, J.A., 2019. Neoadjuvant metformin added to systemic therapy decreases the proliferative capacity of residual breast cancer. Journal of Clinical Medicine 8, 2180.

Markosian, C., Di Costanzo, L., Sekharan, M., Shao, C., Burley, S.K., Zardecki, C., 2018. Analysis of impact metrics for the Protein Data Bank. Scientific Data 5, 180212.

Martin-Castillo, B., Pernas, S., Dorca, J., Álvarez, I., Martínez, S., Pérez-Garcia, J.M., Batista-López, N., Rodríguez-Sánchez, C.A., Amillano, K., Domínguez, S., Luque, M., Stradella, A., Morilla, I., Viñas, G., Cortés, J., Cuyàs, E., Verdura, S., FernándezOchoa, Á., Fernández-Arroyo, S., Segura-Carretero, A., Joven, J., Pérez, E., Bosch, N., Garcia, M., López-Bonet, E., Saidani, S., Buxó, M., Menendez, J.A., 2018. A phase 2 trial of neoadjuvant metformin in combination with trastuzumab and chemotherapy in women with early HER2-positive breast cancer: the METTEN study. Oncotarget 9, 35687-35704.

Mason, M.D., Clarke, N.W., James, N.D., Dearnaley, D.P., Spears, M.R., Ritchie, A.W.S., Attard, G., Cross, W., Jones, R.J., Parker, C.C., Russell, J.M., Thalmann, G.N., Schiavone, F., Cassoly, E., Matheson, D., Millman, R., Rentsch, C.A., Barber, J., Gilson, C., Ibrahim, A., Logue, J., Lydon, A., Nikapota, A.D., O’Sullivan, J.M., Porfiri, E., Protheroe, A., Srihari, N.N., Tsang, D., Wagstaff, J., Wallace, J., Walmsley, C., Parmar, M.K.B., Sydes, M.R., 2017. Adding celecoxib with or without zoledronic acid for hormone-naïve prostate cancer: long-term survival results from an adaptive, multiarm, multistage, platform, randomized controlled trial. Journal of Clinical Oncology $35,1530-1541$.

Masuda, T., Tsuruda, Y., Matsumoto, Y., Uchida, H., Nakayama, K.I., Mimori, K., 2020. Drug repositioning in cancer: The current situation in Japan. Cancer Science 111, 10391046. 
Maycotte, P., Aryal, S., Cummings, C.T., Thorburn, J., Morgan, M.J., Thorburn, A., 2012. Chloroquine sensitizes breast cancer cells to chemotherapy independent of autophagy. Autophagy 8, 200-212.

Merino, G., Alvarez, A.I., Prieto, J.G., Kim, R.B., 2002. The Anthelminthic Agent Albendazole Does Not Interact with P-Glycoprotein. Drug Metabolism and Disposition 30, 365-369.

Mikhael, J., Ismaila, N., Cheung, M.C., Costello, C., Dhodapkar, M.V., Kumar, S., Lacy, M., Lipe, B., Little, R.F., Nikonova, A., Omel, J., Peswani, N., Prica, A., Raje, N., Seth, R., Vesole, D.H., Walker, I., Whitley, A., Wildes, T.M., Wong, S.W., Martin, T., 2019. Treatment of Multiple Myeloma: ASCO and CCO Joint Clinical Practice Guideline. Journal of Clinical Oncology 37, 1228-1263.

Milman, N., Ginini, L., Gil, Z., 2019. Exosomes and their role in tumorigenesis and anticancer drug resistance. Drug Resistance Updates 45, 1-12.

Monaghan, D., O’Connell, E., Cruickshank, F.L., O’Sullivan, B., Giles, F.J., Hulme, A.N., Fearnhead, H.O., 2014. Inhibition of protein synthesis and JNK activation are not required for cell death induced by anisomycin and anisomycin analogues. Biochemical and Biophysical Research Communications 443, 761-767.

Montanari, F., Ecker, G.F., 2015. Prediction of drug-ABC-transporter interaction - Recent advances and future challenges. Advanced Drug Delivery Reviews 86, 17-26.

Montanari, F., Lu, M., Marcus, S., Saran, A., Malankar, A., Mazumder, A., 2014. A Phase II trial of chloroquine in combination with bortezomib and cyclophosphamide in patients with relapsed and refractory multiple myeloma. Blood 124, 5775-5775.

Morales, D.R., Morris, A.D., 2015. Metformin in cancer treatment and prevention. Annual Review of Medicine 66, 17-29.

Moreau, P., Attal, M., Hulin, C., Arnulf, B., Belhadj, K., Benboubker, L., Béné, M.C., Broijl, A., Caillon, H., Caillot, D., Corre, J., Delforge, M., Dejoie, T., Doyen, C., Facon, T., Sonntag, C., Fontan, J., Garderet, L., Jie, K.-S., Karlin, L., Kuhnowski, F., Lambert, J., Leleu, X., Lenain, P., Macro, M., Mathiot, C., Orsini-Piocelle, F., Perrot, A., Stoppa, A.M., van de Donk, N.W., Wuilleme, S., Zweegman, S., Kolb, B., Touzeau, C., Roussel, 
M., Tiab, M., Marolleau, J.-P., Meuleman, N., Vekemans, M.-C., Westerman, M., Klein, S.K., Levin, M.-D., Fermand, J.P., Escoffre-Barbe, M., Eveillard, J.-R., Garidi, R., Ahmadi, T., Zhuang, S., Chiu, C., Pei, L., de Boer, C., Smith, E., Deraedt, W., Kampfenkel, T., Schecter, J., Vermeulen, J., Avet-Loiseau, H., Sonneveld, P., 2019. Bortezomib, thalidomide, and dexamethasone with or without daratumumab before and after autologous stem-cell transplantation for newly diagnosed multiple myeloma (CASSIOPEIA): a randomised, open-label, phase 3 study. The Lancet 394, 29-38.

Moreau, P., Hulin, C., Macro, M., Caillot, D., Chaleteix, C., Roussel, M., Garderet, L., Royer, B., Brechignac, S., Tiab, M., Puyade, M., Escoffre, M., Stoppa, A.-M., Facon, T., Pegourie, B., Chaoui, D., Jaccard, A., Slama, B., Marit, G., Laribi, K., Godmer, P., Luycx, O., Eisenmann, J.-C., Allangba, O., Dib, M., Araujo, C., Fontan, J., Belhadj, K., Wetterwald, M., Dorvaux, V., Fermand, J.-P., Rodon, P., Kolb, B., Glaisner, S., Malfuson, J.-V., Lenain, P., Biron, L., Planche, L., Caillon, H., Avet-Loiseau, H., Dejoie, T., Attal, M., 2016. VTD is superior to VCD prior to intensive therapy in multiple myeloma: results of the prospective IFM2013-04 trial. Blood 127, 2569-2574.

Mori, T., Ito, T., Liu, S., Ando, H., Sakamoto, S., Yamaguchi, Y., Tokunaga, E., Shibata, N., Handa, H., Hakoshima, T., 2018. Structural basis of thalidomide enantiomer binding to cereblon. Scientific Reports 8, 1294.

Motohashi, N., Kurihara, T., Satoh, K., Sakagami, H., Mucsi, I., Pusztai, R., Szabó, M., Molnár, J., 1999. Antitumor activity of benzo[a]phenothiazines. Anticancer Research $19,1837-1842$.

Mudduluru, G., Walther, W., Kobelt, D., Dahlmann, M., Treese, C., Assaraf, Y.G., Stein, U., 2016. Repositioning of drugs for intervention in tumor progression and metastasis: Old drugs for new targets. Drug Resistance Updates 26, 10-27.

Niewerth, D., Jansen, G., Assaraf, Y.G., Zweegman, S, Kaspers, G.J., Cloos, J., 2015. Molecular basis of resistance to proteasome inhibitors in hematological malignancies. Drug Resistance Updates 18, 18-35. 
Nobili, S., Landini, I., Giglioni, B., Mini, E., 2006. Pharmacological strategies for overcoming multidrug resistance. Current Drug Targets 7, 861-879.

Nowak-Sliwinska, P., Scapozza, L., Ruiz i Altaba, A., 2019. Drug repurposing in oncology: Compounds, pathways, phenotypes and computational approaches for colorectal cancer. Biochimica et Biophysica Acta (BBA) - Reviews on Cancer 1871, 434-454.

Nygren, P., Fryknäs, M., Ågerup, B., Larsson, R., 2013. Repositioning of the anthelmintic drug mebendazole for the treatment for colon cancer. Journal of Cancer Research and Clinical Oncology 139, 2133-2140.

Ohlow, M.J., Moosmann, B., 2011. Phenothiazine: the seven lives of pharmacology's first lead structure. Drug Discovery Today 16, 119-131.

Palmeira, A., Rodrigues, F., Sousa, E., Pinto, M., Vasconcelos, M.H., Fernandes, M.X., 2011. New uses for old drugs: Pharmacophore-based screening for the discovery of Pglycoprotein inhibitors. Chemical Biology \& Drug Design 78, 57-72.

Palmeira, A., Sousa, E., Vasconcelos, M.H., Pinto, M.M., 2012. Three decades of P-gp inhibitors: Skimming through several generations and scaffolds. Current Medicinal Chemistry 19, 1946-2025.

Pajeva, I.K., Wiese, M., 2002. Pharmacophore model of drugs involved in P-glycoprotein multidrug resistance: Explanation of structural variety (hypothesis). Journal of Medicinal Chemistry 45, 5671-5686.

Pan, C., Lara, P., Evans, C.P., Parikh, M., Dall'era, M., Liu, C., Robles, D., Gao, A., 2018. Niclosamide in combination with abiraterone and prednisone in men with castrationresistant prostate cancer (CRPC): initial results from a phase Ib/II trial. Journal of Clinical Oncology 36, 192-192.

Pan, Y., Chothe, P.P., Swaan, P.W., 2013. Identification of novel breast cancer resistance protein (BCRP) Inhibitors by virtual screening. Molecular Pharmaceutics 10, 12361248. 
Pannocchia, A., Revelli, S., Tamponi, G., Giorgianni, A., Todde, R., Bosia, A., Ghigo, D., 1996. Reversal of doxorubicin resistance by the amiloride analogue EIPA in multidrug resistant human colon carcinoma cells. Cell Biochemistry and Function 14, 11-18.

Pantziarka, P., Sukhatme, V., Bouche, G., Meheus, L., Sukhatme, V.P., 2015. Repurposing Drugs in Oncology (ReDO)-itraconazole as an anti-cancer agent. Ecancer, 9, 521.

Park, J., Kim, Y., Park, E.H., Lee, S., Kim, H., Kim, A., Lee, S.B., Shim, S., Jang, H., Myung, J.K., Park, S., Lee, S., Kim, M.J., 2019. Effects of metformin and phenformin on apoptosis and epithelial-mesenchymal transition in chemoresistant rectal cancer. Cancer Science 110, 2834-2845.

Park, M.S., Dong, S.M., Kim, B.-R., Seo, S.H., Kang, S., Lee, E.-J., Lee, S.-H., Rho, S.B., 2014. Thioridazine inhibits angiogenesis and tumor growth by targeting the VEGFR2/PI3K/mTOR pathway in ovarian cancer xenografts. Oncotarget 5, 4929-4934.

Parker, C.C., James, N.D., Brawley, C.D., Clarke, N.W., Hoyle, A.P., Ali, A., Ritchie, A.W.S., Attard, G., Chowdhury, S., Cross, W., Dearnaley, D.P., Gillessen, S., Gilson, C., Jones, R.J., Langley, R.E., Malik, Z.I., Mason, M.D., Matheson, D., Millman, R., Russell, J.M., Thalmann, G.N., Amos, C.L., Alonzi, R., Bahl, A., Birtle, A., Din, O., Douis, H., Eswar, C., Gale, J., Gannon, M.R., Jonnada, S., Khaksar, S., Lester, J.F., O’Sullivan, J.M., Parikh, O.A., Pedley, I.D., Pudney, D.M., Sheehan, D.J., Srihari, N.N., Tran, A.T.H., Parmar, M.K.B., Sydes, M.R., 2018. Radiotherapy to the primary tumour for newly diagnosed, metastatic prostate cancer (STAMPEDE): a randomised controlled phase 3 trial. The Lancet 392, 2353-2366.

Pascolo, S., 2016. Time to use a dose of Chloroquine as an adjuvant to anti-cancer chemotherapies. European Journal of Pharmacology 771, 139-144.

Pemovska, T., Johnson, E., Kontro, M., Repasky, G.A., Chen, J., Wells, P., Cronin, C.N., McTigue, M., Kallioniemi, O., Porkka, K., Murray, B.W., Wennerberg, K., 2015. Axitinib effectively inhibits BCR-ABL1(T315I) with a distinct binding conformation. Nature 519, $102-105$. 
Penzotti, J.E., Lamb, M.L., Evensen, E., Grootenhuis, P.D.J., 2002. A computational ensemble pharmacophore model for identifying substrates of P-glycoprotein. Journal of Medicinal Chemistry 45, 1737-1740.

Pham, Y.-T., Régina, A., Farinotti, R., Couraud, P.-O., Wainer, I.W., Roux, F., Gimenez, F., 2000. Interactions of racemic mefloquine and its enantiomers with P-glycoprotein in an immortalised rat brain capillary endothelial cell line, GPNT. Biochimica et Biophysica Acta (BBA) - General Subjects 1524, 212-219.

Philip, P., Joel, S., Monkman, S., Dolega-Ossowski, E., Tonkin, K., Carmichael, J., Idle, J., Harris, A., 1992. A phase I study on the reversal of multidrug resistance (MDR) in vivo: nifedipine plus etoposide. British Journal of Cancer 65, 267-270.

Piccart-Gebhart, M., Holmes, E., Baselga, J., de Azambuja, E., Dueck, A.C., Viale, G., Zujewski, J.A., Goldhirsch, A., Armour, A., Pritchard, K.I., McCullough, A.E., Dolci, S., McFadden, E., Holmes, A.P., Tonghua, L., Eidtmann, H., Dinh, P., Di Cosimo, S., Harbeck, N., Tjulandin, S., Im, Y.-H., Huang, C.-S., Diéras, V., Hillman, D.W., Wolff, A.C., Jackisch, C., Lang, I., Untch, M., Smith, I., Boyle, F., Xu, B., Gomez, H., Suter, T., Gelber, R.D., Perez, E.A., 2016. Adjuvant lapatinib and trastuzumab for early human epidermal growth factor receptor 2-positive breast cancer: Results from the randomized phase III adjuvant lapatinib and/or trastuzumab treatment optimization trial. Journal of Clinical Oncology 34, 1034-1042.

Pimentel, I., Chen, B.E., Lohmann, A.E., Ennis, M., Ligibel, J.A., Shepherd, L.E., Hershman, D.L., Stambolic, V., Mayer, I.A., Hobday, T.J., Lemieux, J., Thompson, A.M., Rastogi, P., Gelmon, K.A., Whelan, T.J., Rabaglio-Poretti, M., Dowling, R.J., Parulekar, W.R., Goodwin, P.J., 2019. The effect of metformin on sex hormones in non-diabetic breast cancer patients in CCTG MA.32: A Phase III randomized adjuvant trial of metformin versus placebo in addition to standard therapy. Journal of Clinical Oncology 37,529 529.

Pounds, R., Leonard, S., Dawson, C., Kehoe, S., 2017. Repurposing itraconazole for the treatment of cancer. Oncology Letters 14, 2587-2597. 
Pujalte Martin, M., Borchiellini, D., Viotti, J., Guillot, A., Paoli, J.B., Besson, D., Hilgers, W., El Kouri, C., Cavaglione, G., Priou, F., Lharidon, T., Largillier, R., Deville, J.-L., Hoch, B., Schiappa, R., Tanti, J.F., Bost, F., Ferrero, J.-M., 2019. TAXOMET: A French prospective multicenter randomized controlled phase II study comparing docetaxel plus metformin versus docetaxel plus placebo in mCRPC. Journal of Clinical Oncology 37, 5004-5004.

Pushpakom, S., Iorio, F., Eyers, P.A., Escott, K.J., Hopper, S., Wells, A., Doig, A., Guilliams, T., Latimer, J., McNamee, C., Norris, A., Sanseau, P., Cavalla, D., Pirmohamed, M., 2018. Drug repurposing: progress, challenges and recommendations. Nature Reviews Drug Discovery 18, 41-58.

Qu, C., Zhang, W., Zheng, G., Zhang, Z., Yin, J., He, Z., 2014. Metformin reverses multidrug resistance and epithelial-mesenchymal transition (EMT) via activating AMP-activated protein kinase (AMPK) in human breast cancer cells. Molecular and Cellular Biochemistry 386, 63-71.

Rafiee, P., Stein, D.J., Nelson, V.M., Otterson, M.F., Shaker, R., Binion, D.G., 2010. Thalidomide inhibits inflammatory and angiogenic activation of human intestinal microvascular endothelial cells (HIMEC). American Journal of PhysiologyGastrointestinal and Liver Physiology 298, G167-G176.

Rao, D.K., Liu, H., Ambudkar, S.V., Mayer, M., 2014. A Combination of Curcumin with Either Gramicidin or Ouabain Selectively Kills Cells That Express the Multidrug Resistancelinked ABCG2 Transporter. Journal of Biological Chemistry 289, 31397-31410.

Riccioni, R., Dupuis, M.L., Bernabei, M., Petrucci, E., Pasquini, L., Mariani, G., Cianfriglia, M., Testa, U., 2010. The cancer stem cell selective inhibitor salinomycin is a pglycoprotein inhibitor. Blood Cells, Molecules, and Diseases 45, 86-92.

Rijpma, S.R., van den Heuvel, J.J., van der Velden, M., Sauerwein, R.W., Russel, F.G., Koenderink, J.B., 2014. Atovaquone and quinine anti-malarials inhibit ATP binding cassette transporter activity. Malaria Journal 13, 359. 
Rojas-Puentes, L.L., Gonzalez-Pinedo, M., Crismatt, A., Ortega-Gomez, A., GamboaVignolle, C., Nuñez-Gomez, R., Dorantes-Gallareta, Y., Arce-Salinas, C., Arrieta, O., 2013. Phase II randomized, double-blind, placebo-controlled study of whole-brain irradiation with concomitant chloroquine for brain metastases. Radiation Oncology 8, 209.

Ronald, S., Awate, S., Rath, A., Carroll, J., Galiano, F., Dwyer, D., Kleiner-Hancock, H., Mathis, J.M., Vigod, S., De Benedetti, A., 2013. Phenothiazine inhibitors of TLKs affect double-strand break repair and DNA damage response recovery and potentiate tumor killing with radiomimetic therapy. Genes \& Cancer 4, 39-53.

Rowland, T.L., McHugh, S.M., Deighton, J., Dearman, R.J., Ewan, P.W., Kimber, I., 1998. Differential regulation by thalidomide and dexamethasone of cytokine expression in human peripheral blood mononuclear cells. Immunopharmacology 40, 11-20.

Rudin, C.M., Brahmer, J.R., Juergens, R.A., Hann, C.L., Ettinger, D.S., Sebree, R., Smith, R., Aftab, B.T., Huang, P., Liu, J.O., 2013. Phase 2 study of pemetrexed and itraconazole as second-line therapy for metastatic nonsquamous non-small-cell lung cancer. Journal of Thoracic Oncology 8, 619-623.

Ruiter, R., Visser, L.E., van Herk-Sukel, M.P.P., Coebergh, J.-W.W., Haak, H.R., GeelhoedDuijvestijn, P.H., Straus, S.M.J.M., Herings, R.M.C., Stricker, B.H.C., 2011. Lower risk of cancer in patients on metformin in comparison with those on sulfonylurea derivatives: Results from a large population-based follow-up study. Diabetes Care 35, $119-124$.

Rutteman, G.R., Erich, S.A., Mol, J.A., Spee, B., Grinwis, G.C., Fleckenstein, L., London, C.A., Efferth, T., 2013. Safety and efficacy field study of artesunate for dogs with nonresectable tumours. Anticancer Research 33, 1819-1827.

Safa, A. R., Glover, C. J., Sewell, J. L., Meyers, M. B., Biedler, J. L., Felsted, R. L., 1987. Identification of the multidrug resistance-related membrane glycoprotein as an acceptor for calcium channel blockers. The Journal of Biological Chemistry 262, 7884-7888. 
Salentin, S., Adasme, M.F., Heinrich, J.C., Haupt, V.J., Daminelli, S., Zhang, Y., Schroeder, M., 2017. From malaria to cancer: Computational drug repositioning of amodiaquine using PLIP interaction patterns. Scientific Reports 7, 11401.

Saraei, P., Asadi, I., Kakar, M.A., Moradi-Kor, N., 2019. The beneficial effects of metformin on cancer prevention and therapy: a comprehensive review of recent advances. Cancer Management and Research 11, 3295-3313.

Sarmento-Ribeiro, A.B., Scorilas, A., Gonçalves, A.C., Efferth, T., Trougakos, I.P., 2019. The emergence of drug resistance to targeted cancer therapies: Clinical evidence. Drug Resistance Updates 47:100646.

Sasaki, K., Tsuno, N.H., Sunami, E., Kawai, K., Hongo, K., Hiyoshi, M., Kaneko, M., Murono, K., Tada, N., Nirei, T., Takahashi, K., Kitayama, J., 2012. Resistance of colon cancer to 5-fluorouracil may be overcome by combination with chloroquine, an in vivo study. AntiCancer Drugs 23, 675-682.

Sbaraglini, M.L., Vanrell, M.C., Bellera, C.L., Benaim, G., Carrillo, C., Talevi, A., Romano, P.S., 2016. Neglected tropical protozoan diseases: drug repositioning as a rational option. Current Topics in Medicinal Chemistry 16, 2201-2222.

Schinkel, A.H., Smit, J.J.M., van Tellingen, O., Beijnen, J.H., Wagenaar, E., van Deemter, L., Mol, C.A.A.M., van der Valk, M.A., Robanus-Maandag, E.C., te Riele, H.P.J., Berns, A.J.M., Borst, P., 1994. Disruption of the mouse mdr1a P-glycoprotein gene leads to a deficiency in the blood-brain barrier and to increased sensitivity to drugs. Cell $77,491-$ 502.

Schmidt, B., Schieffer, B., 2003. Angiotensin II AT1 receptor antagonists. Clinical implications of active metabolites. Journal of Medicinal Chemistry 46, 2261-2270.

Schweizer, M.T., Haugk, K., McKiernan, J.S., Gulati, R., Cheng, H.H., Maes, J.L., Dumpit, R.F., Nelson, P.S., Montgomery, B., McCune, J.S., Plymate, S.R., Yu, E.Y., 2018. A phase I study of niclosamide in combination with enzalutamide in men with castrationresistant prostate cancer. PLOS ONE 13, e0198389. 
Seervi, M., Rani, A., Sharma, A.K., Santhosh Kumar, T.R., 2018. ROS mediated ER stress induces Bax-Bak dependent and independent apoptosis in response to thioridazine. Biomedicine \& Pharmacotherapy 106, 200-209.

Segarra, M., Lozano, E., Corbera-Bellalta, M., Vilardell, C., Cibeira, M.T., Esparza, J., Izco, N., Blade, J., Cid, M.C., 2010. Thalidomide decreases gelatinase production by malignant B lymphoid cell lines through disruption of multiple integrin-mediated signaling pathways. Haematologica 95, 456-463.

Serafin, M.B., Bottega, A., da Rosa, T.F., Machado, C.S., Foletto, V.S., Coelho, S.S., da Mota, A.D., Hörner, R., 2019. Drug repositioning in oncology. American Journal of Therapeutics 10.1097/MJT.0000000000000906

Shafiei-Irannejad, V., Samadi, N., Salehi, R., Yousefi, B., Rahimi, M., Akbarzadeh, A., Zarghami, N., 2018a. Reversion of Multidrug Resistance by Co-Encapsulation of Doxorubicin and Metformin in Poly(lactide-co-glycolide)-d-a-tocopheryl Polyethylene Glycol 1000 Succinate Nanoparticles. Pharmaceutical Research 35, 119.

Shafiei-Irannejad, V., Samadi, N., Yousefi, B., Salehi, R., Velaei, K., Zarghami, N., 2018b. Metformin enhances doxorubicin sensitivity via inhibition of doxorubicin efflux in P-gpoverexpressing MCF-7 cells. Chemical Biology \& Drug Design 91, 269-276.

Shapira, A., Livney, Y.D., Broxterman, H.J., Assaraf, Y.G., 2011. Nanomedicine for targeted cancer therapy: towards the overcoming of drug resistance. Drug Resistance Updates $14,150-163$.

Shen, J., Zheng, H., Ruan, J., Fang, W., Li, A., Tian, G., Niu, X., Luo, S., Zhao, P., 2013. Autophagy inhibition induces enhanced proapoptotic effects of ZD6474 in glioblastoma. British Journal of Cancer 109, 164-171.

Shi, X.-N., Li, H., Yao, H., Liu, X., Li, L., Leung, K.-S., Kung, H., Lu, D., Wong, M.-H., Lin, M.C., 2015. In silico identification and in vitro and in vivo validation of anti-psychotic drug fluspirilene as a potential CDK2 inhibitor and a candidate anti-cancer drug. PLOS ONE 10, e0132072.

Shoichet, B.K., 2004. Virtual screening of chemical libraries. Nature 432, 862-865. 
Shortt, J., Hsu, A.K., Johnstone, R.W., 2013. Thalidomide-analogue biology: immunological, molecular and epigenetic targets in cancer therapy. Oncogene 32, 4191-4202.

Shukla, S., Kouanda, A., Silverton, L., Talele, T.T., Ambudkar, S.V., 2014. Pharmacophore modeling of nilotinib as an inhibitor of ATP-binding cassette drug transporters and bcrabl kinase using a three-dimensional quantitative structure-activity relationship approach. Molecular Pharmaceutics 11, 2313-2322.

Shukla, S., Robey, R.W., Bates, S.E., Ambudkar, S.V., 2006. The calcium channel blockers, 1,4-dihydropyridines, are substrates of the multidrug resistance-linked $A B C$ drug transporter, ABCG2†. Biochemistry 45, 8940-8951.

Singh, N.P., Panwar, V.K., 2006. Case report of a pituitary macroadenoma treated with artemether. Integrative Cancer Therapy 5, 391-394.

Skelhorne-Gross, G., Nicol, C.J.B., 2012. The key to unlocking the chemotherapeutic potential of Ppar $\mathrm{Y}$-Ligands: Having the right combination. PPAR Research 2012, 1-13.

Slipicevic, A., Øy, G.F., Rosnes, A.K.R., Stakkestad, Ø., Emilsen, E., Engesæter, B., Mælandsmo, G.M., Flørenes, V.A., 2013. Low-dose anisomycin sensitizes melanoma cells to TRAIL induced apoptosis. Cancer Biology \& Therapy 14, 146-154.

Sonnenblick, A., Agbor-Tarh, D., Bradbury, I., Di Cosimo, S., Azim, H.A., Jr, Fumagalli, D., Sarp, S., Wolff, A.C., Andersson, M., Kroep, J., Cufer, T., Simon, S.D., Salman, P., Toi, M., Harris, L., Gralow, J., Keane, M., Moreno-Aspitia, A., Piccart-Gebhart, M., de Azambuja, E., 2017. Impact of diabetes, insulin, and metformin use on the outcome of patients with human epidermal growth factor receptor 2-positive primary breast cancer: Analysis from the ALTTO phase III randomized trial. Journal of Clinical Oncology 35, $1421-1429$.

Soranna, D., Scotti, L., Zambon, A., Bosetti, C., Grassi, G., Catapano, A., La Vecchia, C., Mancia, G., Corrao, G., 2012. Cancer risk associated with use of metformin and sulfonylurea in type 2 diabetes: A meta-analysis. The Oncologist 17, 813-822.

Sotelo, J., Briceño, E., López-González, M.A., 2006. Adding chloroquine to conventional treatment for glioblastoma multiforme. Annals of Internal Medicine 144, 337. 
Speers, A.G., 2006. Furosemide reverses multidrug resistance status in bladder cancer cells in vitro. Journal of Clinical Pathology 59, 912-915.

Spengler, G., Molnar, J., Viveiros, M., Amaral, L., 2011. Thioridazine induces apoptosis of multidrug-resistant mouse lymphoma cells transfected with the human ABCB1 and inhibits the expression of P-glycoprotein. Anticancer Research 31, 4201-4205.

Spengler, G., Takács, D., Horváth, A., Riedl, Z., Hajós, G., Amaral, L., Molnár, J., 2014. Multidrug resistance reversing activity of newly developed phenothiazines on Pglycoprotein (ABCB1)-related resistance of mouse T-lymphoma cells. Anticancer Research 34, 1737-1741.

Stangier, J., Su, C.A., Hendriks, M.G., van Lier, J.J., Sollie, F.A., Oosterhuis, B., Jonkman, J. H., 2000. The effect of telmisartan on the steady-state pharmacokinetics of digoxin in healthy male volunteers. Journal of Clinical Pharmacology 40, 1373-1379.

Stankovic, C., Heinemann, S., Delfino, J., Sigworth, F., Schreiber, S., 1989. Transmembrane channels based on tartaric acid-gramicidin A hybrids. Science 244, 813-817.

Stark, M., Silva, T.F.D., Levin, G., Machuqueiro, M., Assaraf, Y.G., 2020. The lysosomotropic activity of hydrophobic weak base drugs is mediated via their intercalation into the lysosomal membrane. Cells 9, 1082.

Stelitano, G., Sammartino, J.C., Chiarelli, L.R., 2020. Multitargeting compounds: a promising strategy to overcome multi-drug resistant tuberculosis. Molecules 25, 1239.

Stephens, T.D., Fillmore, B.J., 2000. Hypothesis: thalidomide embryopathy-proposed mechanism of action. Teratology 61, 189-195.

Stevens, R.J., Ali, R., Bankhead, C.R., Bethel, M.A., Cairns, B.J., Camisasca, R.P., Crowe, F.L., Farmer, A.J., Harrison, S., Hirst, J.A., Home, P., Kahn, S.E., McLellan, J.H., Perera, R., Plüddemann, A., Ramachandran, A., Roberts, N.W., Rose, P.W., Schweizer, A., Viberti, G., Holman, R.R., 2012. Cancer outcomes and all-cause mortality in adults allocated to metformin: systematic review and collaborative metaanalysis of randomised clinical trials. Diabetologia 55, 2593-2603.

Stewart, A.K., 2014. How thalidomide works against cancer. Science 343, 256-257. 
Stewart, A.K., Jacobus, S., Fonseca, R., Weiss, M., Callander, N.S., Chanan-Khan, A.A., Rajkumar, S.V., 2015. Melphalan, prednisone, and thalidomide vs melphalan, prednisone, and lenalidomide (ECOG E1A06) in untreated multiple myeloma. Blood 126, 1294-1301.

Sun, H., Li, T., Zhuang, R., Cai, W., Zheng, Y., 2017. Do renin-angiotensin system inhibitors influence the recurrence, metastasis, and survival in cancer patients? Medicine 96, e6394.

Sundaresan, L., Kumar, P., Manivannan, J., Balaguru, U.M., Kasiviswanathan, D., Veeriah, V., Anishetty, S., Chatterjee, S., 2019. Thalidomide and its analogs differentially target fibroblast growth factor receptors: Thalidomide suppresses FGFR gene expression while pomalidomide dampens FGFR2 activity. Chemical Research in Toxicology 32, $589-602$.

Sydes, M.R., Spears, M.R., Mason, M.D., Clarke, N.W., Dearnaley, D.P., de Bono, J.S., Attard, G., Chowdhury, S., Cross, W., Gillessen, S., Malik, Z.I., Jones, R., Parker, C.C., Ritchie, A.W.S., Russell, J.M., Millman, R., Matheson, D., Amos, C., Gilson, C., Birtle, A., Brock, S., Capaldi, L., Chakraborti, P., Choudhury, A., Evans, L., Ford, D., Gale, J., Gibbs, S., Gilbert, D.C., Hughes, R., McLaren, D., Lester, J.F., Nikapota, A., O'Sullivan, J., Parikh, O., Peedell, C., Protheroe, A., Rudman, S.M., Shaffer, R., Sheehan, D., Simms, M., Srihari, N., Strebel, R., Sundar, S., Tolan, S., Tsang, D., Varughese, M., Wagstaff, J., Parmar, M.K.B., James, N.D., 2018. Adding abiraterone or docetaxel to long-term hormone therapy for prostate cancer: directly randomised data from the STAMPEDE multi-arm, multi-stage platform protocol. Annals of Oncology 29, 12351248.

Taddia, L., D’Arca, D., Ferrari, S., Marraccini, C., Severi, L., Ponterini, G., Assaraf, Y., Marverti, G., Costi, M., 2015. Inside the biochemical pathways of thymidylate synthase perturbed by anticancer drugs: Novel strategies to overcome cancer chemoresistance. Drug Resistance Updates, 23, 20-54. 
Takara, K., Sakaeda, T., Okumura, K., 2004. Carvedilol: a new candidate for reversal of MDR1/P-glycoprotein-mediated multidrug resistance. Anti-Cancer Drugs 15, 303-309.

Tang, G.H., Satkunam, M., Pond, G.R., Steinberg, G.R., Blandino, G., Schünemann, H.J., Muti, P., 2018. Association of metformin with breast cancer incidence and mortality in patients with type ii diabetes: A GRADE-assessed systematic review and metaanalysis. Cancer Epidemiology Biomarkers \& Prevention 27, 627-635.

Tang, M.-C., Wu, M.-Y., Hwang, M.-H., Chang, Y.-T., Huang, H.-J., Lin, A.M.-Y., Yang, J.C.H., 2015. Chloroquine enhances gefitinib cytotoxicity in gefitinib-resistant nonsmall cell lung cancer cells. PLOS ONE 10, e0119135.

Taylor, S., Spugnini, E.P., Assaraf, Y.G., Azzarito, T., Rauch, C., Fais, S., 2015. Microenvironment acidity as a major determinant of tumor chemoresistance: Proton pump inhibitors (PPIs) as a novel therapeutic approach. Drug Resistance Updates 23, $69-78$.

Thakkar, B., Aronis, K.N., Vamvini, M.T., Shields, K., Mantzoros, C.S., 2013. Metformin and sulfonylureas in relation to cancer risk in type ii diabetes patients: A meta-analysis using primary data of published studies. Metabolism 62, 922-934.

Therapontos, C., Erskine, L., Gardner, E.R., Figg, W.D., Vargesson, N., 2009. Thalidomide induces limb defects by preventing angiogenic outgrowth during early limb formation. Proceedings of the National Academy of Sciences 106, 8573-8578.

To, K.K.W., Tomlinson, B., 2013. Targeting the ABCG2-overexpressing multidrug resistant (MDR) cancer cells by PPARY agonists. British Journal of Pharmacology 170, 11371151.

Tsakovska, I., Pajeva, I., 2006. Phenothiazines and structurally related compounds as modulators of cancer multidrug resistance. Current Drug Targets 7, 1123-1134.

Tsilidis, K.K., Capothanassi, D., Allen, N.E., Rizos, E.C., Lopez, D.S., van Veldhoven, K., Sacerdote, C., Ashby, D., Vineis, P., Tzoulaki, I., Ioannidis, J.P.A., 2014. Metformin does not affect cancer risk: A cohort study in the U.K. clinical practice research datalink analyzed like an intention-to-treat trial. Diabetes Care 37, 2522-2532. 
Tsubamoto, H., Sonoda, T., Inoue, K., 2014a. Impact of itraconazole on the survival of heavily pre-treated patients with triple-negative breast cancer. Anticancer Research, 34, 3839-3844.

Tsubamoto, H., Sonoda, T., Yamasaki, M., Inoue, K., 2014b. Impact of combination chemotherapy with itraconazole on survival for patients with recurrent or persistent ovarian clear cell carcinoma. Anticancer Research, 34, 2007-2014.

Tsubamoto, H., Sonoda, T., Ikuta, S., Tani, S., Inoue, K., Yamanaka, N., 2015a. Combination chemotherapy with itraconazole for treating metastatic pancreatic cancer in the second-line or additional setting. Anticancer Research, 35, 4191-4196.

Tsubamoto, H., Sonoda, T., Ikuta, S., Tani, S., Inoue, K., Yamanaka, N., 2015b. Impact of itraconazole after first-line chemotherapy on survival of patients with metastatic biliary tract cancer. Anticancer Research 35, 4923-4927.

Tsubamoto, H., Ueda, T., Inoue, K., Sakata, K., Shibahara, H., Sonoda, T., 2017. Repurposing itraconazole as an anticancer agent. Oncology Letters 14, 1240-1246.

Tsuruo, T., lida, H., Tsukagoshi, S., Sakurai, Y., 1981. Overcoming of vincristine resistance in P388 leukemia in vivo and in vitro through enhanced cytotoxicity of vincristine and vinblastine by verapamil. Cancer Research 41, 1967-1972.

Tuynder, M., Fiucci, G., Prieur, S., Lespagnol, A., Geant, A., Beaucourt, S., Duflaut, D., Besse, S., Susini, L., Cavarelli, J., Moras, D., Amson, R., Telerman, A., 2004. Translationally controlled tumor protein is a target of tumor reversion. Proceedings of the National Academy of Sciences 101, 15364-15369.

Valeria R. Villella, Antonella Tosco, Speranza Esposito, Gianni Bona, Valeria Raia, Luigi Maiuri, 2019. Mutation-specific therapies and drug repositioning in cystic fibrosis. Minerva Pediatr 71.

Varga, B., Csonka, Á., Csonka, A., Molnár, J., Amaral, L., Spengler, G., 2017. Possible biological and clinical applications of phenothiazines. Anticancer Research, 37, 59835993. 
Vasconcelos, M.H., Caires, H.R., Ābols, A., Xavier, C.P.R., Linē, A., 2019. Extracellular vesicles as a novel source of biomarkers in liquid biopsies for monitoring cancer progression and drug resistance. Drug Resistance Updates 47, 100647.

Vazquez-Martin, A., Oliveras-Ferraros, C., Cufí, S., Del Barco, S., Martin-Castillo, B., Menendez, J.A., 2010. Metformin regulates breast cancer stem cell ontogeny by transcriptional regulation of the epithelial-mesenchymal transition (EMT) status. Cell cycle 9, 3807-3814.

Veliceasa, D., Schulze-Hoëpfner, F.T., Volpert, O.V., 2008. PPAR and agonists against cancer: Rational design of complementation treatments. PPAR Research 2008, 1-13.

Verbaanderd, C., Maes, H., Schaaf, M.B., Sukhatme, V.P., Pantziarka, P., Sukhatme, V., Agostinis, P., Bouche, G., 2017. Repurposing Drugs in Oncology (ReDO)—chloroquine and hydroxychloroquine as anti-cancer agents. Ecancer 11, 781.

Vial, G., Detaille, D., Guigas, B., 2019. Role of mitochondria in the mechanism(s) of action of metformin. Frontiers in Endocrinology 10, 294.

Vokinger, K.N., Kesselheim, A.S., 2019. Application of orphan drug designation to cancer treatments (2008-2017): a comprehensive and comparative analysis of the USA and EU. BMJ Open 9, e028634

von Hagens, C., Walter-Sack, I., Goeckenjan, M., Osburg, J., Storch-Hagenlocher, B., Sertel, S., Elsässer, M., Remppis, B.A., Edler, L., Munzinger, J., Efferth, T., Schneeweiss, A., Strowitzki, T., 2017. Prospective open uncontrolled phase I study to define a welltolerated dose of oral artesunate as add-on therapy in patients with metastatic breast cancer (ARTIC M33/2). Breast Cancer Research and Treatment 164(2):359-369.

Vreugdenhil, G., Raemaekers, J.M.M., van Dijke, B.J., de Pauw, B.E., 1993. Itraconazole and multidrug resistance: Possible effects on remission rate and disease-free survival in acute leukemia. Annals of Hematology 67, 107-109.

Wang, E. -j., Lew, K., Casciano, C.N., Clement, R.P., Johnson, W.W., 2002. Interaction of common azole antifungals with $\mathrm{P}$ glycoprotein. Antimicrobial Agents and Chemotherapy 46, 160-165. 
Wang, S.-J., 2002. Inhibition of glutamate release by fluspirilene in cerebrocortical nerve terminals (synaptosomes). Synapse $44,36-41$.

Wang, Y.-J., Zhang, Y.-K., Kathawala, R., Chen, Z.-S., 2014. Repositioning of tyrosine kinase inhibitors as antagonists of ATP-binding cassette transporters in anticancer drug resistance. Cancers 6, 1925-1952.

Wang, X., Wu, X., Zhang, Z., Ma, C., Wu, T., Tang, S., Zeng, Z., Huang, S., Gong, C., Yuan, C., Zhang, L., Feng, Y., Huang, B., Liu, W., Zhang, B., Shen, Y., Luo, W., Wang, X., Liu, B., Lei, Y., Ye, Z., Zhao, L., Cao, D., Yang, L., Chen, X., Haydon, R.C., Luu, H.H., Peng, B., Liu, X., He, T.-C., 2018. Monensin inhibits cell proliferation and tumor growth of chemo-resistant pancreatic cancer cells by targeting the EGFR signaling pathway. Scientific Reports 8, 17914.

Wei, G., Twomey, D., Lamb, J., Schlis, K., Agarwal, J., Stam, R.W., Opferman, J.T., Sallan, S.E., den Boer, M.L., Pieters, R., Golub, T.R., Armstrong, S.A., 2006. Gene expression-based chemical genomics identifies rapamycin as a modulator of MCL1 and glucocorticoid resistance. Cancer Cell 10, 331-342.

Weiss, J., Sauer, A., Divac, N., Herzog, M., Schwedhelm, E., Böger, R.H., Haefeli, W.E., Benndorf, R.A., 2010. Interaction of angiotensin receptor type 1 blockers with ATPbinding cassette transporters. Biopharmaceutics \& Drug Disposition 31, 150-161.

Weiss, J., Sauer, A., Herzog, M., Böger, R.H., Haefeli, W.E., Benndorf, R.A., 2009. Interaction of thiazolidinediones (glitazones) with the ATP-binding cassette transporters P-glycoprotein and breast cancer resistance protein. Pharmacology 84, 264-270.

Wermuth, C.G., Ganellin, C.R., Lindberg, P., Mitscher, L.A., 1998. Glossary of terms used in medicinal chemistry (IUPAC Recommendations 1998). Pure and Applied Chemistry 70, $1129-1143$.

Wheaton, W.W., Weinberg, S.E., Hamanaka, R.B., Soberanes, S., Sullivan, L.B., Anso, E., Glasauer, A., Dufour, E., Mutlu, G.M., Budigner, G.S., Chandel, N.S., 2014. Metformin inhibits mitochondrial complex I of cancer cells to reduce tumorigenesis. eLife 3 , e02242. 
Wijdeven, R., Pang, B., Assaraf, Y. and Neefjes, J., 2016. Old drugs, novel ways out: Drug resistance toward cytotoxic chemotherapeutics. Drug Resistance Updates 28, 65-81.

Wishart, D.S., Knox, C., Guo, A.C., Cheng, D., Shrivastava, S., Tzur, D., Gautam, B., Hassanali, M., 2007. DrugBank: a knowledgebase for drugs, drug actions and drug targets. Nucleic Acids Research 36, D901-D906.

Wiysonge, C.S., Bradley, H.A., Volmink, J., Mayosi, B.M., Opie, L.H., 2017. Beta-blockers for hypertension. Cochrane Database of Systematic Reviews CD002003.

Wu, L., Zhu, J., Prokop, L.J., Murad, M.H., 2015. Pharmacologic therapy of diabetes and overall cancer risk and mortality: a meta-analysis of 265 studies. Scientific Reports 5, 10147.

Xiao, H., Bid, H.K., Chen, X., Wu, X., Wei, J., Bian, Y., Zhao, C., Li, H., Li, C., Lin, J., 2017. Repositioning bazedoxifene as a novel IL-6/GP130 signaling antagonist for human rhabdomyosarcoma therapy. PLOS ONE 12, e0180297.

Xie, X., White, E.P., Mehnert, J.M., 2013. Coordinate autophagy and mTOR pathway inhibition enhances cell death in melanoma. PLoS ONE 8, e55096.

Xu, R., Ji, Z., Xu, C., Zhu, J., 2018. The clinical value of using chloroquine or hydroxychloroquine as autophagy inhibitors in the treatment of cancers. Medicine 97, e12912.

Xu, X., Zhang, H.Y., 2017. The immunogenetics of psoriasis and implications for drug repositioning. International Journal of Molecular Sciences 18, 2650.

Xue, C., Wang, C., Liu, Q., Meng, Q., Sun, H., Huo, X., Ma, X., Liu, Z., Ma, X., Peng, J., Liu, K., 2016. Targeting P-glycoprotein expression and cancer cell energy metabolism: combination of metformin and 2-deoxyglucose reverses the multidrug resistance of K562/Dox cells to doxorubicin. Tumor Biology 37, 8587-8597.

Xue, C., Wang, C., Sun, Y., Meng, Q., Liu, Z., Huo, X., Sun, P., Sun, H., Ma, X., Ma, X., Peng, J., Liu, K., 2017. Targeting P-glycoprotein function, p53 and energy metabolism: Combination of metformin and 2-deoxyglucose reverses the multidrug resistance of MCF-7/Dox cells to doxorubicin. Oncotarget 8, 8622-8632. 
Yabu, T., Tomimoto, H., Taguchi, Y., Yamaoka, S., Igarashi, Y., Okazaki, T., 2005. Thalidomide-induced antiangiogenic action is mediated by ceramide through depletion of VEGF receptors, and is antagonized by sphingosine-1-phosphate. Blood 106, 125134.

Yang, C.-E., Lee, W.-Y., Cheng, H.-W., Chung, C.-H., Mi, F.-L., Lin, C.-W., 2019. The antipsychotic chlorpromazine suppresses YAP signaling, stemness properties, and drug resistance in breast cancer cells. Chemico-Biological Interactions 302, 28-35.

Yang, E.J., Wu, C., Liu, Y., Lv, J., Sup Shim, J., 2016. Revisiting non-cancer drugs for cancer therapy. Current Topics in Medicinal Chemistry 16, 2144-2155.

Yin, M., Zhou, J., Gorak, E.J., Quddus, F., 2013. Metformin Is associated with survival benefit in cancer patients with concurrent type 2 diabetes: A systematic review and meta-analysis. The Oncologist 18, 1248-1255.

Yong, M., Yu, T., Tian, S., Liu, S., Xu, J., Hu, J., Hu, L., 2017. DR2 blocker thioridazine: A promising drug for ovarian cancer therapy. Oncology Letters 14, 8171-8177.

Yoon, M.J., Kang, Y.J., Kim, I.Y., Kim, E.H., Lee, J.A., Lim, J.H., Kwon, T.K., Choi, K.S., 2013. Monensin, a polyether ionophore antibiotic, overcomes TRAIL resistance in glioma cells via endoplasmic reticulum stress, DR5 upregulation and C-FLIP downregulation. Carcinogenesis 34, 1918-1928.

Yosipof, A., Guedes, R.C., García-Sosa, A.T., 2018. Data mining and machine learning models for predicting drug likeness and their disease or organ category. Frontiers in Chemistry 6, 162.

Yousefi, B., Samadi, N., Baradaran, B., Rameshknia, V., Shafiei-Irannejad, V., Majidinia, M., Targhaze, N., Zarghami, N., 2015. Differential effects of peroxisome proliferatoractivated receptor agonists on doxorubicin-resistant human myelogenous leukemia (K562/DOX) cells. Cellular and Molecular Biology, 61, 118-122.

Yu, C., Li, W., Liu, J., Lu, J., Feng, J., 2017. Autophagy: novel applications of nonsteroidal anti-inflammatory drugs for primary cancer. Cancer Medicine 7, 471-484. 
Yu, H., Zhong, X., Gao, P., Shi, J., Wu, Z., Guo, Z., Wang, Z., Song, Y., 2019. The potential effect of metformin on cancer: An umbrella review. Frontiers in Endocrinology 10, 617.

Zhang, C., Gong, P., Liu, P., Zhou, N., Zhou, Y., Wang, Y., 2016. Thioridazine elicits potent antitumor effects in colorectal cancer stem cells. Oncology Reports 37, 1168-1174.

Zhang, H., Jing, X., Wu, X., Hu, J., Zhang, X., Wang, X., Su, P., Li, W., Zhou, G., 2015a. Suppression of multidrug resistance by rosiglitazone treatment in human ovarian cancer cells through downregulation of FZD1 and MDR1 genes. Anti-Cancer Drugs 26, 706-715.

Zhang, H.-Q., Fang, N., Liu, X.-M., Xiong, S.-P., Liao, Y.-Q., Jin, W.-J., Song, R.-F., Wan, Y.Y., 2015b. Antitumor activity of chloroquine in combination with cisplatin in human gastric cancer xenografts. Asian Pacific Journal of Cancer Prevention 16, 3907-3912.

Zhang, Z.-J., Li, S., 2014. The prognostic value of metformin for cancer patients with concurrent diabetes: a systematic review and meta-analysis. Diabetes, Obesity and Metabolism 16, 707-710.

Zhang, S.-D., Gant, T.W., 2009. sscMap: An extensible Java application for connecting small-molecule drugs using gene-expression signatures. BMC Bioinformatics 10, 236.

Zhang, J., Wu, J., He, Q., Liang, W., He, J., 2018. The prognostic value of metformin for advanced non-small cell lung cancer: a systematic review and meta-analysis. Translational Lung Cancer Research 7, 389-396.

Zhitomirsky, B., Assaraf, Y.G., 2014. Lysosomal sequestration of hydrophobic weak base chemotherapeutics triggers lysosomal biogenesis and lysosome-dependent cancer multidrug resistance. Oncotarget 6, 1143-1156.

Zhitomirsky, B., Assaraf, Y.G., 2016. Lysosomes as mediators of drug resistance in cancer. Drug Resistance Updates 24, 23-33.

Zhong, Z., Virshup, D.M., 2020. Wnt Signaling and Drug Resistance in Cancer. Molecular Pharmacology 97, 72-89.

Zhou, X.L., Xu, P., Chen, H.H., Zhao, Y., Shen, J., Jiang, C., Jiang, S., Ni, S.Z., Xu, B., Li, L., 2017a. Thalidomide inhibits TGF-beta1-induced epithelial to mesenchymal transition in 
alveolar epithelial cells via Smad-dependent and Smad-independent signaling pathways. Scientific Reports 7, 14727.

Zhou, X.-L., Xue, W.-H., Ding, X.-F., Li, L.-F., Dou, M.-M., Zhang, W.-J., Lv, Z., Fan, Z.-R., Zhao, J., Wang, L.-X., 2017b. Association between metformin and the risk of gastric cancer in patients with type 2 diabetes mellitus: a meta-analysis of cohort studies. Oncotarget 8, 55622-55631. 


\section{FIGURES}

Figure 1. Schematic representation of the steps involved in traditional drug discovery and drug repurposing strategy.

\section{TRADITIONAL DRUG DISCOVERY}

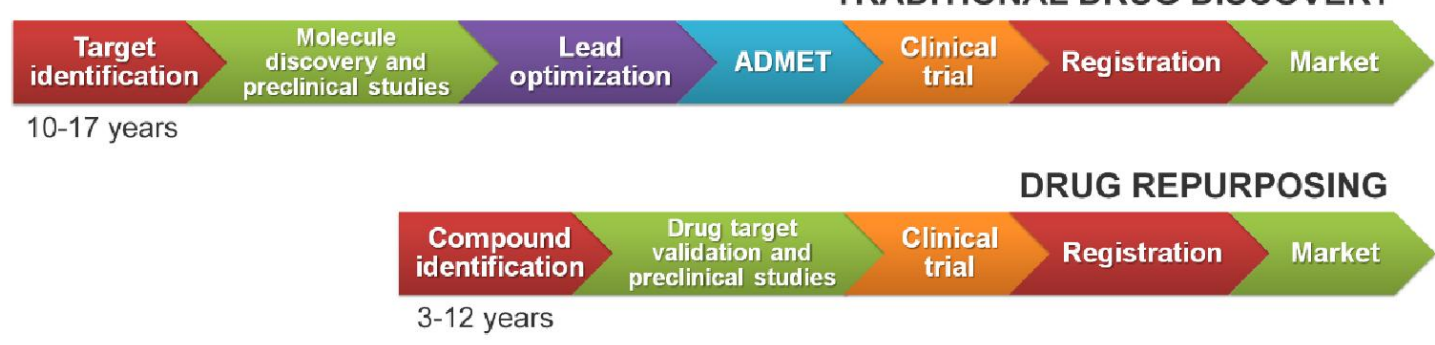

Figure 2. Different in silico and experimental approaches for drug discovery and validation during drug repurposing process.

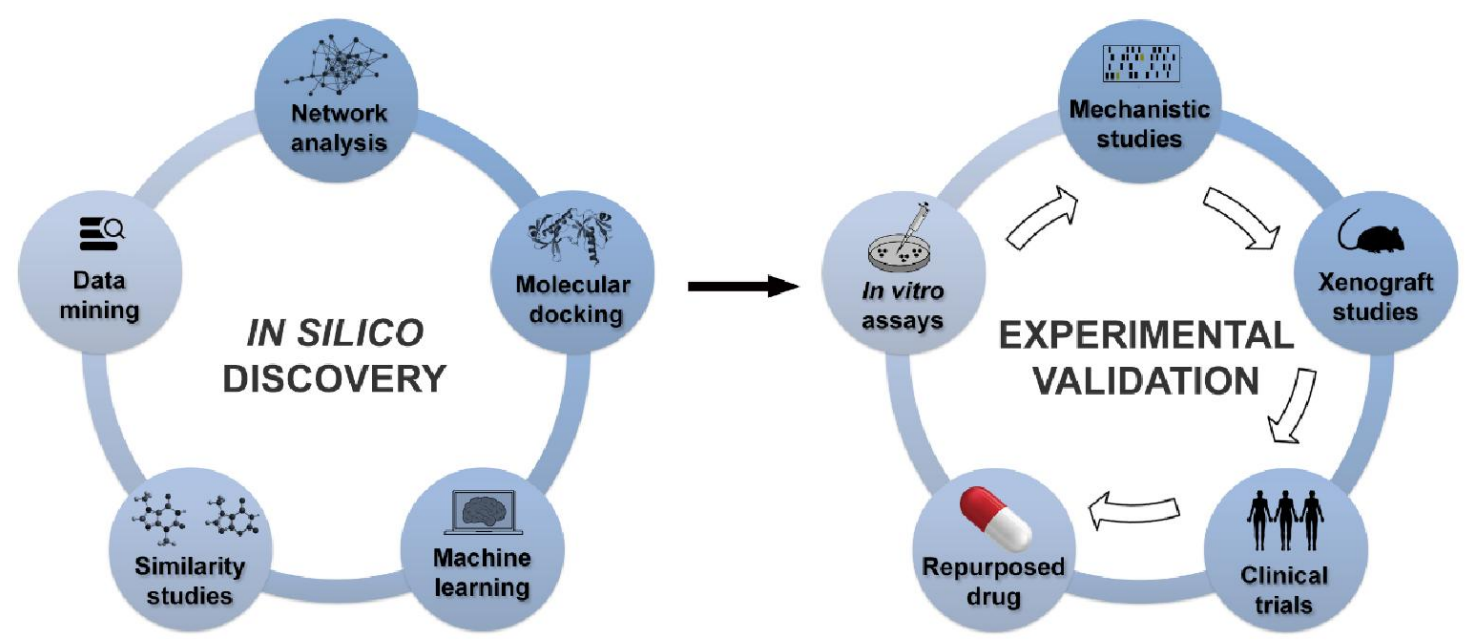


Figure 3. Chemical structure of drugs undergoing preclinical investigation for repurposing in cancer.

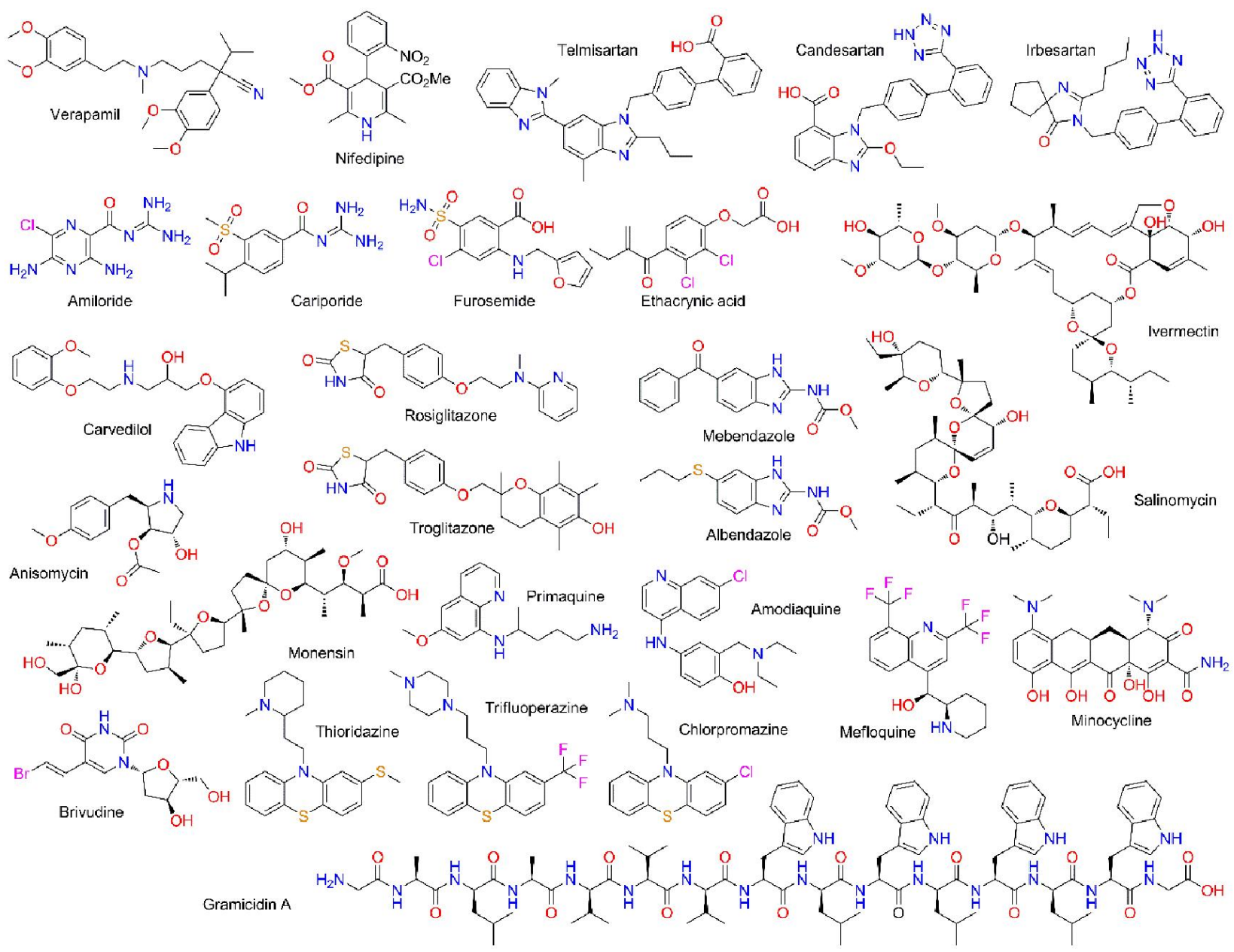


Figure 4. Chemical structure of drugs being repurposed in cancer clinical trials.<smiles></smiles>

Thalidomide $\mathrm{X}=\mathrm{CO} ; \mathrm{R}=\mathrm{H}$

Lenalidomide $X=\mathrm{CH}_{2} ; \mathrm{R}=\mathrm{NH}_{2}$

Pomalidomide $\mathrm{X}=\mathrm{CO} ; \mathrm{R}=\mathrm{NH}_{2}$<smiles>[R]CCN(CC)CCCC(C)Nc1ccnc2cc(Cl)ccc12</smiles><smiles>CCONc1ccc([N+](=O)[O-])cc1Cl</smiles><smiles>NNc1nncc2ccccc12</smiles>

Hydralazine<smiles>CN(C)C(=N)N=C(N)N</smiles><smiles>C[C@@H]1CC[C@H]2[C@@H](C)[C@H](OC(=O)CCC(=O)[O-])O[C@@H]3O[C@]4(C)CC[C@@H]1[C@@]23OO4</smiles><smiles>CCCCOCCOCCOc1ccc(N2CCN(c3ccc(-n4cnn(C(C)CC)c4=O)cc3)CC2)cc1</smiles> 


\section{TABLES}

Table 1. Drug repositioning opportunities in cancer therapy.

\begin{tabular}{llc}
\hline \multicolumn{1}{c}{ Drug } & \multicolumn{1}{c}{ Indication (drug in combination) } & Status $^{\text {a }}$ \\
\hline IMiDs & & \\
\cline { 2 - 3 } Thalidomide & Multiple myeloma (dexamethasone) & 2006 \\
& Multiple myeloma (daratumumab-bortezomib- & 2019 \\
& dexamethasone) & \\
Lenalidomide & Myelodysplastic syndromes with 5q deletion & 2005 \\
& Multiple myeloma & 2006 \\
& Relapsed or refractory mantle cell lymphoma & 2013 \\
& Follicular or marginal lymphoma (rituximab) & 2019 \\
Pomalidomide & Relapsed and/or refractory multiple myeloma & 2013
\end{tabular}

Antihypertensives

Hydralazine Ovarian and cervical cancer (valproate) Phase III

Breast and rectal cancer, refractory solid tumors, and Phase II

myelodysplastic syndromes (valproate)

Antidiabetics

Metformin Oral, breast, colorectal, and prostate cancer, and Phase III hepatocellular carcinoma

Metastatic prostate cancer (multiple drugs)

Recurrent endometrial cancer (paclitaxel-carboplatin)

\section{Anthelmintics}

Niclosamide

Hormone-resistant prostate cancer (abiraterone-prednisone)

Phase II

Metastatic colorectal cancer, and familial adenomatous polyposis

Antimalarials

Chloroquine

Glioblastoma multiforme

Phase III

High grade gliomas (temozolomide)

Hydroxychloroquine

Metastatic pancreatic, breast and prostate cancer

Phase II

Resectable pancreatic cancer (capecitabine)

Metastatic prostate cancer (docetaxel)

Hepatocellular cancer (sorafenib)

Colorectal cancer (vorinostat)

Metastatic breast cancer (ixabepilone) 
V04/06/2020 (Revised version)

\author{
Breast cancer stage IIB (everolimus) \\ Metastatic colorectal cancer (capecitabine-oxaliplatin- \\ bevacizumab)
}

Artesunate Colorectal, lung, and cervical cancer

Phase II

\section{Antifungals}

Itraconazole Ovarian cancer

Phase III

Prostate, lung, esophageal, and skin cancer, and basal cell

Phase II carcinoma

Non-small cell lung cancer (pemetrexed)

Prostate cancer (orterenol)

Platinum-resistant ovarian cancer (hydroxychloroquine)

${ }^{a}$ Year of approval or most advanced clinical trials 